\title{
Photocatalytic nitrogen reduction to ammonia: Insights into the role of defect engineering in photocatalysts
}

\author{
Huidong Shen ${ }^{1}$, Mengmeng Yang ${ }^{1}$, Leiduan $\mathrm{Hao}^{1}$, Jinrui Wang ${ }^{1}$, Jennifer Strunk ${ }^{2}(\varangle)$, and Zhenyu Sun ${ }^{1}$ \\ ${ }^{1}$ State Key Laboratory of Organic-Inorganic Composites, College of Chemical Engineering, Beijing University of Chemical Technology, Beijing \\ 100029, China \\ ${ }^{2}$ Leibniz Institute for Catalysis at the University of Rostock, Rostock 18059, Germany
}

(C) The Author(s) 2021

Received: 2 May 2021 / Revised: 24 June 2021 / Accepted: 29 June 2021

\begin{abstract}
Engineering of defects in semiconductors provides an effective protocol for improving photocatalytic $\mathrm{N}_{2}$ conversion efficiency. This review focuses on the state-of-the-art progress in defect engineering of photocatalysts for the $\mathrm{N}_{2}$ reduction toward ammonia. The basic principles and mechanisms of thermal catalyzed and photon-induced $\mathrm{N}_{2}$ reduction are first concisely recapped, including relevant properties of the $\mathrm{N}_{2}$ molecule, reaction pathways, and $\mathrm{NH}_{3}$ quantification methods. Subsequently, defect classification, synthesis strategies, and identification techniques are compendiously summarized. Advances of in situ characterization techniques for monitoring defect state during the $\mathrm{N}_{2}$ reduction process are also described. Especially, various surface defect strategies and their critical roles in improving the $\mathrm{N}_{2}$ photoreduction performance are highlighted, including surface vacancies (i.e., anionic vacancies and cationic vacancies), heteroatom doping (i.e., metal element doping and nonmetal element doping), and atomically defined surface sites. Finally, future opportunities and challenges as well as perspectives on further development of defect-engineered photocatalysts for the nitrogen reduction to ammonia are presented. It is expected that this review can provide a profound guidance for more specialized design of defect-engineered catalysts with high activity and stability for nitrogen photochemical fixation.
\end{abstract}

\section{KEYWORDS}

photocatalysis, nitrogen reduction, ammonia synthesis, defect engineering

\section{Introduction}

Ammonia is an indispensable raw material which is widely applied in the production of agricultural fertilizers, industrial and household chemicals [1-4]. Use of ammonia to produce fertilizers quadrupled crop yield and global population [2]. In addition, ammonia is also proposed as a potential hydrogen carrier and distribution medium of the future, because it possesses high hydrogen content (17.6 wt.\%), large energy density $\left(4.3 \mathrm{kWh} \cdot \mathrm{L}^{-1}\right.$ at $-33.3{ }^{\circ} \mathrm{C}$ and $\left.1 \mathrm{bar}, 6.25 \mathrm{kWh} \cdot \mathrm{kg}^{-1}\right)$, and $\mathrm{CO}_{x}$-free emissions [5-8]. Equally importantly, ammonia is readily liquified $\left(-33^{\circ} \mathrm{C}\right)$ at atmospheric pressure $[9,10]$. The technology of liquefaction, storage, and pipeline transport of ammonia has been well achieved in existing industries compared to liquid hydrogen [11].

In nature, nitrogen from the atmosphere is transformed into ammonia via nitrogenase enzymes under mild conditions $\left(<40{ }^{\circ} \mathrm{C}\right.$, atmospheric pressure), called biological nitrogen fixation [12]. The most common nitrogenases enzymes mainly contain FeMo nitrogenases, which are composed of two components including Fe proteins as electron-transfer media and FeMo proteins as $\mathrm{N}_{2}$-binding and reduction active sites [13-15]. Unfortunately, enzyme nitrogenases are susceptible to oxygen $[16,17]$. Additionally, biological nitrogen fixation to ammonia has low space-time yield and hardly meets the demands of modern societies with rapidly growing population worldwide $[18,19]$. One of the greatest scientific achievements in the $20^{\text {th }}$ century was accredited to the discovery and implementation of industrial ammonia synthesis, i.e., the Haber-Bosch process named according to its primary inventors Fritz Haber and Carl Bosch [20, 21]. The Haber-Bosch process involves the reaction of nitrogen and hydrogen on iron-based catalysts to synthesize ammonia [4, 22]. The heterogeneous catalyst, already developed in 1910 by Alwin Mittasch, is still used today with only minor alterations $[21,23]$. However, the classical Haber-Bosch process takes place under very harsh reaction conditions $\left(400-500{ }^{\circ} \mathrm{C}, 15-25 \mathrm{MPa}\right)$. Annually, nearly 200 million tons of ammonia are synthesized through the Haber process. Apart from nitrogen, hydrogen is used as a feedstock which is usually obtained from methane steam reforming, and as a result, industrial ammonia synthesis consumes about $1 \%-3 \%$ of the world's total energy and leads to more than 300 million tons of carbon dioxide emissions [20, 24, 25]. From these scenarios, it is highly desirable to explore and develop an environmentally-friendly, ambient, and sustainable $\mathrm{N}_{2}$ fixation approach.

To date, various alternative strategies have been exploited for nitrogen fixation under mild conditions $\left(<300^{\circ} \mathrm{C},<1 \mathrm{MPa}\right)$, including biomimetic, thermo-catalytic, plasma-catalytic, photocatalytic, electrocatalytic, and chemical looping methods [26-32]. Among these routes, photocatalytic nitrogen reduction into ammonia using water as a coreactant instead of hydrogen 
(Overall reaction: $\mathrm{N}_{2}(\mathrm{~g})+3 \mathrm{H}_{2} \mathrm{O}(\mathrm{l}) \rightarrow 2 \mathrm{NH}_{3}(\mathrm{~g})+3 / 2 \mathrm{O}_{2}(\mathrm{~g})$ ), mimicking natural photo-synthesis, shows potential for clean and sustainable $\mathrm{NH}_{3}$ fabrication [33, 34]. It solely requires inexhaustible solar energy, water as proton source, and $\mathrm{N}_{2}$ reactant $[35,36]$. Photocatalytic $\mathrm{NH}_{3}$ synthesis correlates with two coupled redox half reactions, including the oxidation of water $\left(3 \mathrm{H}_{2} \mathrm{O}(\mathrm{l})+6 \mathrm{~h}^{+} \rightarrow 6 \mathrm{H}^{+}(\mathrm{aq})+3 / 2 \mathrm{O}_{2}(\mathrm{~g})\right)$ with photogenerated holes in the valence band (VB) and the reduction of nitrogen $\left(\mathrm{N}_{2}(\mathrm{~g})+6 \mathrm{H}^{+}(\mathrm{aq})+6 \mathrm{e}^{-} \rightarrow 2 \mathrm{NH}_{3}(\mathrm{~g})\right)$ with photogenerated electrons in the conduction band (CB) [37-39]. Pioneering work for nitrogen fixation was reported by Schrauzer et al. on $\mathrm{TiO}_{2}$-based photocatalysts under ultraviolet (UV) light in 1977 [40]. Since then, significant research efforts have been made to optimize the photocatalytic performance for $\mathrm{N}_{2}$ fixation [41]. The nature of the photocatalyst plays a vital role in photo-catalyzing $\mathrm{N}_{2}$ reduction. Diversified photocatalysts have been explored for $\mathrm{N}_{2}$ reduction reaction, such as metal oxides [42-45], metal sulfides [46, 47], $g$ - $C_{3} \mathrm{~N}_{4}[48,49]$, and MXene $\left(\mathrm{Ti}_{3} \mathrm{C}_{2}\right)[50,51]$, among others. Nonetheless, the overall solar-to-chemical conversion efficiency for $\mathrm{N}_{2}$ reduction is still as low as $0.1 \%$ which is far from the value required in industry or even any reasonable technological interest $[2,52-54]$. This is essentially associated with the issues of low light utilization, lack of effective active sites, rapid recombination of photoexcited electron-hole pairs, in addition to the inertness and stability of the nonpolar $\mathrm{N} \equiv \mathrm{N}$ triple bond and poor adsorption/activation capability $[55,56]$. To address these challenges, several photocatalyst modification strategies have been explored to improve the performance of photocatalytic nitrogen fixation [57].

Defect engineering is a simple, useful, and appealing approach to enhance photocatalytic $\mathrm{N}_{2}$ fixation by altering the electronic structure and chemical properties of semiconductors [58-64]. Generally, knowledge-driven and well-planned defect engineering not only improves light absorption ability and accelerates charge carrier separation, but also provides active sites for $\mathrm{N}_{2}$ adsorption and activation [65-67]. Furthermore, introduction of defects on the surface of photocatalysts can endow an electron-rich state and high surface energy, thereby enriching the lowest unoccupied molecular orbital (LUMO) electron density of $\mathrm{N}_{2}$ via $\mathrm{e}^{-} \rightarrow \pi^{*}$-orbital (N) transition and favoring $\mathrm{N}_{2}$ adsorption and activation [39]. To elucidate the relationship between the structure of defects and catalytic performance, major endeavors have been attempted by combining experiments and theoretical calculations [38, 68-70]. Despite recent progress that has been achieved in this regard, many challenges remain to be solved including precise quantification, fine structure tuning, and stability enhancement of defects [71, 72].

Herein, we provide an up-to-date review on defect engineering over semiconductor-based photocatalysts for the nitrogen reduction towards ammonia. Fundamentals such as the properties of $\mathrm{N}_{2}$ molecules, photoreduction principles of $\mathrm{N}_{2}$, reaction pathways, and $\mathrm{NH}_{3}$ measurement methods are initially elaborated. In the following, the defect classification, synthesis strategies, and identification techniques are reviewed. Especially, the critical roles of defect engineering on photocatalytic nitrogen reduction are discussed. Additionally, recent achievements of defect-engineered photocatalysts for nitrogen reduction to ammonia are presented. Finally, we provide perspectives on future opportunities and challenges on defect-engineering of photocatalysts to promote the nitrogen reduction to ammonia. We expect that this review can provide profound guidance for more specialized design of defect-engineered photocatalysts with high activity, stability, and selectivity for ammonia synthesis.

\section{Basic understanding of photocatalytic nitrogen reduction}

\subsection{Fundamental properties of $\mathrm{N}_{2}$ molecules}

It is generally known that nitrogen molecules are formed by two nitrogen atoms connected by a strong nonpolar $\mathrm{N} \equiv \mathrm{N}$ triple bond. Each atom possesses a pair of electrons in the $2 \mathrm{~s}$ orbital with opposite spin direction and three lone-pair electrons dispersed in the $2 \mathrm{p}$ orbitals with the same spin direction [41]. Hybridization of the s-p atomic orbitals leads to the formation of four bonding orbitals (two $\sigma$ and two $\pi$ orbitals) and four antibonding orbitals (two $\sigma^{*}$ and two $\pi^{*}$ orbitals), with the shared electrons in the $\pi$ and $2 \sigma$ orbitals forming an $\mathrm{N} \equiv \mathrm{N}$ bond [73]. The large energy gap between the highest occupied molecular orbital (HOMO) and LUMO is $10.82 \mathrm{eV}$, which severely impedes electron transfer [74]. The $\mathrm{N}_{2}$ molecule is extremely stable and kinetically inert with a high $\mathrm{N} \equiv \mathrm{N}$ cleavage energy $\left(945 \mathrm{~kJ} \cdot \mathrm{mol}^{-1}\right)$ and first-bond breaking energy (410 $\mathrm{kJ} \cdot \mathrm{mol}^{-1}$ ) [37]. Among others, an $\mathrm{N}_{2}$ molecule has both large ionization potential $(15.85 \mathrm{eV})$ and negative electron affinity $(-1.9 \mathrm{eV})$, making it difficult to be oxidized or reduced [41]. Indeed, activating $\mathrm{N}_{2}$ molecules at ambient conditions is a formidable challenge.

\subsection{Conventional heterogeneous catalysts for ammonia} synthesis

Although the classical heterogeneous ammonia synthesis process is named as the Haber-Bosch process, the development of the catalyst was primarily the achievement of Alwin Mittasch at BASF, who tested in the early $20^{\text {th }}$ century more than 2,000 different catalyst formulations in more than 6,000 experiments [75]. It is even more remarkable that the multiply promoted iron catalyst resulting from Mittasch's experiments is still used today with only minor alterations. The composition and nanostructure of this catalyst have been described most conclusively by R. Schlögl $[21,22]$. Early on, it was already established that the catalyst would only show high activity, if a particular starting mineral was used, or if the compositions of this mineral was artificially mixed. Only when magnetite $\left(\mathrm{Fe}_{3} \mathrm{O}_{4}\right)$ was promoted with defined amounts of $\mathrm{K}_{2} \mathrm{O}, \mathrm{Al}_{2} \mathrm{O}_{3}$, and potentially $\mathrm{CaO}$ in an oxide melt, a particular active structure would form under reaction conditions, which is termed as "ammonia iron". Iron can easily form nitrides in presence of ammonia, and the formation of different surface nitrides has been proposed. The major bulk part of the iron, however, remains in the likely defective $\alpha$-Fe phase. In conclusion, the microstructure of the industrial catalyst, the "ammonia iron", is highly complex and defective, being likely composed of bulk iron particles, kept apart from each other by the irreducible promoter oxides, and surrounded by partially nitride defective iron platelets $[21,22]$. This structure is schematically depicted in Fig. 1(a).

Nitrogen dissociation is the rate-determining step in ammonia synthesis over iron [21, 22]. $\mathrm{N}_{2}$ is first adsorbed molecularly in a precursor state before dissociation occurs. From surface science experiments with model single crystal surfaces, important influences of the potassium promoter on accelerating nitrogen dissociation and ammonia desorption have been identified [21,76]. After $\mathrm{N}_{2}$ has dissociated into nitrogen atoms, it is successively hydrogenated, forming adsorbed ${ }^{\star} \mathrm{NH},{ }^{\star} \mathrm{NH}_{2}$, and ${ }^{\star} \mathrm{NH}_{3}$, before ammonia desorption occurs [21].

The only other industrially used catalyst for ammonia synthesis is based on ruthenium. The high price of Ru prohibits the use 

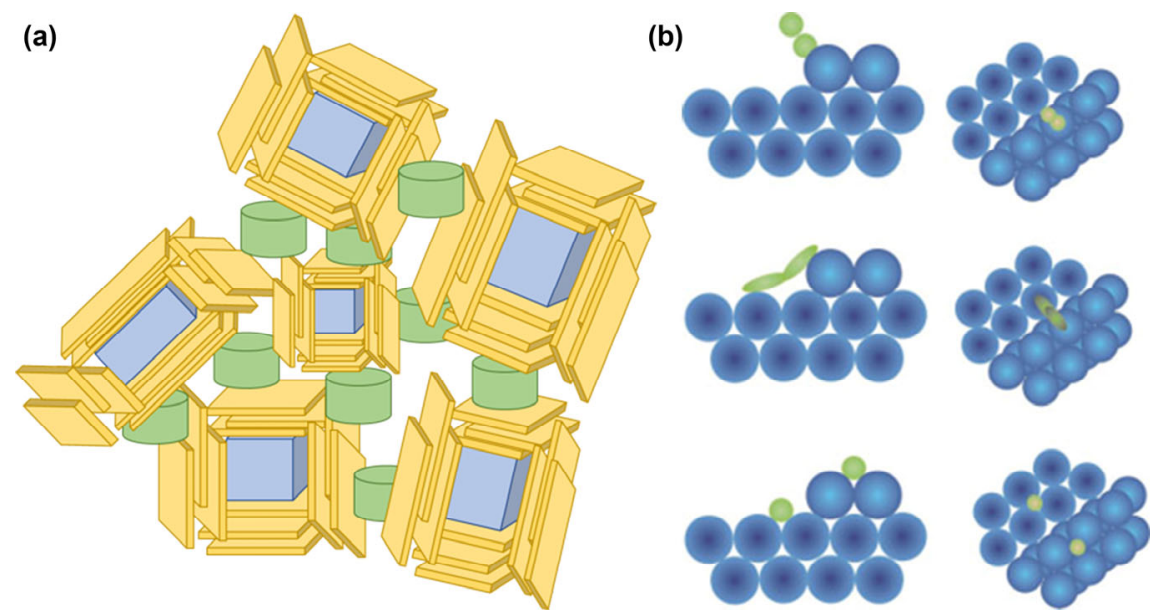

Figure 1 The microstructure of the industrial catalyst. (a) Schematic representation of "ammonia iron", with partially nitrided iron platelets (yellow), bulk $\alpha$-Fe phase (blue) and irreducible spacer oxides (green). (b) Artist's impression of the function of the active site for nitrogen dissociation on a stepped Ru surface. Reproduced with permission from Ref. [21], @ Wiley-VCH Verlag GmbH \& Co. KGaA 2008.

of a bulk material, so $\mathrm{Ru}$ is used in nanoparticulate form on oxide or carbon supports [75]. It may also be beneficial for catalytic reasons to use $\mathrm{Ru}$ nanoparticles instead of larger structures, because such "rough" particles may exhibit more active sites [21]. For Ru-based catalysts, nitrogen dissociation is also the rate-determining step, but it proceeds without a molecular precursor state [21, 77]. It is by now well known that nitrogen activation critically depends on the exposure of surface steps (Fig. 1(b)) [21,78]. Due to the better stabilization of adsorbed $\mathrm{N}_{2}$ at the step compared to the bare terrace, nitrogen dissociation can proceed nine orders of magnitude faster at the step site compared to the bare terrace. This has been verified by poisoning the steps sites by gold deposition [78] The interaction of hydrogen with $\mathrm{Ru}$ is much stronger, but desorption limitation of ammonia is less of an issue than in case of iron. Except for the lack of a molecularly adsorbed nitrogen precursor state, the proposed reaction mechanism on $\mathrm{Ru}$ is similar to the mechanism on $\mathrm{Fe}$, although the rate of the individual elementary steps differs. Since hydrogen adsorbs very strongly on $\mathrm{Ru}$, it is beneficial to use a synthesis gas with nitrogen excess rather than a stoichiometric one [77].

It is interesting to observe the commonalities of the two systems: In both cases, nitrogen dissociation is the ratedetermining step, and only a small fraction of all exposed sites can efficiently dissociate nitrogen $[21,78,79]$. Alkali promoters are used in both cases in order to optimize adsorption energetics of reactants and products [21,75]. And finally, highly defective structures with steps $(\mathrm{Ru})$ and partial nitridation $(\mathrm{Fe})$ are needed in order to form the active sites. Guiding design principles may be derived here which may also be relevant for the photocatalytic process: Even if reaction pathways differ (see below), the photocatalyst eventually must also dissociate $\mathrm{N}_{2}$, and $\mathrm{NH}_{3}$ desorption at room temperature must be feasible. Knowing that $\mathrm{N}_{2}$ dissociation might be more easily accomplished at step sites or partially nitrided surfaces, for example, is then very valuable.

\subsection{Basic principles of $\mathrm{N}_{2}$ photoreduction to $\mathrm{NH}_{3}$}

According to energy band theory, semiconductor materials possess a $\mathrm{CB}$ and a $\mathrm{VB}$. The potential difference between the $\mathrm{CB}$ and $\mathrm{VB}$ is referred to as bandgap energy $\left(E_{\mathrm{g}}\right)$ (Fig. 2(a)) [80]. Photocatalytic $\mathrm{N}_{2}$ reduction to $\mathrm{NH}_{3}$ proceeds through three fundamental steps (Fig. 2(b)): (1) generation of charge carriers (i.e., electrons and holes) by photon excitation $\left(E_{\mathrm{hv}} \geq E_{\mathrm{g}}\right)$, (2) separation and migration of electrons and holes to the catalyst surface, (3) redox reactions between surface-adsorbed species and electron-hole pairs, i.e., $\mathrm{N}_{2}$ reduction to produce $\mathrm{NH}_{3}$ and water oxidation to $\mathrm{O}_{2}$ and $\mathrm{H}^{+}$[81-83]. The capability of a semiconductor to absorb light and its photoreaction thermodynamics are dependent on its bandgap and the $\mathrm{CB} / \mathrm{VB}$ potential value [84]. Therefore, in designing photocatalysts, it is essential to consider the redox potentials of photoexcited conduction band electrons and valence band holes to satisfy corresponding $\mathrm{N}_{2}$ reduction and water oxidation.

\subsection{Proposed reaction pathways of $\mathrm{N}_{2}$ reduction}

The photocatalytic $\mathrm{N}_{2}$ reduction process over semiconductors involves the following fundamental steps, encompassing
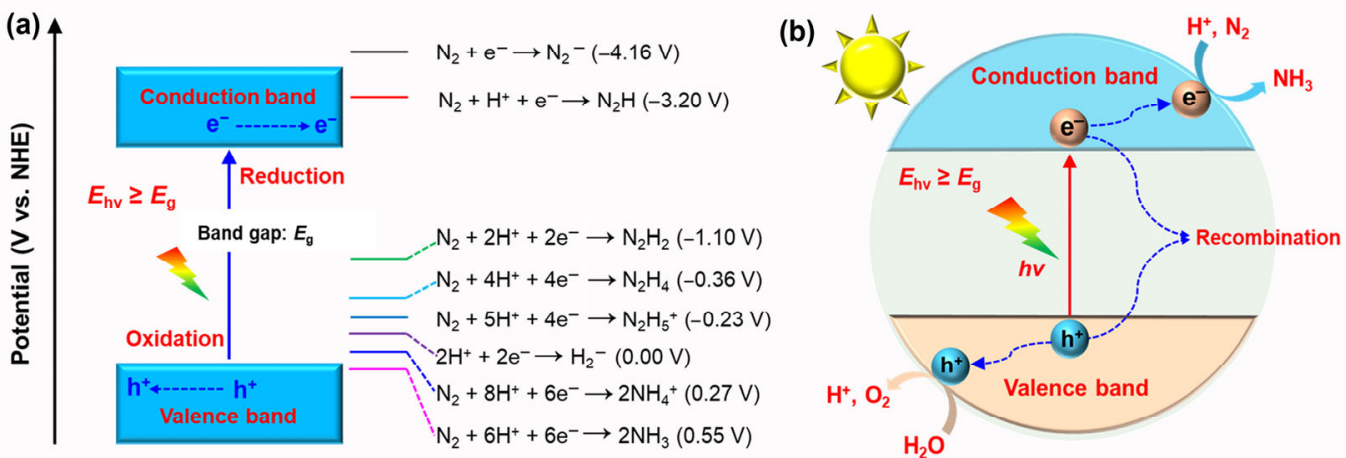

Figure 2 Schematic representation of nitrogen photoreduction to ammonia processes. (a) Schematic energy diagram for $\mathrm{N}_{2}$ reduction and (b) illustration of the overall photocatalytic $\mathrm{N}_{2}$ reduction to $\mathrm{NH}_{3}$ over semiconductor-based photocatalysts. 
multi-step injections of electrons $[85,86]$. First, under visible light irradiation, photoexcited holes $\left(\mathrm{h}^{+}\right)$react with water to generate $\mathrm{H}^{+}$and $\mathrm{O}_{2}$ (Eq. (1)). Meanwhile, $\mathrm{N}_{2}$ is reduced by photoexcited electrons (e $e^{-}$) to form $\mathrm{NH}_{3}$ (Eq. (2)). Consequently, $\mathrm{NH}_{3}$ is produced from $\mathrm{H}_{2} \mathrm{O}$ and $\mathrm{N}_{2}$ under solar energy (Eq. (3)).

Step 1: $3 \mathrm{H}_{2} \mathrm{O}(\mathrm{l})+6 \mathrm{~h}^{+} \rightarrow 3 / 2 \mathrm{O}_{2}(\mathrm{~g})+6 \mathrm{H}^{+}(\mathrm{aq}) \quad E_{\mathrm{NHE}}^{\circ}=1.23 \mathrm{~V}$ (1)

Step 2: $\mathrm{N}_{2}(\mathrm{~g})+6 \mathrm{H}^{+}(\mathrm{aq})+6 \mathrm{e}^{-} \rightarrow 2 \mathrm{NH}_{3}(\mathrm{~g}) \quad E_{\mathrm{NHE}}^{\circ}=-0.05 \mathrm{~V}$

Overall reaction:

$$
\mathrm{N}_{2}(\mathrm{~g})+3 \mathrm{H}_{2} \mathrm{O}(\mathrm{l}) \rightarrow 2 \mathrm{NH}_{3}(\mathrm{~g})+3 / 2 \mathrm{O}_{2}(\mathrm{~g}) \quad \Delta G=7.03 \mathrm{eV}
$$

During the photocatalytic $\mathrm{N}_{2}$ reduction reaction, the first electron is transferred from the photocatalyst to $\mathrm{N}_{2}$, making the $\mathrm{N} \equiv \mathrm{N}$ triple bond unstable. This is usually the most difficult step in $\mathrm{N}_{2}$ reduction due to the fact that the photoexcited electrons need to overcome the maximum energy transition state during either the first electron transfer $(-4.16 \mathrm{~V}$ vs. normal hydrogen electrode (NHE)) or proton-assisted electron transfer to $\mathrm{N}_{2}(-3.2 \mathrm{~V}$ vs. NHE) $[55,87]$. The defect sites in photocatalysts possess a strong binding to $\mathrm{N}_{2}$, generating adsorbed $\mathrm{N}_{2}{ }^{2-}$ while the electron-rich cations around defects promote the reduction of adsorbed $\mathrm{N}_{2}$ through proton coupled electron transfer via $\mathrm{HN}-\mathrm{NH}$ and $-\mathrm{NH}_{2}$ intermediates [67].

The photocatalytic reduction of nitrogen to ammonia generally involves a dissociative mechanism and an associative mechanism (Fig. 3) [88]. For the dissociative mechanism (Fig. 3(a)), the $\mathrm{N} \equiv \mathrm{N}$ triple bond is split into two nitrogen atoms followed by subsequent hydrogenation of individual nitrogen atoms to form $\mathrm{NH}_{3}$. This mechanism resembles the classical Haber-Bosch process [89, 90]. It is known that breaking the $\mathrm{N} \equiv \mathrm{N}$ triple bond $\left(945 \mathrm{~kJ} \cdot \mathrm{mol}^{-1}\right)$ requires extremely high energy inputs, so only very limited photocatalysts can successfully drive this reaction process. If experiments indicate that this mechanism is the dominant one for a certain type of photocatalyst, the design principles from thermal catalysis outlined above might be worth to try for improvement of the catalytic function. In the associative mechanism, the hydrogenation of adsorbed $\mathrm{N}_{2}$ molecules occurs without cleavage of the $\mathrm{N} \equiv \mathrm{N}$ bond, analogous to biological nitrogen fixation. It is regarded as the dominated mechanism for photocatalytic $\mathrm{N}_{2}$ conversion to $\mathrm{NH}_{3}$. Two possible pathways i.e., distal and alternating pathways, may be involved, leading to distinct intermediates [91, 92]. For the distal pathway, continuous protonation is carried out on the nitrogen atom farthest from the surface of the catalyst to generate an $\mathrm{NH}_{3}$, which is then released, leaving another nitrogen atom on the surface for further hydrogenation (Fig. 3(b)). In regard to the alternating pathway, two nitrogen atoms are hydrogenated alternately to yield $\mathrm{N} \equiv \mathrm{NH}^{*}, \mathrm{NH}=\mathrm{NH}^{*}, \mathrm{NH}-\mathrm{NH}_{2}{ }^{*}, \mathrm{NH}_{2}-\mathrm{NH}_{2}{ }^{*}$, and finally to $\mathrm{NH}_{3}$ (Fig. 3(c)).

\subsection{Oxidation half-reaction and effect of $\mathrm{O}_{2} / \mathrm{CO}_{2}$ on $\mathrm{N}_{2}$ reduction}

Photocatalytic $\mathrm{N}_{2}$ reduction to $\mathrm{NH}_{3}$ comprises two coupled redox half reactions, and the overall reaction entails transfer of six electrons. However, most studies only focused on the reduction reaction, the oxidation half-reaction is usually ignored. The photocatalytic redox reaction is determined by the relative position of the reduction potential of the reactants and the energy band structure of the semiconductor. From the perspective of thermodynamics, if the VB potential of a semiconductor is higher than the oxidation potential of water, it is thermodynamically feasible for photo-generated holes to react with water to generate $\mathrm{O}_{2}$, or possibly even strongly oxidizing hydroxyl radicals $\cdot \mathrm{OH}\left(2 \mathrm{H}_{2} \mathrm{O}+4 \mathrm{~h}^{+} \rightarrow \mathrm{O}_{2}+4 \mathrm{H}^{+}\right.$, $E_{\text {redox }}^{0}=0.81 \mathrm{~V}$ vs. $\mathrm{NHE}$ at $\mathrm{pH}=7$ or $\mathrm{H}_{2} \mathrm{O}+\mathrm{h}^{+} \rightarrow \cdot \mathrm{OH}+\mathrm{H}^{+}$, $E_{\text {redox }}^{0}=2.32 \mathrm{~V}$ vs. $\mathrm{NHE}$ at $\mathrm{pH}=7$ ) [93]. The impact of $\mathrm{O}_{2}$ on the photoreduction of $\mathrm{N}_{2}$ is still open for further exploration. Recently, Hirakawa and co-workers demonstrated that bubbling with air could suppress $\mathrm{NH}_{3}$ formation over $\mathrm{TiO}_{2}$ [67]. This was supposed to arise from the easier reduction of $\mathrm{O}_{2}$ compared to $\mathrm{N}_{2}$ using the electrons in the $\mathrm{CB}\left(\mathrm{O}_{2}+\mathrm{e}^{-} \rightarrow \mathrm{O}_{2}{ }^{-}\right.$, $E^{0}=-0.137 \mathrm{~V}$ vs. $\mathrm{NHE}$ at $\left.\mathrm{pH}=7\right)[52,93]$. Furthermore, the $\mathrm{OH}$ originating from self-oxidation of $\mathrm{H}_{2} \mathrm{O}$ could oxidize the photo-formed $\mathrm{NH}_{3}$ to yield nitrite or nitrate. Consequently, the $\mathrm{O}_{2}$ or $\cdot \mathrm{OH}$ resulting from the oxidation half-reaction is unfavorable for the reduction of $\mathrm{N}_{2}$.

Some semiconductors exhibit poor ability for water oxidation, hence a hole sacrificial reagent (i.e., $\mathrm{Na}_{2} \mathrm{SO}_{3}$, amines, alcohols, and ethylene diamine tetraacetic acid) is always needed to consume accumulated holes and improve the $\mathrm{N}_{2}$ conversion to $\mathrm{NH}_{3}$ [94]. Methanol is demonstrated to be more suitable and effective than the other hole sacrificial reagents, because it loses electrons more easily owing to its lower HOMO [95]. The impact of $\mathrm{CO}_{2}$ on the photoreduction of $\mathrm{N}_{2}$ also requires further investigation. It was recently reported that methanol added during a photocatalytic process could be easily oxidized to form formic acid and $\mathrm{CO}_{2}$ by photogenerated holes $\left(\mathrm{h}^{+}\right)$on

(a) $\mathrm{C}=0$

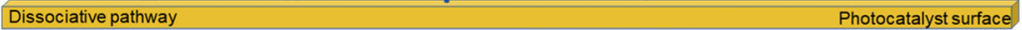

(b)

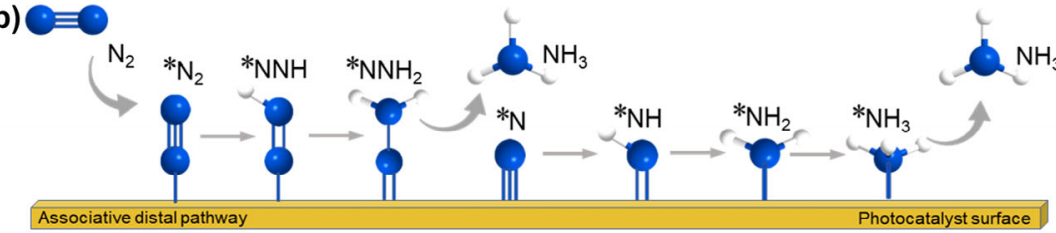

(c)

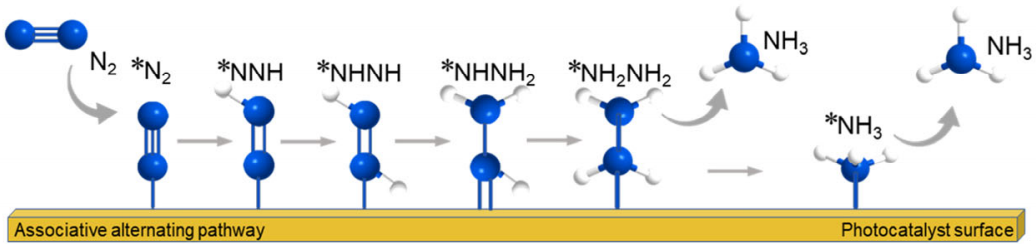

Figure 3 Proposed mechanisms for $\mathrm{N}_{2}$ reduction to produce ammonia [88]. 
Au/HCNS-NV (Au nanoparticle-embedded hollow mesoporous carbon nitride spheres with abundant nitrogen vacancy) [96]. $\mathrm{CO}_{2}$ was demonstrated to be readily adsorbed on the surface of $g-\mathrm{C}_{3} \mathrm{~N}_{4}$ nanosheets to generate $\mathrm{CO}_{2}{ }^{--}$intermediates, which accelerated the $\mathrm{N}_{2}$ photoreduction to $\mathrm{NH}_{3}$ owing to its strong reducing capability $\left(E_{\mathrm{CO} 2} / \mathrm{CO}_{2--}=1.8 \mathrm{~V}\right)\left(5 \mathrm{~N}_{2}+2 \mathrm{CO}_{2}{ }^{-{ }^{-}}+4 \mathrm{H}_{2} \mathrm{O}\right.$ $\left.\rightarrow 2 \mathrm{NH}_{3}+2 \mathrm{CO}_{2}+2 \mathrm{OH}^{-}\right)[97,98]$. However, the introduction of hole sacrificial reagents is not a sustainable process, and it may also interfere subsequent $\mathrm{NH}_{3}$ quantification and cause photocatalyst corrosion $[99,100]$. In this regard, the use of hole sacrificial reagents is a double-edged sword and should be carefully considered.

\subsection{Photon-driven disproportionation reaction of $\mathrm{N}_{2}$}

As described in section 2.5, the $\mathrm{N}_{2}$ reduction to $\mathrm{NH}_{3}$ involves two coupled redox half reactions and disproportionation reaction may concurrently take place (overall reaction: $4 \mathrm{~N}_{2}+$ $9 \mathrm{H}_{2} \mathrm{O} \rightarrow 5 \mathrm{NH}_{3}+3 \mathrm{HNO}_{3}$ ), leading to the formation of different products (such as $\mathrm{N}_{2} \mathrm{H}_{4}, \mathrm{NO}_{3}{ }^{-}$) $[101,102]$. The selectivity of $\mathrm{N}_{2}$ reduction to $\mathrm{NH}_{3}$ is substantially reduced as a result of the disproportionation reaction. It is thus desirable to identify the oxidation products, especially when using water as a proton source, because the oxidation half reaction may generate oxidizing substances, such as $\mathrm{HClO}, \cdot \mathrm{OH}, \mathrm{H}_{2} \mathrm{O}_{2}$, or others, which may oxidize ammonia to nitrate [103]. For example, the by-product nitrate $\left(\mathrm{NO}_{3}^{-}\right)$was observed during photocatalytic $\mathrm{N}_{2}$ reduction in pure water over $\mathrm{W}_{18} \mathrm{O}_{49}$ nanowires rich in oxygen vacancies (OVs) under simulated solar light from 427 to $515 \mathrm{~nm}$ [104]. The production of $\mathrm{NH}_{4}{ }^{+}$and $\mathrm{NO}_{3}{ }^{-}$resulting from the disproportionation reaction severely limits the $\mathrm{N}_{2}$ photo-reduction efficiency and selectivity. Note that, the exact mechanism on the disproportionation of $\mathrm{N}_{2}$ remains elusive thus far. Alternatively, Fe-doped $\mathrm{TiO}_{2}$ microspheres with OVs were also found to disproportionate nitrogen into nitrate under photon illumination [105]. It was speculated that Fe doping introduced energy levels in the $\mathrm{TiO}_{2}$ band gap, thus altering the redox ability of photogenerated carriers [106], which favored the formation of $\mathrm{H}_{2} \mathrm{O}_{2}$ from $\mathrm{H}_{2} \mathrm{O}$ adsorbed on the catalyst surface. The formed $\mathrm{H}_{2} \mathrm{O}_{2}$ then oxidized $\mathrm{NH}_{3}$ into nitrate. Using catalysts such as plasmonic Au nanoparticles that are effective for $\mathrm{H}_{2} \mathrm{O}_{2}$ decomposition can combat the further oxidation of ammonia in favor of the reductive reaction [107]. Consequently, elemental doping or/and plasmon modification appears a method of choice to suppress photon-driven disproportionation reaction of $\mathrm{N}_{2}$ and improve the selectivity towards $\mathrm{NH}_{3}$.

To inhibit the oxidation of $\mathrm{N}_{2}$ reduction products and improve the $\mathrm{NH}_{3}$ selectivity, a three-phase suspension system can be applied for the $\mathrm{N}_{2}$ photoreduction [27]. Specifically, the semiconductor material is suspended at the gas-liquid interface towing to the presence of surface tension, while $\mathrm{N}_{2}$ gas is continuously introduced to the water/photocatalyst interface. The $\mathrm{N}_{2}$ concentration in the gas phase above the photocatalyst can be about 140 times that of water saturation, so the $\mathrm{N}_{2}$ concentration on the photocatalyst surface of the three-phase system is dramatically higher than in the two-phase system, thus remarkably improving the $\mathrm{NH}_{3}$ production rate [27]. Perhaps more importantly, $\mathrm{O}_{2}$ and $\mathrm{NH}_{3}$ are separated by the gas phase and the water phase on both sides of the photocatalyst in the three-phase system. This can effectively suppress the oxidation of $\mathrm{NH}_{3}$.

\subsection{Measurement and quantification of $\mathrm{NH}_{3}$}

A variety of techniques have been attempted to determine the amount of $\mathrm{NH}_{3}$ produced during nitrogen photoreduction reaction and can be mainly divided into six types, including (1) spectrophotometry (or colorimetry), (2) ion chromatography (IC), (3) ion-selective electrode (ISE), (4) fluorescence, (5) ${ }^{1} \mathrm{H}$ NMR spectroscopy, and (6) ultrahigh performance liquid chromatography-mass spectrometry (UPLC-MS) [108, 109]. Currently, photocatalytic nitrogen reduction studies are heavily reliant on the spectrophotometric/colorimetric methods using indophenol blue [110] and Nessler's reagents [111]. The methods have been well established with advantages of good sensitivity $\left(0-0.6 \mathrm{mg}_{\mathrm{NH}_{3}-\mathrm{N}} \cdot \mathrm{L}^{-1}\right)$ and low cost. Recently, a frequencyselective pulse nuclear magnetic resonance (NMR) technique was proposed to detect the micromolar concentration of $\mathrm{NH}_{3}$ (present in the assay as $\mathrm{NH}_{4}^{+}$) in an electrolyte after electrocatalysis [112]. This NMR technique was supposed to be suitable for various conditions, including nondeuterated, nonaqueous and aqueous electrolytes, and would not require separation of $\mathrm{NH}_{3}$ from the electrolyte. Its sensitivity to $\mathrm{NH}_{3}$ can reach $1 \mu \mathrm{M}$ with isotopic and chemical specificity. An alternative gas chromatographic (GC) method was attempted for in situ ammonia detection [113]. The in situ GC method was shown to quantify ammonia present in the gas phase in less than 5 min analysis time with a detection limit of about $150 \mathrm{ppb} v / v\left(\sim 110 \mathrm{ng} / \mathrm{L} \mathrm{NH}_{3}\right.$ or $6.5 \mathrm{nM} \mathrm{NH}_{3}$ in the gas phase), a threshold level relevant to studying and screening (electro)catalysts. This GC method can also determine the ammonia concentration in the electrolyte solution, enabling full quantification of the analyte under consideration. More recently, a nonperturbative approach to ammonia detection was presented based on all-optical detection of surfaceenhanced Raman signals (SERS) [114]. This approach was claimed to feature with chemical selectivity to ammonia, allowing rapid detection of sub-1 ppm ammonia in under $1 \mathrm{~s}$, which shows potential for ultra-sensitive in situ/operando chemical experiments. Another advantage is that SERS detection does not have any restrictions on the identity or morphology of electrodes. Ammonia close to the electrode on a micro- and macro-scale can be detected, providing a local reading of ammonia closest to the reaction site.

It should be pointed out that each of these methods has advantages and limits for assaying ammonia. To attain an overall level of accuracy and accountability, it is strongly recommended to use a combination of different approaches [115]. Moreover, it is imperative to develop more selective, sensitive, accurate, and robust protocols for ammonia quantification, as well as in situ and continuous processes for monitoring the nitrogen photoreduction process.

\subsection{Impact of impurities on $\mathrm{NH}_{3}$ detection}

It becomes more and more recognized that the very small yields nowadays achievable in photo- and electrocatalysis bear the danger that impurities present in the catalyst or in the reactor construction materials may be liberated under reaction conditions, participate in the target reaction, and be consequently falsely detected as reaction products. This is by now well established for photocatalytic $\mathrm{CO}_{2}$ reduction $[93,116,117]$. It is easily conceivable that organic impurities, such as leftovers from solvents and precursors, or rubber- and grease-based sealing materials, may be present that could contribute to the formation of organic products such as methane or methanol. For nitrogen, being predominantly present as gaseous dinitrogen that one is anyway intending to convert, this is not so straightforward. However, in 2019 potential sources of error have been discussed extensively for electrochemical ammonia synthesis, leading to a complicated, but rigorous, measurement protocol capable of detecting false positive results (Fig. 4) [109, 118]. 


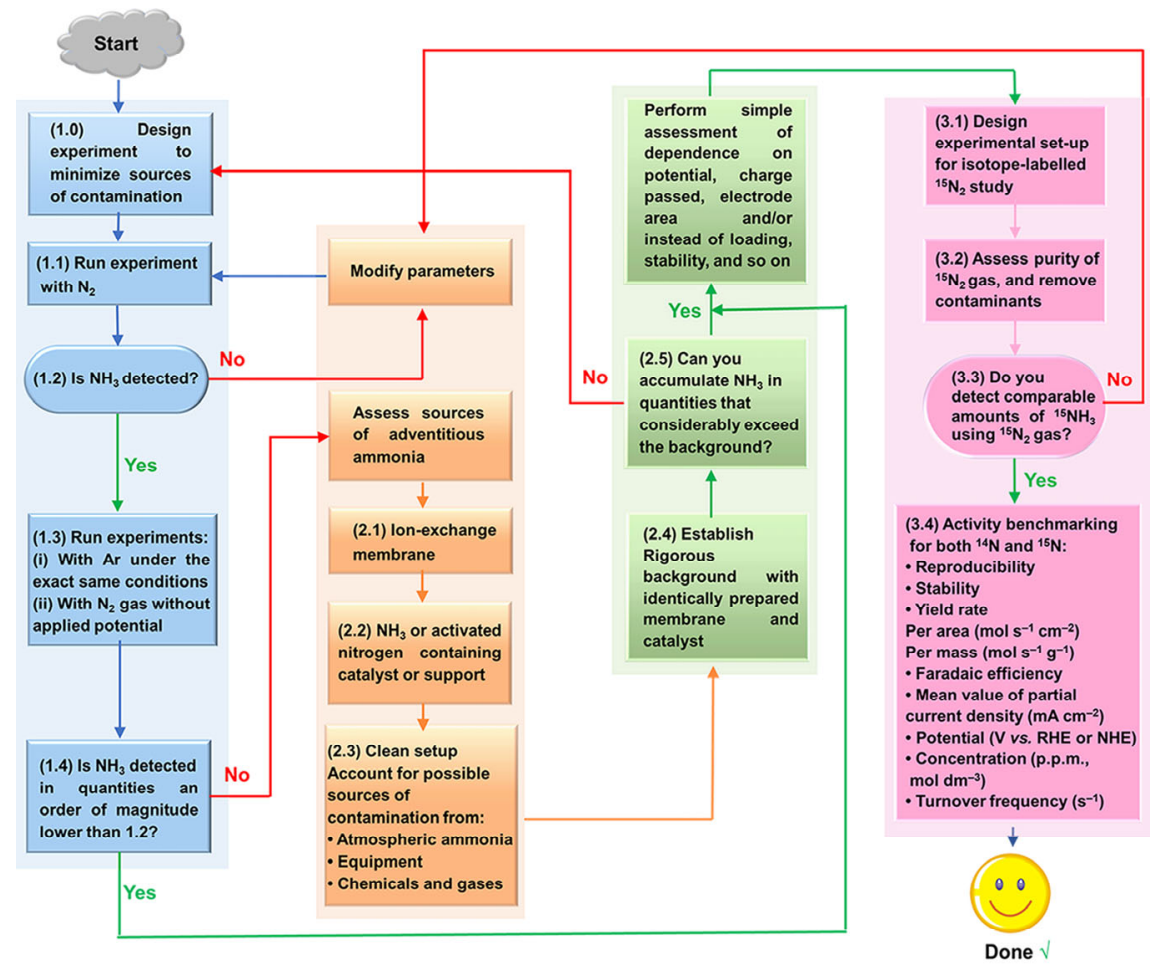

Figure 4 Suggested rigorous measurement protocol for electrochemical nitrogen reduction to ammonia. Reproduced with permission from Ref. [109], (c) Elsevier Inc. 2021.

Adventitious sources of nitrogen were proposed to be (1) membranes in the electrochemical setup, for example made from Nafion which can accumulate ammonium ions, (2) small amounts of ammonia present in air ( $<1$ to $250 \mathrm{ppm}$ ) of human breath $\left(\sim\right.$ few ppm), or (3) $\mathrm{NO}_{x}$ impurities in the nitrogen gas. Consequently, as already suggested in 2018 [119, 120], control experiments using Ar instead of $\mathrm{N}_{2}$ are advised, a procedure also adopted in photocatalysis [121]. Furthermore, ${ }^{15} \mathrm{~N}_{2}$ should be used whenever possible to confirm that yields of ${ }^{15} \mathrm{NH}_{3}$ are as high as for the unlabeled case. But even then, the ${ }^{15} \mathrm{~N}_{2}$ may similarly contain ${ }^{15} \mathrm{NO}_{x}$ or ${ }^{15} \mathrm{NH}_{3}$, so careful monitoring and purification of the gas supply is also required for the labeled gas.

Other researchers [122] particularly highlighted the potential presence of nitrogen-containing species in the electrolyte, for example resulting from nitrate impurities in lithium salts. Control experiments with pure electrolyte in an Ar atmosphere are required to identify these impurities. For photocatalytic nitrogen reduction to ammonia, care must also be taken that carbon impurities are excluded, because they too may contribute to the reaction [123]. It has even been suggested that activation of nitrogen on titania can take place exclusively in presence of carbon on the surface, because carbon radicals are involved in the process. By a combination of ambient pressure X-ray photoelectron spectroscopy (XPS) and density functional theory (DFT) calculations, a reaction pathway has been proposed in which a $\mathrm{CN}_{2}$ species is hydrogenated to liberate ammonia in the end [124].

The above discussion highlights the complexity of the potential sources and influences of impurities. In order to correctly determine the mode of action of carefully designed defects in photocatalytic ammonia formation, care must be taken to address these issues in their entirety.

\subsection{Aspects to be taken into consideration}

Although encouraging advances have been made in ambient photocatalytic ammonia synthesis, there are several factors that need to be taken into consideration [57]. (1) The amounts of ammonia evolved are usually determined by ion chromatography, aqueous-based spectrophotometric/colorimetric assays, ion-selective electrode, and fluorescence methods [99, 125]. However, in many photocatalytic nitrogen reduction processes, sacrificial agents are used, which may disturb the measurements [100]. Multiple combined quantification methods are thus recommended to further confirm the reliability of the test results. (2) The diffusion of nitrogen molecules to the active sites of heterogeneous photocatalytic materials is a critical step in the $\mathrm{N}_{2}$ reduction reaction [41]. The extremely low solubility of dinitrogen gas in water-based electrolytes (0.66 $\mathrm{mmol} \cdot \mathrm{L}^{-1}$ under room temperature and atmospheric pressure) [126], however, drastically restricts the diffusion and local nitrogen concentration on the catalyst surface, thus affecting ammonia yield. This issue can be ameliorated by increasing the $\mathrm{N}_{2}$ chamber pressure to enhance dissolution of nitrogen [127]. (3) The origin of nitrogen in ammonia should be carefully tracked because it may come from potential exogenous nitrogen contaminants which may be present in the air, environment, human respiration, sample tubing, lab coat, latex glove, stale Milli-Q water, etc $[122,128]$. Any possible contaminants could give rise to uncertainty and even false positives data on the photocatalytic nitrogen reduction performance. Therefore, it is urgently desired to establish reliable and accurate methods for quantifying $\mathrm{NH}_{3}$ production and rule out other extraneous contamination sources [129]. Performing isotope labeling using ${ }^{15} \mathrm{~N}_{2}$ both qualitatively and quantitatively is strongly suggested to verify the $\mathrm{N}$ source of the detected $\mathrm{NH}_{3}$ and elucidate reaction mechanisms especially for metal nitride semiconductors [118]. (4) Side reactions may happen during the photocatalytic nitrogen reduction, yielding products such as $\mathrm{N}_{2} \mathrm{H}_{4}, \mathrm{NO}_{3}^{-}$, and $\mathrm{H}_{2}$, which thus lowers the selectivity of $\mathrm{N}_{2}$ reduction to $\mathrm{NH}_{3}$ [105]. Also, $\mathrm{H}_{2} \mathrm{O}$ is used as a source of protons. The oxidation half reaction may generate oxidizing substances, such as $\mathrm{O}_{2}, \cdot \mathrm{OH}, \mathrm{H}_{2} \mathrm{O}_{2}$, or others, which may oxidize ammonia to nitrate. (5) The stability of photocatalyst 
is a crucial metrics in evaluating the performance for practical applications. An efficient and robust photocatalyst is expected to remain excellent stability during continuous photocatalytic processes. Nevertheless, most current stability tests of the photocatalyst only involve a few cycles and the total reaction time is a few hours, which are far from practical industrial applications [130]. The poisoning and deactivation of photocatalysts remain to be further explored and clarified. Overall, the photocatalytic ammonia synthesis is still in the initial stage, and deserves enormous research efforts to address the above-mentioned issues and upgrade this technology.

\section{Defect engineering of semiconductor photocatalysts}

Defects are usually present in semiconductor photocatalysts. Defect engineering enables one to modulate the local surface microstructure, electronic band structure, and chemical properties of a photocatalyst to enhance its performance for the nitrogen reduction to ammonia $[72,131]$. The activity of a photocatalyst for ammonia synthesis is closely related to the nature of defects. It must be pointed out that the role of defects is complicated in photocatalysis, as they may not be associated exclusively with beneficial effects but may also reduce photocatalytic activity. As will be discussed below, they may also act as recombination centers or undesired trap states. As such, understanding the structure and property of defects would help rationally design high-performance semiconductor photocatalysts. In this section, we will provide brief discussions on the classification, synthesis strategies, and characterization of defects.

\subsection{Categories of defects}

Defects can be classified according to their atomic structure and location in semiconductor photocatalysts. (1) Depending on their dimensions, defects can be categorized as zerodimensional (0D) point defects (e.g., vacancy and doping), one-dimensional (1D) line defects (e.g., screw dislocation and edge dislocation), two-dimensional (2D) planar defects (e.g., grain boundary and twin boundary), and three-dimensional (3D) volume defects (e.g., lattice disorder and void) (Fig. 5) $[132,133]$. At present, 1D and high-dimensional defects are relatively less discussed in photocatalytic nitrogen reduction. $0 \mathrm{D}$ point defects (i.e., vacancies and impurities) were observed to play predominant roles in improving nitrogen reduction. Hence, we mainly correlate the photocatalytic $\mathrm{N}_{2}$ reduction performance with the point defects. (2) Depending on their location, defects are grouped into surface/interface defects, subsurface and bulk defects $[134,135]$. Recent results revealed that bulk defects could act as recombination centers for photogenerated electrons and holes, being unfavorable for photocatalytic activity $[135,136]$. In contrast, surface defects may offer new active sites for transfer of photogenerated carriers to the adsorbate, accelerating carrier separation and adsorption of small target molecules on the photocatalyst, benefiting photocatalysis [67]. A spatial and electronic synergy was put forth by introducing surface defects and bulk defects. This not only promotes bulk separation of electrons and holes but also can efficiently lower the conduction band and serve as a capture center for electrons [137]. Subsurface oxygen vacancies were found to enhance conductivity and electron transfer of $\mathrm{TiO}_{2}$, benefiting photocatalytic activity [138]. Interface defects are regarded as the most complex defects, in which the defects exist between the interfacial contacts. Interface defects can promote the interaction between different semiconductors.

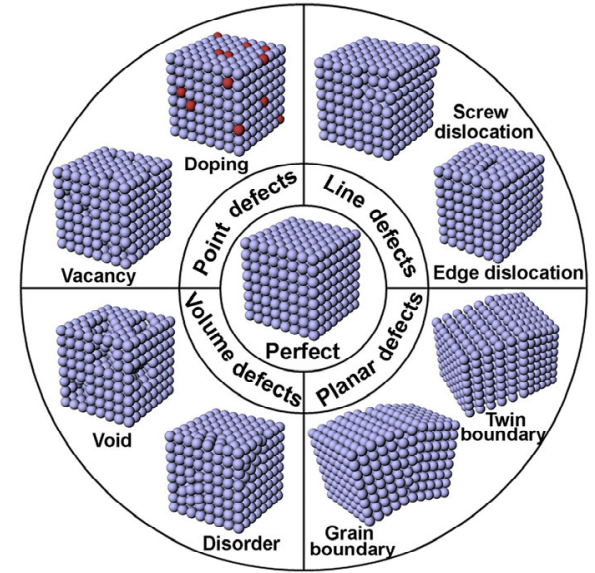

Figure 5 Schematic illustration of the types of common defects in semiconductor photocatalysts. Reproduced with permission from Ref. [133], @ Elsevier Ltd. 2018.

Due to the differences in the electronic structure of the defects, there may be a strong interaction between the crystals and the defects, which is conducive to the transfer of photogenerated carriers [134]. It has been demonstrated that supersaturated vacancies are prone to precipitate into voids or defect clusters [139]. The aggregation of defects, therefore, may induce the process of phase separation and further evolve to interface/ grain boundaries. Moreover, simulations indicated that energy barriers for defect migration were lower near the interface in composites [139]. This can explain the higher activity on the interface, where the density of defects should be higher than the bulk [140]. On the other hand, defects in semiconductors can optimize the contact interface, transforming the type II heterojunction into a direct $\mathrm{Z}$-scheme structure, thereby enhancing redox ability [141, 142]. (3) According to the involved elements, the defects can be subdivided into OVs, nitrogen vacancies (NVs), sulfur vacancies (SVs), carbon vacancies (CVs), fluorine vacancies (FVs), and other elements vacancies. Additionally, starting from a broader definition, single-atom catalysts is also considered as defects $[38,143]$.

As already briefly addressed above, the type and location of a defect may decide whether it has beneficial or detrimental effects. The knowledge base in photocatalysis obtained so far makes it difficult to define generally valid design rules, because a defect beneficial in one material may be detrimental in another. Yet, the following general rules have been developed until today: (1) Surface defects are usually preferred over bulk defects when they are supposed to act as trap states, because charge carriers trapped in the bulk cannot participate in the catalytic process $[135,136]$; (2) charge carriers located at defects must still provide sufficient oxidation or reduction potential to allow for the target reaction to occur, so shallow traps are usually preferred over deep traps; and (3) catalytic active sites often need defective structures, because low-coordinated sites are usually needed for reactant activation [144].

\subsection{Synthetic strategies for defects}

The synthetic strategy determines the defect type and consequently impacts the performance of photocatalytic materials $[145,146]$. Diverse synthetic protocols for creating defects have been developed for the $\mathrm{N}_{2}$ photoreduction, which can be mainly split into post-treatment methods and in situ synthetic strategies.

\subsubsection{Post-treatment methods}

A post-treatment method to introduce defects involves two 
steps, including photocatalyst synthesis and further partial reduction of semiconductor photocatalysts.

\subsubsection{Chemical reduction}

Chemical reduction is believed to be an effective strategy to introduce defects in semiconductors. This can be achieved by thermal treatment in reducing gas atmospheres $\left(\mathrm{H}_{2}, \mathrm{CO}, \mathrm{NH}_{3}\right.$, and $\mathrm{H}_{2} \mathrm{~S}$ ) or through an electro-reduction route. The concentrations of different defects in semiconducting materials can be readily tuned by manipulation of the treatment temperature, time, and reducing gas composition. $\mathrm{H}_{2}$ atmosphere is able to reduce $\mathrm{Bi}_{5} \mathrm{O}_{7} \mathrm{I}, \mathrm{Bi}_{2} \mathrm{MoO}_{6}$, and $\mathrm{TiO}_{2}$, creating large amounts of exposed OVs [147-149]. NVs were also reported through $\mathrm{H}_{2}$ treatment $[52,150,151] . \mathrm{NH}_{3}$ is also employed as a reducing gas to treat $g-\mathrm{C}_{3} \mathrm{~N}_{4}$ and generate CVs $[152,153]$.

Compared to thermal treatments in reducing atmospheres, the electrochemical reduction method is more convenient, greener, and energy-saving. Defective $\mathrm{TiO}_{2}$ nanobamboo arrays $\left(\mathrm{DTiO}_{2}\right.$ NBAs) were synthesized by using the electro-reduction strategy and were shown to effectively catalyze the $\mathrm{N}_{2}$ reduction to $\mathrm{NH}_{3}$ in the visible and near infrared light range [154].

\subsubsection{Thermal treatment}

Conventional thermal processing can create various defects as a result of atom escape accelerated by high temperature [155-157]. As an example, hollow porous prismatic $g-\mathrm{C}_{3} \mathrm{~N}_{4}$ with NVs and oxygen doping was attained by combining low-temperature hydrothermal treatment and a subsequent annealing process [84]. It was proposed that the photogenerated electrons in the $\mathrm{CB}$ quickly migrated to the NVs inducing a mid-gap state, which thus promoted the separation and transfer of photogenerated carriers and boosted the photocatalytic $\mathrm{N}_{2}$ reduction to $\mathrm{NH}_{3}$. Likewise, OVs rich- $-\mathrm{TiO}_{2}$ nanosheets decorated with $\mathrm{Au}$ nanocrystals were obtained through low-temperature hydrothermal synthesis followed by thermal treatment in Ar atmosphere [158]. The OVs and Au nanocrystals in the hybrid were hypothesized to contribute to the $\mathrm{N}_{2}$ photoreduction by a "working-in-tandem" mechanism, akin to the nitrogenase enzyme system. NVs were also introduced in $g-\mathrm{C}_{3} \mathrm{~N}_{4}$ using a similar facile thermal treatment approach either in air [159] or $\mathrm{N}_{2}$ atmosphere [160] for enhanced $\mathrm{N}_{2}$ photoreduction.

\subsubsection{Force-induced strategies}

Defects on semiconductor materials can be induced after subject to plasma etching, alkali assisted etching, and ultrasound irradiation. Plasma etching can construct various intrinsic defects into the semiconductors [161]. Nitride-based photosensitizing semiconductors (i.e., $p$-GaN, $i-\mathrm{GaN}$, and $n-\mathrm{GaN}$ ) with NVs have been prepared by plasma-assisted molecular beam epitaxy on commercially available $\mathrm{Si}(111)$ wafer [162]. Dielectric barrier discharge plasma treatment was demonstrated to construct $\mathrm{NVs}$ and sulfur co-doped $g-\mathrm{C}_{3} \mathrm{~N}_{4}$ for active photocatalytic $\mathrm{N}_{2}$ reduction to $\mathrm{NH}_{3}$ [163].

Alkali assisted etching is another force-induced defect method with benefits of simpleness, efficiency, and low cost. OVs enriched $\mathrm{Bi}_{2} \mathrm{MoO}_{6}$ [164] and bimetallic layered-doublehydroxide (LDH) (ZnCr-LDH, ZnAl-LDH, and NiAl-LDH) nanosheets [165] were produced via an alkali etching approach. Alternatively, ultrasound irradiation was also shown to create defects mainly due to cavitation and induced ultrasonication chemistry $[46,166-168]$.

\subsubsection{In situ synthetic strategies}

As opposed to post-treatment methods, the type and density of intrinsic defects in semiconductors are directly regulated during the synthesis process.

\subsubsection{Hydro/solvothermal method}

The hydro/solvothermal method using water, alcohol, or a mixture of both as solvents has been intensively applied to introduce various defects on semiconductor materials with features of convenience, simple operation, and cost-effectiveness [145]. MIIMIII-LDH (MII = Mg, Zn, Ni, Cu; MIII = Al, Cr) nanosheet photocatalysts with OV defects have been synthesized based on a one-step hydrothermal method [169]. The introduction of OVs in the CuCr-LDH nanosheets was surmised to induce distortion of $\mathrm{MO}_{6}$ octahedrons, contributing to the superior $\mathrm{N}_{2}$ photoreduction to $\mathrm{NH}_{3}$. Analogously, SVs and O-doping were collaboratively introduced into $1 \mathrm{~T}-\mathrm{MoS}_{2}$ nanosheets, significantly enhancing the $\mathrm{N}_{2}$ adsorption and activation [170]. Hydrothermal treatment by microwave was also reported to construct $1 \mathrm{D}$ attapulgite (ATP) mineral supported $\mathrm{Pr}^{3+}: \mathrm{CeF}_{3}$ nanocomposite with abundant FVs [171]. The FVs along with $\mathrm{Pr}^{3+}$ doping was supposed to expand light absorption range and also provide abundant active sites, jointly facilitating the adsorption of $\mathrm{N}_{2}$ and weakening the $\mathrm{N} \equiv \mathrm{N}$ triple bond. Moreover, $\mathrm{BiOBr}$ nanosheets with desirable OVs and dominant exposed (001) facets were fabricated by controlling the addition of polyvinylpyrrolidone (PVP) during the solvothermal process [172]. Single-unit-cell $\mathrm{Bi}_{3} \mathrm{O}_{4} \mathrm{Br}$ nanosheets with tunable surface defects were also prepared and showed boosted photocatalytic nitrogen fixation by mediating electron-hole separation [173].

\subsubsection{Low-valence metal doping}

Introduction of low-valence metals can alter redistribution of the electronic structures of semiconductors, defects are hence generated to balance the positive and negative charges. Lowvalence metal species can serve as the coordinatively unsaturated sites with electron-rich properties, conducive to adsorption and activation of reactants on the catalyst surface, thereby improving photocatalytic activity $[41,174,175]$. For instance, $\mathrm{W}_{18} \mathrm{O}_{49}$ ultrathin nanowires with $\mathrm{OVs}$ were synthesized via subtle Mo doping [66]. The doped low-valence Mo species was calculated to polarize the chemisorbed $\mathrm{N}_{2}$ molecules and facilitate the electron transfer from coordinatively unsaturated sites to $\mathrm{N}_{2}$ adsorbates, making dissociation of the $\mathrm{N} \equiv \mathrm{N}$ bond more feasible. In addition, the defect-band center was elevated toward the Fermi level, preserving the energy of photoexcited electrons for $\mathrm{N}_{2}$ reduction. $\mathrm{TiO}_{2}$ nanosheets with $\mathrm{OVs}$ and intrinsic compressive strain were obtained by employing a $\mathrm{Cu}$-doping strategy [176]. Based on a similar route, OVs were introduced in ZnAl-LDH nanosheets [177]. It was supposed that $\mathrm{Cu}$ addition gave rise to OVs and coordinatively electronrich unsaturated $\mathrm{Cu}^{\delta+}(\delta<2)$. This accelerated separation of photogenerated carriers and promoted $\mathrm{N}_{2}$ adsorption and activation, thereby enhancing photocatalytic $\mathrm{N}_{2}$ reduction to $\mathrm{NH}_{3}$.

\subsubsection{Light irradiation}

Light irradiation enables one to create defects in some semiconductors during a photocatalytic process $[108,178,179]$. Creation of $\mathrm{OVs}$ on the surface of $\mathrm{Bi}_{5} \mathrm{O}_{7} \mathrm{Br}$ nanotubes was observed upon visible-light photoirradiation [180, 181]. In light of the high $\mathrm{O}$ atom concentration, low bond energy, and long bond length of the $\mathrm{Bi}-\mathrm{O}$ bond in $\mathrm{Bi}_{5} \mathrm{O}_{7} \mathrm{Br}$, the $\mathrm{Bi}-\mathrm{O}$ bonds were easily dissociated by UV light irradiation. $\mathrm{O}$ atoms were dragged away through strong interactions with solvent ligands, leaving the OVs on the $\mathrm{Bi}_{5} \mathrm{O}_{7} \mathrm{Br}$ surface. However, this method is unsuitable to break the strong metal-oxygen bonds to generate OVs for metal oxides.

Apart from the above-mentioned methods, there are also several promising synthesis strategies that haven't been explored 
in photocatalytic $\mathrm{N}_{2}$ reduction reaction. For instance, ball milling deforms the material structure, substantially reduces the volume, and exposes defects, providing an economical, effective, and reliable approach to creating vacancy edge defects [182]. Molten salt (MS) synthesis can induce vacancy defects in metal compounds and $g-\mathrm{C}_{3} \mathrm{~N}_{4}[183,184]$. An alternative lithium reduction strategy can implant defects into a series of metal oxides, such as $\mathrm{TiO}_{2}, \mathrm{ZnO}, \mathrm{SnO}_{2}, \mathrm{CeO}_{2}$ and their mixtures at ambient conditions [185-187]. Among others, vapor diffusion can allow one to construct defects on photocatalysts with desired location and density [188].

\subsection{Identification of defects}

Although the introduction of defects by suitable defect engineering has a positive effect on photocatalysis, the recognition and quantification of defects at the atomic level is still a grand challenge. The further one clarifies the atomic structures of defects and specifies their concentrations by advanced characterization technologies, the more helpful it is to establish the relationship between defect structure and catalytic behavior. This can then guide researchers towards rational design of photocatalysts. To date, several characterization techniques including ex situ and in situ/operando methods have been attempted to identify and quantify the defects in semiconductors for the $\mathrm{N}_{2}$ photoreduction to $\mathrm{NH}_{3}$.

\subsubsection{Ex situ technique studies}

\subsubsection{Transmission electron microscopy (TEM)}

TEM provides the most direct tool for defect investigation, through which surface defects can be visually observed to acquire information with respect to the type and density of vacancies over semiconductor materials. By high-resolution TEM, it is possible to vividly see some lattice defects [168]. Nevertheless, it is still challenging to distinguish the difference between surface defects and bulk defects by TEM. Another issue is that only a small amount of samples is probed by electron microscopy. To confirm the TEM results, it is necessary to couple with other spectroscopic or resonance methods that can examine larger amounts and areas of a particular sample.

\subsubsection{X-ray powder diffraction (XRD)}

XRD is commonly used to identify catalyst defects given that the material diffraction signals may change upon introduction of defects $[189,190]$. It has been recognized that doping with other metal elements can broaden the XRD reflection peaks [191]. For example, the sharpness and relative intensity of XRD peaks of $\mathrm{V}_{\mathrm{O}}-\mathrm{BiOBr}$ nanosheets became significantly reduced compared to $\mathrm{BiOBr}$ nanoplates, implying the presence of OVs in $\mathrm{V}_{\mathrm{O}}-\mathrm{BiOBr}$ nanosheets [172]. Additionally, the XRD peaks may shifted, indicating variation of lattice parameters of a catalyst due to lattice expansion or distortion caused by defects [192]. It was noticed that the (110) Bragg reflections for both $\mathrm{CuCr}-\mathrm{NS}$ and $\mathrm{ZnAl}-\mathrm{NS}$ shifted to higher $2 \theta$ angles relative to bulk $\mathrm{CuCr}$ and $\mathrm{ZnAl}$. This suggested an in-plane biaxial compressive strain in the plane, induced by surface OVs [169]. Although the XRD technique can qualitatively reflect the existence of defects, it fails to provide information on the type and exact location of defects and cannot quantitatively determine the concentration of defects.

\subsubsection{XPS}

XPS is a well-established comparatively surface-sensitive ( $\approx 10 \mathrm{~nm}$ depth) method. It has been intensively applied to detect the surface defect type of a semiconductor photocatalyst
[193, 194]. Commonly, the existing defects in materials can change the electronic structure and chemical environment of the elements, giving rise to differences in the XP spectrum, namely peak shift, intensity variation, or the appearance of new peaks $[181,195]$.

Several papers have appeared nowadays, in which a signal in an X-ray photoelectron spectrum (XP spectrum) in the range of the $\mathrm{O} 1 \mathrm{~s}$ orbital around $530 \mathrm{eV}$ has been assigned to an oxygen vacancy $[181,196,197]$. However, thinking about this logically, it is plainly impossible that an atom that is not there liberates a photoelectron upon irradiation with $\mathrm{X}$ rays. Furthermore, an electron trapped in a vacancy, if liberated, would certainly not show up in an XP spectrum in the range of the $\mathrm{O} 1 \mathrm{~s}$ orbital, because it is much more loosely bound. More reasonable assignments refer to changes in the electronic state of (surface) oxygen atoms caused by the presence of the OVs and associated charge imbalances. For example, a signal at $\sim 530.5 \mathrm{eV}$ has been assigned to highly oxidative oxygen species in a perovskite-type mixed lanthanum cerium ferrite, whereby these particular oxygen species are closely associated with the presence of surface OVs [198]. In a related manner, a signal at $530.55 \mathrm{eV}$ has been assigned to surface oxygen atoms bound to $\mathrm{Ti}^{3+}$ in $\mathrm{TiO}_{2}$ [199]. Indirectly, this signal can also be associated with OVs, because $\mathrm{Ti}^{3+}$ is indicative of a reduced sample. Many other examples may be found, which is outside the scope of this review article. In summary, it has to be kept in mind that OVs cannot be monitored directly by means of XPS, but can be monitored by secondary effects they have on the electronic structure of the sample of interest.

\subsubsection{Electron paramagnetic resonance (EPR)}

EPR is a powerful magnetic resonance technology fundamentally based on the magnetic moment of unpaired electrons, which can be used to qualitatively and quantitatively detect the unpaired electrons contained in the atoms or molecules of substances (e.g., vacancy defects), and to explore the structural characteristics of their chemical environments [200]. Unpaired electrons in various chemical environments can be monitored by EPR in terms of the $g$ value. Different $g$ values and signal intensities are closely related to the type and relative concentration of defects $[201,202]$. In general, for oxide-based materials, signals with $g$ values smaller than 2 are usually associated with foreign dopant atoms, or with pretreatment-induced self-doping (e.g., $\mathrm{Ti}^{3+}$ or $\mathrm{Zn}^{+}$in $\mathrm{TiO}_{2}$ or $\mathrm{ZnO}$ caused by reductive pretreatment) [203-206]. Isotropic signals appearing in very close proximity of the free electron $(g=2.0023)$ are usually attributed to unpaired electrons trapped in (anion) vacancies, such as OVs [203, 205]. Care must be taken to properly distinguish them from anisotropic signals near $g=2$, because they may originate from oxygen-centered radicals, such as superoxide [207, 208]. For instance, an EPR peak with a $g$-value of 1.999 was observed for $\mathrm{BiOBr}$, verifying the presence of OVs. After Fe doping, the EPR peak signal increased apparently. This can be mainly ascribed to the size difference between Fe and $\mathrm{Bi}$ atoms, which brought about structural distortion, and thus created abundant OVs [209]. Apart from identification of anion vacancies, EPR can also probe cation vacancies. Recently, Qiu and co-workers utilized the EPR to detect Ti defect of the $\mathrm{NH}_{2}$-MIL-125 (Ti) [210].

\subsubsection{Raman spectroscopy}

Raman spectroscopy has been widely employed to characterize and analyze chemical bonding energy on the surface of semiconductor $[211,212]$. It is worthwhile mentioning that Raman spectroscopy frequently helps to obtain more detailed 
information on intrinsic defects of carbon materials [212]. For instance, $\mathrm{Li}$ and co-workers used Raman spectroscopy to identify intrinsic defects of graphdiyne@- $\mathrm{Fe}_{3} \mathrm{O}_{4}$ (GDY@Fe-A and GDY@Fe-B) [213]. The level of defects was reflected by the relative intensity ratio of $\mathrm{D}$ to $\mathrm{G}$-band $\left(I_{\mathrm{D}} / I_{\mathrm{G}}\right)$ [212]. Compared with pure GDY $\left(I_{\mathrm{D}} / I_{\mathrm{G}}=0.80\right)$, both GDY@Fe-A $\left(I_{\mathrm{D}} / I_{\mathrm{G}}=0.83\right)$ and GDY@Fe-B $\left(I_{\mathrm{D}} / I_{\mathrm{G}}=0.86\right)$ displayed larger $I_{\mathrm{D}} / I_{\mathrm{G}}$, indicating the existence of much more defects. The Raman peak position of the anatase $\mathrm{E}_{\mathrm{g}}$ mode was observed to have a linear red shift with the concentration of OVs [214]. Raman spectroscopy was also applied to elucidate the dependence of $\mathrm{N}_{2}$ photoreduction rate on $\mathrm{OV}$ concentration [158]. A decrease in the concentration of OVs in $\mathrm{TiO}_{2}$ was observed to induce an increase in the lattice spacing, hence resulting in a red shift of the $\mathrm{E}_{\mathrm{g}}$ mode of anatase in the Raman spectrum. It was further demonstrated that the $\mathrm{N}_{2}$ photoreduction rate decreased nearly linearly with the reduction of $\mathrm{OV}$ concentration.

\subsubsection{Spectroscopic ellipsometry (SE)}

$\mathrm{SE}$ is regarded as a versatile and nondestructive technique, which can be used to characterize thin films and heterostructures, with benefits of high sensitivity to material properties and surface morphology $[215,216]$. For example, SE has been applied to confirm the OVs on a- $\mathrm{TiO}_{2}$ (Fig. 6) [217]. Figures 6(a) and 6(b) illustrate that several intraband absorptions exist in $\mathrm{TiO}_{2}$, which were attributed to the defects of $\mathrm{a}-\mathrm{TiO}_{2}$, resulting in nonzero density of states in the band gap.

\subsubsection{X-ray absorption spectroscopy (XAS)}

XAS has emerged as an effective and indispensable analytical technique which is extensively employed to obtain quantitative
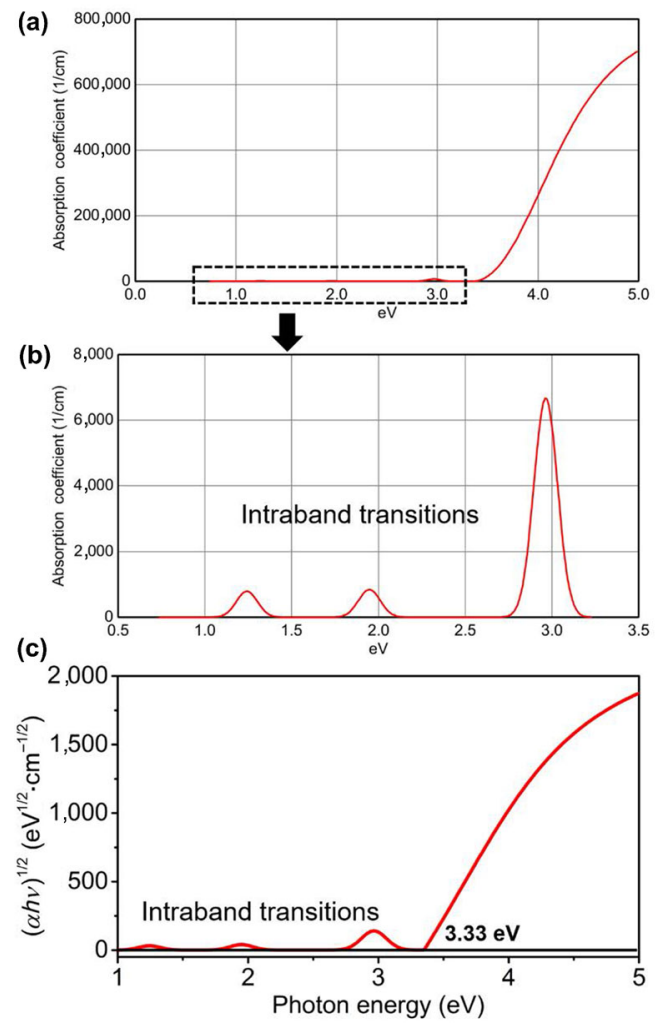

Figure $6 \mathrm{SE}$ spectra of $\mathrm{N}_{2}$ photoreduction reaction on a-TiO $\mathrm{T}_{2}$. (a) Absorption coefficient of ALD a- $\mathrm{TiO}_{2}$ obtained from spectroscopic ellipsometry. (b) Enlarged section in the region of 1.0-3.5 eV, showing several intraband transitions. (c) The intersection with the horizontal axis indicates an optical bandgap of $3.33 \mathrm{eV}$. Reproduced with permission from Ref. [217], (c) Wiley-VCH Verlag GmbH \& Co. KGaA 2018. structural information for semiconductor at the atomic scale (i.e., the oxidation state, bond length, coordination number, and atomic species) [218]. Furthermore, XAS can also enable identification and analysis of the energy-dependent fine structure of the X-ray absorption coefficient $(\mu(E))$ near the absorption edge of a particular element [219]. The $\mu(E)$ represents a smooth function of the photo energy, which can be calculated by $\mu(E)=d Z_{4} / m E_{3}$ where $d, Z$, and $m$ are the target density, atomic number, and atomic mass, respectively. Generally, when the energy of the photon exceeds the binding energy of the core electron, a new absorption channel will be created, resulting in a sharp increase in the absorption coefficient. When the energy is higher than the energy gap between the unoccupied bound state and the core energy level, the photoelectron is promoted to a continuous state, which generates a wave that propagates outward and is scattered on adjacent atoms (Figs. 7(a) and 7(b)) [220]. The interference mode of the emitted and scattered waves is determined by the geometry of the absorbing environment and the wavelength of the photoelectron.

Hence, XAS is commonly categorized as XANES (X-ray absorption near-edge structure, approximately $40 \mathrm{eV}$ and below) and EXAFS (extended X-ray absorption fine structure beyond the XANES region) dependent on the difference in the relative absorption threshold of energy (Fig. 7(c)). For instance, the local coordination of copper ions in $0.5 \%-\mathrm{ZnAl}-\mathrm{LDH}$ and CuZnAl-LDH has been explored by XANES (Figs. 7(d)-7(f)) [177]. The $\mathrm{Cu} \mathrm{K}$-edge oscillations in the range of $0-10 \AA$ were found to be different (Figs. 7(d) and 7(e)), suggesting subtle variations in the local environments around the $\mathrm{Cu}$ atoms in the two samples (Fig. 7(f)). The EXAFS R-space spectra exhibited two peaks, corresponding to the first $\mathrm{Cu}-\mathrm{O}$ shell and $\mathrm{Cu}$-metal shell. The 0.5\%-ZnAl-LDH samples showed a longer $\mathrm{Cu}-\mathrm{O}$ distance $(1.99 \AA)$ and a lower coordination number (5.38) compared with CuZnAl-LDH (an average $\mathrm{Cu}-\mathrm{O}$ distance of $1.93 \AA$ and a coordination number of 6.0 for the first $\mathrm{Cu}-\mathrm{O}$ coordination sphere). This reveals that $\mathrm{Cu}$ in $0.5 \%-\mathrm{ZnAl}-\mathrm{LDH}$ possessed a high degree of coordinative unsaturation and abundant OVs, causing structural distortion and strain within the LDH nanosheets. The formation of surface OVs on $\mathrm{TiO}_{2}$ was also characterized by XAS with increased relative intensity of pre-edge peaks in the $\mathrm{V}_{\mathrm{O}}-\mathrm{TiO}_{2}$, an indication of distortion from the octahedral $\mathrm{TiO}_{6}$ unit (Fig. 7(g)) [221]. While modification by $\mathrm{F}$ atoms led to decrease of peak intensity, manifesting that the partial distortion might be recovered. The partial OVs were supposed to be taken by $\mathrm{F}$ atoms. Likewise, $\mathrm{N}$-defects in the heptazine rings of $g-\mathrm{C}_{3} \mathrm{~N}_{4}$ and $\mathrm{mCNN}$ can be probed by performing $\mathrm{C}$ K-edge and $\mathrm{N}$ K-edge synchrotron-based XANES measurements (Figs. 7(h) and 7(i)) [222].

\subsubsection{Positron annihilation spectroscopy (PAS)}

PAS, a novel, sensitive, and non-destructive spectroscopy, has recently sparked extensive attention since it can provide direct information on defect structures including defect types and relative concentrations in photocatalysts, based on analyzing the positron lifetime and intensity [223-225]. After entering the material, positrons are converted into $\gamma$ photons with electrons. When there is a lattice defect (e.g., vacancies and vacant clusters), the positrons will be trapped in the bound state of this defect, thereby altering the positron annihilation spectrum [225, 226]. As an example, the positron lifetime spectra of defect-rich SUC $\mathrm{Bi}_{3} \mathrm{O}_{4} \mathrm{Br}$ and defect-deficient $\mathrm{Bi}_{3} \mathrm{O}_{4} \mathrm{Br}$ were observed to exhibit three lifetime components, confirming the existence of Bi vacancy related clusters (Fig. 8(a)) [173]. 
(a)
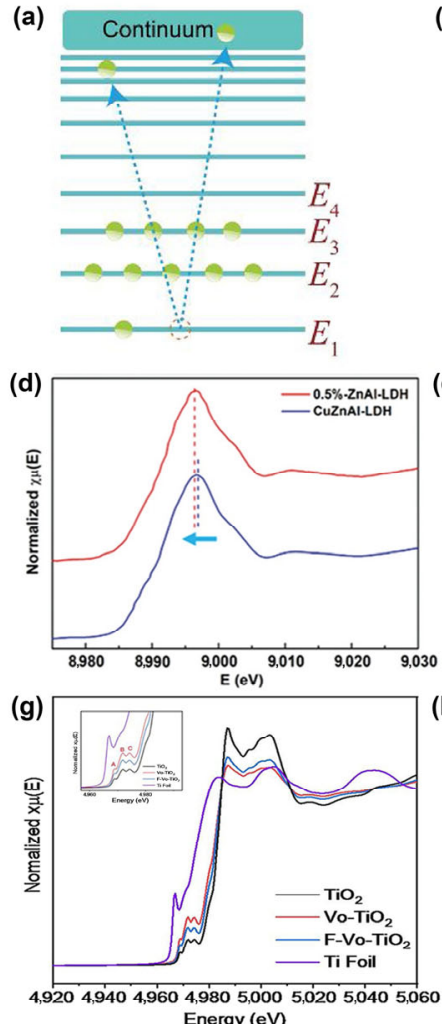

(b)
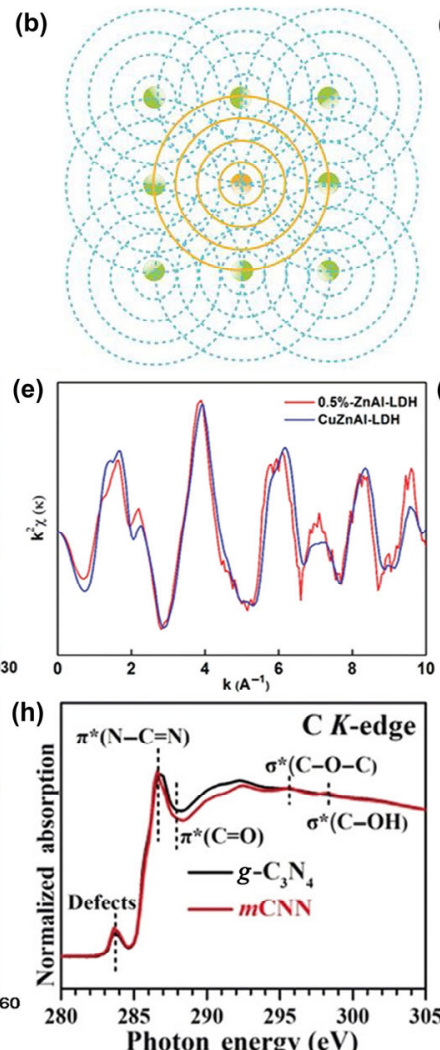

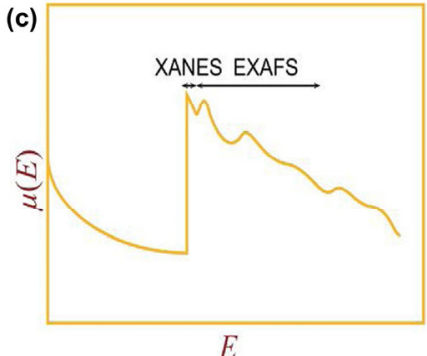

(c)
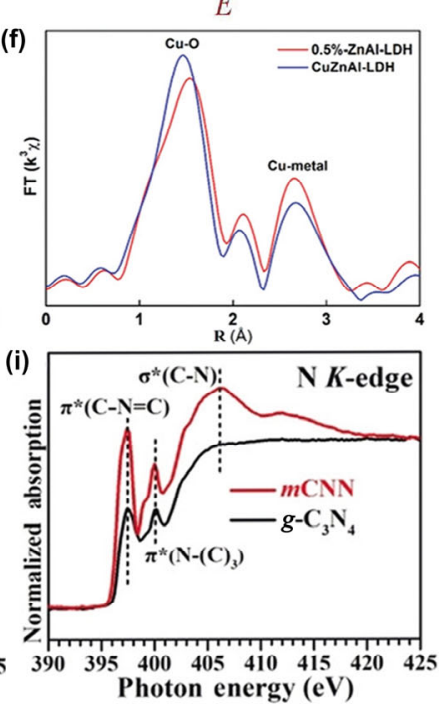

Figure 7 XAS characterization for $\mathrm{N}_{2}$ photoreduction reaction. Schematic illustrations of (a) the absorption process and (b) the absorbing atom and its first nearing neighbors. (c) Absorption coefficient $\mu(E)$ versus photon energy above the edge, which is divided into XANES and EXAFS. Reproduced with permission from Ref. [220], ๑ Elsevier Ltd. 2019. (d) Cu K-edge XANES spectra. (e) Cu K-edge EXAFS oscillation functions k2 $\chi(\mathrm{k})$. (f) Magnitude of $\mathrm{k}_{2}$-weighted FT of $\mathrm{Cu}$ K-edge EXAFS spectra for 0.5\%-ZnAl-LDH and CuZnAl-LDH. Reproduced with permission from Ref. [177], () Wiley-VCH Verlag $\mathrm{GmbH} \&$ Co. KGaA 2020. (g) XAS spectra of Ti foil, $\mathrm{TiO}_{2}, \mathrm{~V}_{\mathrm{O}}-\mathrm{TiO}_{2}$ and $\mathrm{F}-\mathrm{V}_{\mathrm{O}}-\mathrm{TiO}_{2}$. Reproduced with permission from Ref. [221], ๔ Elsevier Ltd. 2020. XANES spectra of (h) C K-edge and (i) N K-edge for $g-\mathrm{C}_{3} \mathrm{~N}_{4}$ and mCNN. Reproduced with permission from Ref. [222], $\odot$ Elsevier Ltd. 2019.
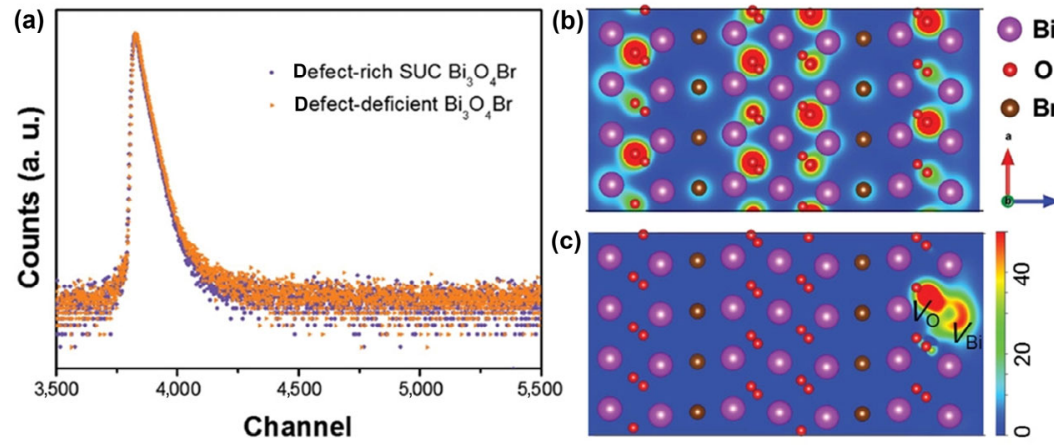

Figure 8 PAS characterization for $\mathrm{N}_{2}$ photoreduction reaction. (a) Positron annihilation lifetime spectra of defect-rich $\mathrm{SUC} \mathrm{Bi}_{3} \mathrm{O}_{4} \mathrm{Br}$ and defect-deficient $\mathrm{Bi}_{3} \mathrm{O}_{4} \mathrm{Br}$. Schematic representations of trapped positrons of (b) defect-deficient $\mathrm{Bi}_{3} \mathrm{O}_{4} \mathrm{Br}$ and (c) defect-rich $\mathrm{SUC} \mathrm{Bi}_{3} \mathrm{O}_{4} \mathrm{Br}$. Reproduced with permission from Ref. [173], @ Wiley-VCH Verlag GmbH \& Co. KGaA 2019.

The Bi vacancy concentration appeared to increase with the increase in the relative intensity of the positron lifetime (Figs. 8(b) and 8(c)).

\subsubsection{In situ or operando technique studies}

Apart from the above ex situ characterization techniques, in situ or operando technologies can provide deeper insight into the defects of photocatalysts although this area is still nascent. Indeed, the emerging in situ or operando XPS, EPR, and XAS can identify the type and concentration of defects and allow real-time monitoring of the defect state and its evolution during the $\mathrm{N}_{2}$ reduction process. These techniques unlikely influence the type and amount of the intermediates due to their not strong energy conditions. In the following, we provide a brief discussion on recent progresses attained regarding in situ or operando investigation of defects during the $\mathrm{N}_{2}$ reduction process and make attempts to understand the structure-performance relationship of defects. This would guide further exploration and development of more efficient defect-engineered photocatalysts for practical applications.

\subsubsection{In situ XPS}

By virtue of quasi in situ XPS, the formation and chemical states of defects can be probed during photocatalysis at the atomic level. In situ XPS has been applied to track the defect structure of $\mathrm{WO}_{3}$ during the $\mathrm{N}_{2}$ photoreduction process (Fig. 9) [179]. Quasi in situ XPS measurements were performed before and after the treatment of a flowing $\mathrm{H}_{2} \mathrm{O}$ vapor of $\mathrm{N}_{2}$ at $25^{\circ} \mathrm{C}$ 

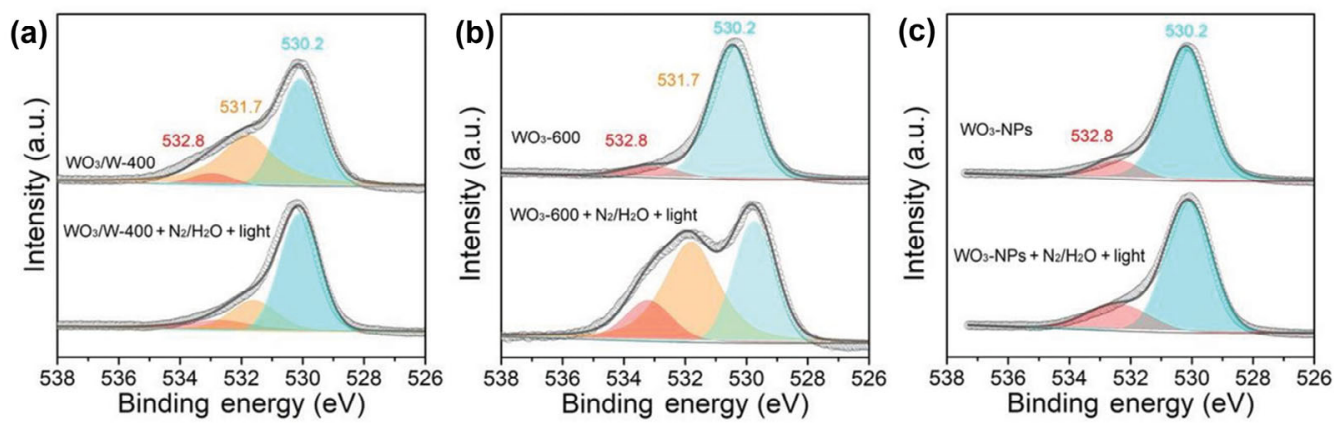

Figure 9 In situ XPS characterization for $\mathrm{N}_{2}$ photoreduction reaction. Quasi in situ O 1s XP spectra of (a) WO $\mathrm{WO}_{3} / \mathrm{W}-400$, (b) $\mathrm{WO}_{3}-600$, and (c) WO $3-\mathrm{NPs}$ before and after the treatment. Reproduced with permission from Ref. [179], (๑) Wiley-VCH Verlag GmbH \& Co. KGaA 2019.

with light for $30 \mathrm{~min}$ in a cell reactor connected with a photoemission end station. The in situ $\mathrm{O}$ 1s XP spectra (Fig. 9) of $\mathrm{WO}_{3} / \mathrm{W}-400, \mathrm{WO}_{3}-600$, and $\mathrm{WO}_{3}-\mathrm{NPs}$ before and after the treatment displayed three main peaks at 530.2, 531.7, and $532.8 \mathrm{eV}$, which were assigned to lattice oxygen, OVs, and surface hydroxyl group, respectively. The peak intensity of OVs for $\mathrm{WO}_{3} / \mathrm{W}-400$ was observed to slightly decrease after the treatment. This was supposed to originate from oxidation of surface OVs by nearby $\mathrm{O}$ atoms from $\mathrm{H}_{2} \mathrm{O}$ (Fig. 9(a)). For $\mathrm{WO}_{3}-600$, the signal of OVs did not emerge before treatments, while a strong signal for OVs appeared after exposure to $\mathrm{N}_{2}$ and $\mathrm{H}_{2} \mathrm{O}$ under light irradiation (Fig. 9(b)). Whereas for $\mathrm{WO}_{3}-\mathrm{NPs}$, no obvious variation of the $\mathrm{O}$ 1s spectra was detected before and after the treatment (Fig. 9(c)).

\subsubsection{In situ EPR}

The attenuation and generation of defects during the $\mathrm{N}_{2}$ photoreduction process have also been verified by in situ EPR measurements [179]. For example, the role of defects and electron-rich $\mathrm{Cu}^{\delta+}$ in promoting the $\mathrm{N}_{2}$ photoreduction was recently revealed by in situ EPR experiments under a constant $\mathrm{N}_{2}$ flow (Fig. 10(a)) [177]. An external magnetic field was applied to the sample to excite those unpaired free electrons on the atomic orbital or molecular orbital to a higher energy level, resulting in a characteristic EPR signal (Fig. 10(b)). Relative to $\mathrm{CuZnAl}-\mathrm{LDH}$ and $\mathrm{ZnAl}-\mathrm{LDH}$, the $0.5 \%-\mathrm{ZnAl}-\mathrm{LDH}$ sample exhibited a more intense EPR signal of $\mathrm{Cu}^{2+}\left(3 \mathrm{~d}^{9}\right)$. This implied
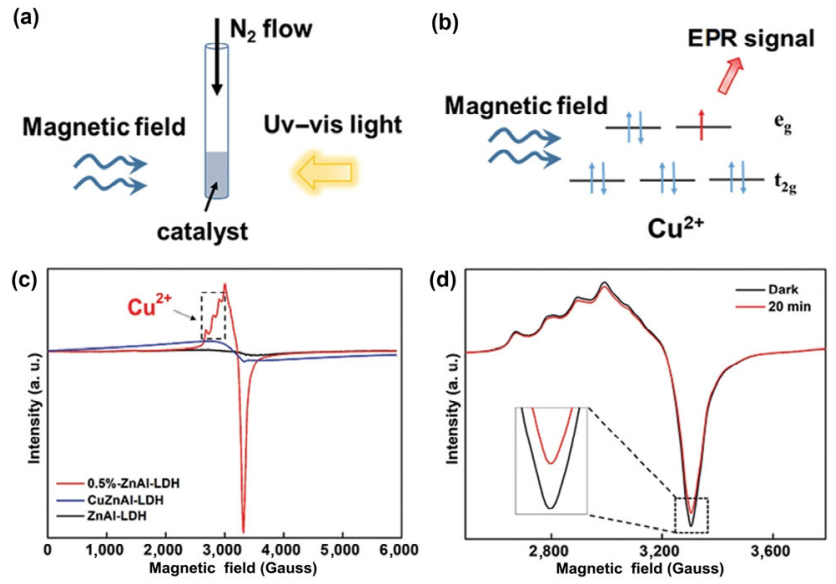

Figure 10 In situ EPR characterization for $\mathrm{N}_{2}$ photoreduction reaction. (a) Schematic illustration of the in situ EPR experiment. (b) Octahedral crystal field diagram showing the unpaired $\mathrm{d}$ electron responsible for the observation of the EPR signal. (c) EPR spectra for ZnAl-LDH, 0.5\%-ZnAl$\mathrm{LDH}$, and CuZnAl-LDH in the dark. (d) In situ EPR spectra for $0.5 \%$-ZnAl-LDH measured in the dark and after 20 min of light irradiation. Reproduced with permission from Ref. [177], ๑ Wiley-VCH Verlag GmbH \& Co. KGaA 2020. that the generation of oxygen defects increased the number of free electrons on the $\mathrm{Cu}$ center in 0.5\%-ZnAl-LDH (Fig. 10(c)). The intensity of the $\mathrm{Cu}^{2+} \mathrm{EPR}$ signal for the $0.5 \%-\mathrm{ZnAl}-\mathrm{LDH}$ decreased under UV-vis illumination (Fig. 10(d)), indicating that the photogenerated electrons were transferred to the $\mathrm{Cu}$ centers, thereby reducing some $\mathrm{Cu}^{2+}$ to low-valence $\mathrm{Cu}^{\delta+}$.

\subsubsection{In situ XAS}

In situ XAS is able to verify the generation of defects during the $\mathrm{N}_{2}$ photoreduction process at the atomic level [227]. The electronic properties of $\mathrm{W}$ element in $\mathrm{WO}_{3}-600$ during $\mathrm{N}_{2}$ photocatalytic reduction were studied by in situ XANES [179].

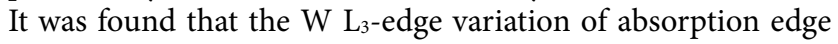
position of $\mathrm{WO}_{3}-600$ was almost negligible when being immersed in water under $\mathrm{N}_{2}$ atmosphere without irradiation (Fig. 11(a)). While the absorption edge position of $\mathrm{WO}_{3}-600$ shifted to lower energy under light irradiation, suggesting that the $\mathrm{W}$ element in $\mathrm{WO}_{3}-600$ was partially reduced to generate OVs during the photocatalytic $\mathrm{N}_{2}$ reduction reaction. Additionally, the coordination number for $\mathrm{W}-\mathrm{O}$ shell in $\mathrm{WO}_{3}-600$ decreased from 5.4 to 4.4 during the photocatalysis (Fig. 11(b)), consistent with the variation of electronic structures of $\mathrm{W}$ element as well as the formation of $\mathrm{NH}_{3}$ on the surface of catalysts due to the generation of operando OVs.

Advances of spectroelectrochemical techniques also make it possible for imaging nano-scale defects and detection of their changes during the $\mathrm{N}_{2}$ reduction $[228,229]$. To obtain real time data regarding morphological and microstructural evolution of defect-engineered photocatalysts at the atomic level during the $\mathrm{N}_{2}$ reduction process, in situ scanning electron microscopy (SEM) and TEM provide a unique possibility [230-232]. More intriguingly, the disorder of vacancy channels and their local rearrangement at different temperatures can be observed by in situ heating TEM [233].

Other techniques that haven't been attempted for photocatalytic $\mathrm{N}_{2}$ reduction include in situ Raman, which enables real-time
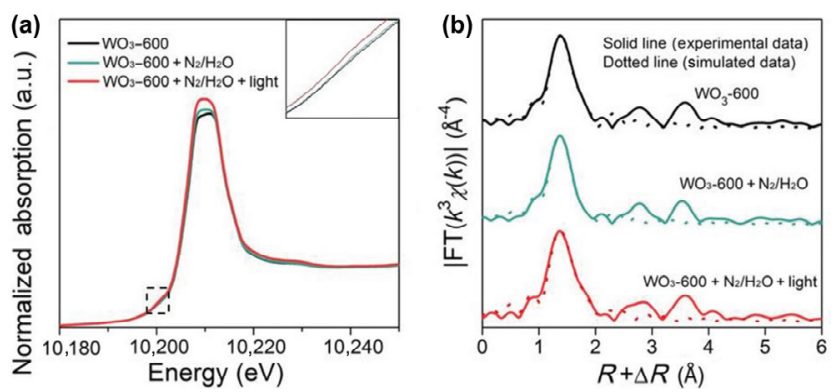

Figure 11 In situ XAS characterization for $\mathrm{N}_{2}$ photoreduction reaction. In situ (a) XANES and (b) Fourier-transformed EXAFS spectra in R space of bare and treated $\mathrm{WO}_{3}-600$. Reproduced with permission from Ref. [179] (c) Wiley-VCH Verlag GmbH \& Co. KGaA 2019. 
detection of chemical bond changes, microstructural evolution and its formation conditions of defective photocatalysts at the atomic level $[234,235]$. Note that laser sources in Raman spectroscopy may affect the evolution and detection of $\mathrm{N}_{2}$ reduction intermediates. To minimize such impact and also avoid other optical responses (such as fluorescence) from catalysts, near-infrared laser is preferred. In situ XRD can monitor the phase transformation and structural evolution of catalysts [236]. Combined operando electrochemical impedance spectroscopy (EIS) with cyclic voltammetry $(\mathrm{CV})$ provides a potentially useful experimental tool to gain insight into the role of defects during catalytic reactions in a dynamic way [237]. Despite these recent advances, further development of advanced and powerful techniques is still urgently demanded to track the evolution of defects for the sake of gaining insight into active sites and reaction mechanism of photocatalytic $\mathrm{N}_{2}$ reduction.

\section{Roles of defects in photocatalytic nitrogen reduction}

In this section, we attempt to summarize and discuss the positive roles of defects toward photocatalytic $\mathrm{N}_{2}$ reduction reaction. For each of the possible aspects that the defect may address, e.g., extension of the light response range, acceleration of charge transfer rates etc., we briefly explain the fundamental physical necessities for this effect to occur, and then give recent examples from literature. It always depends on the specific semiconductor and specific defect, which mode of action is in operation, because the physical characteristics such as reduction and oxidation potential of conduction and valence band edge are different in each case. It is, to the best of our knowledge, not yet possible to unveil general correlations that would allow to predict the exact function in detail.

\subsection{Extending light response range}

The photo response ability of a semiconductor photocatalyst is largely determined by its band gap structure. Narrowing the band gap structure of a semiconductor can effectively extend the range of light absorption. Appropriate engineering of defects enables one to modulate the band gap structure of a semiconductor $[238,239]$. Generation of defects is inferred to introduce electronic states within the bandgap, which helps to narrow the bandgap and serve as mid-gap states for the photoexcited electron, thereby expanding the light response range [240]. The position of mid-gap states can be tuned by tailoring the types and concentrations of defects. On the one hand, the intermediate energy level may be situated below the edge of the $\mathrm{CB}$, decreasing the band gap of semiconductors $[121,130,241]$. As a matter of fact, manipulation of NVs enabled tuning of bandgap of cyano-group-modified $g-\mathrm{C}_{3} \mathrm{~N}_{4}$ nanoribbons (mCNN) from 2.77 to $2.0 \mathrm{eV}$ by creating a sub-gap state $(2.57 \mathrm{eV})$ under the edge of $\mathrm{CB}$, thus extending the absorption of $g$ - $\mathrm{C}_{3} \mathrm{~N}_{4}$ to the entire visible-light and even near infrared regions (Figs. 12(a) and 12(b)) [222]. By controlling the concentration of $\mathrm{OVs}$ in $\mathrm{TiO}_{2}$ nanosheets via $\mathrm{Cu}$-doping [176], the light absorption range was adjusted from 400 to $800 \mathrm{~nm}$ (Fig. 12(c)). A bandgap of $3.0 \mathrm{eV}$ with the valence band maximum (VBM) located at $2.75 \mathrm{eV}$ was attained favoring the $\mathrm{N}_{2}$ photoreduction (Fig. 12(d)). On the other hand, the intermediate energy level may be alternatively above the edge of the VB, also lowering the bandgap of a semiconductor. This is usually at the expense of its oxidation potential [242]. Mid-gap states, namely the surface oxygen-defect states, above and partly overlapped with the $\mathrm{VB}$ of $\mathrm{Bi}_{2} \mathrm{MoO}_{6}$ could be introduced by hydrogen treatments. The VBM was shifted toward the vacuum level by about $0.73 \mathrm{eV}$, reducing the bandgap of the $\mathrm{Bi}_{2} \mathrm{MoO}_{6}$ (Fig. 12(e)) [148]. By introducing the mid-gap states through defect engineering [243], the bandgap of $\mathrm{BiOBr}$ nanosheets was lowered from 2.69 to $2.43 \mathrm{eV}$. Correspondingly, the absorption range of its absorption edge was extended lying between 450 and $750 \mathrm{~nm}$ (Figs. 12(f) and 12(g)) [172]. Likewise, the bandgap of $\mathrm{Bi}_{2} \mathrm{O}_{2} \mathrm{CO}_{3}$ was decreased from 2.42 to $2.24 \mathrm{eV}$ by increasing OVs concentration (Fig. 12(h)) [244].

Recently, it was discovered that defects can also concurrently introduce mid-gap states (i.e., defect states) and minimize bandgaps to extend the absorption edge of a semiconductor [245-247]. For instance, Fe doping was shown to effectively narrow the intrinsic bandgap of $\mathrm{SrMoO}_{4}$, extending the light absorption edge from UV light to visible light region (Fig. 12(i)) [174]. With the increase of Fe dopant concentration, the intrinsic bandgap was lowered accordingly (Figs. 12(j) and 12(k)). Independently, $\mathrm{Fe}$ doped $\mathrm{SrWO}_{4}$ nanoparticles were also synthesized with bandgap tuned in the range from 4.78 to $3.39 \mathrm{eV}$ [245]. Upon Fe doping, the conduction band minimum (CBM) was observed to shift downward while the VBM shifted upward, resulting in narrowed bandgap. Consequently, the absorption range was extended by shifting its absorption edge. The narrowed bandgap achieved either by the shift of the CBM downward or the shift of the VBM upward could both reduce the redox ability correspondingly on the reduction side or the oxidation side. A balance in this regard should be considered when modulating the type and concentration of defects.

\subsection{Modulating charge carrier transfer kinetics}

Defects can also act as reactive sites and capture photoinduced electrons, which can effectively restrain the photoinduced electron/hole pair recombination [154, 248-251]. Several advanced techniques have been employed to characterize charge transfer and separation in defect-engineered photocatalysts, including EIS, photocurrent response, room-temperature photoluminescence (PL) and time-resolved photoluminescence (TR-PL) spectroscopy as well as transient absorption (TA) spectroscopy [252]. It was proposed that the OVs in $\mathrm{BiOBr}$ nanosheets played a key role in promoting photo-generated carrier migration and separation [253]. The interfacial electrons transferred from the excited $\mathrm{BiOBr}$ nanosheets facilitated activation of $\mathrm{N}_{2}$ and further reduction to $\mathrm{NH}_{3}$. Further PL, TR-PL, and photocurrent response results provided evidences that the OVs inhibited the recombination of photogenerated electron/hole pairs and increased the lifetime of charge carriers. Another interesting work from Zhang and coworkers showed that the introduction of OVs and $\mathrm{Ru}$ single atoms (SAs) in $\mathrm{TiO}_{2}$ cooperatively accelerated electron and hole separation and suppressed their recombination, prolonging the lifetime of photogenerated carriers to 0.73 ns \pm 0.03 ns (Figs. 13(a)-13(f)) [254]. Note that the defects in semiconducting photocatalysts is a double-edged sword for charge-carrier separation. An appropriate level of defects introduced in semiconductors is favorable to extend light response range, promote photogenerated carrier separation, and hamper photogenerated electron-hole pair recombination. While excessive defects can serve as recombination centers, resulting in a substantial drop in carrier separation efficiency.

\subsection{Improving $\mathrm{N}_{2}$ adsorption}

Materials that can provide a high density of $\mathrm{N}_{2}$ adsorption sites with adequate strength, are promising for good catalytic performance given that the surface coverage (at given surface area) controls the number of $\mathrm{N}_{2}$ molecules converted per time 

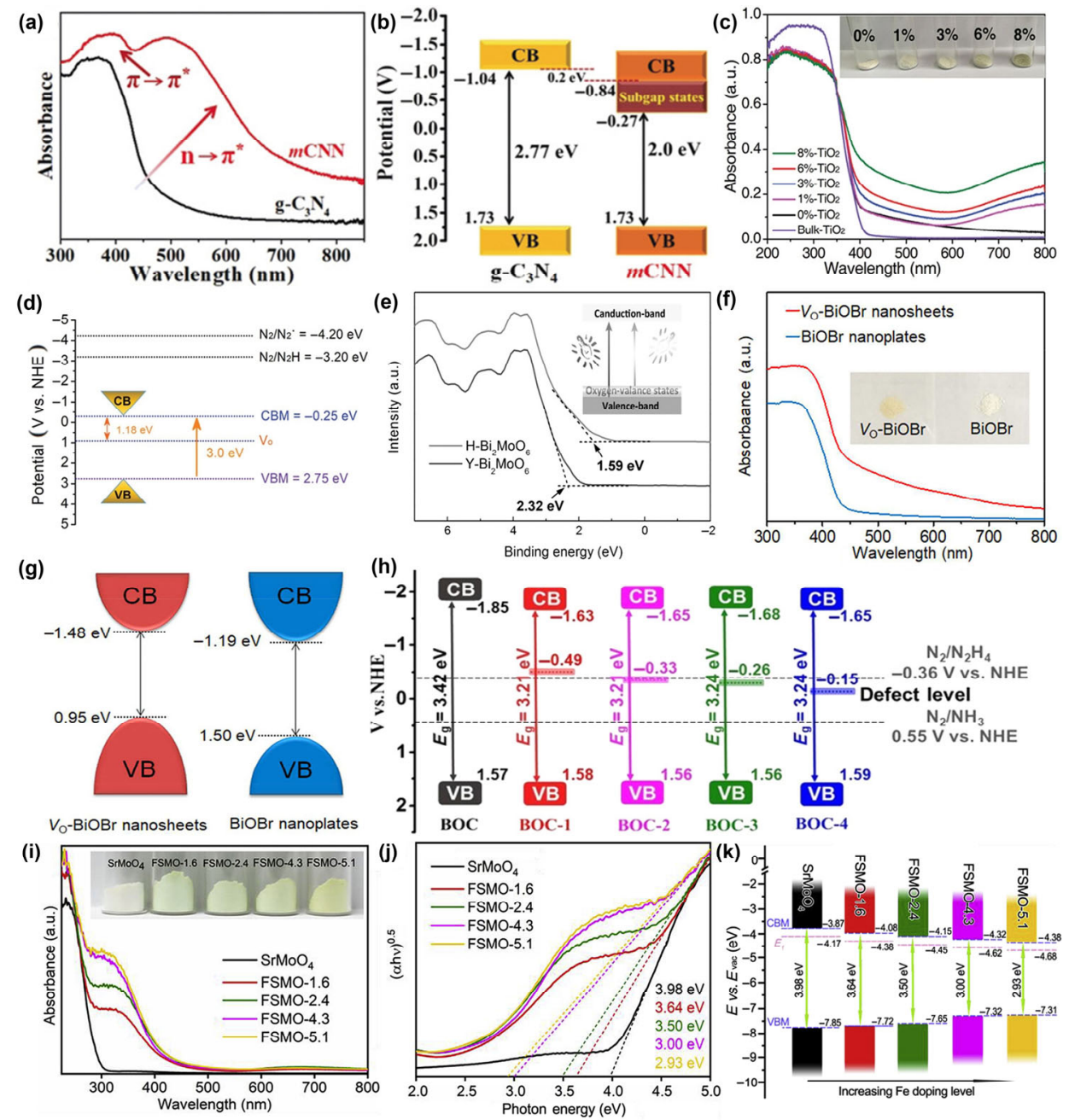

Figure 12 Studies the effect of defect-engineered catalysts on the band-gap structure. (a) UV-vis diffuse reflectance absorption spectra (DRS) curves and (b) schematic diagram of band structures of $g$ - $\mathrm{C}_{3} \mathrm{~N}_{4}$ and mCNN. Reproduced with permission from Ref. [222], ๑ Wiley-VCH Verlag GmbH \& Co. KGaA 2019. (c) UV-DRS of $X \%-\mathrm{TiO}_{2}$ nanosheets $(X=0,1,3,6,8)$ and bulk- $\mathrm{TiO}_{2}$ (the inset shows a photograph of the $X \%$ - $\mathrm{TiO}_{2}$ nanosheets). (d) Electronic energy-level diagram of $6 \%-\mathrm{TiO}_{2}$ nanosheets. Reproduced with permission from Ref. [176], ๑ Wiley-VCH Verlag GmbH \& Co. KGaA 2019. (e) UV-vis diffuse reflectance spectra and Tauc plots of different samples. Reproduced with permission from Ref. [148], @ Wiley-VCH Verlag GmbH \& Co. KGaA 2016. (f) UV-vis DRS curves of $\mathrm{V}_{\mathrm{O}}-\mathrm{BiOBr}$ nanosheets and $\mathrm{BiOBr}$ nanoplates. (g) Band alignments of $\mathrm{VO}-\mathrm{BiOBr}$ nanosheets and BiOBr nanoplates. Reproduced with permission from Ref. [172], () American Chemical Society 2018. (h) Electronic band structures of BOC and BOC-X with the reduction potentials of $\mathrm{N}_{2} / \mathrm{NH}_{3}$ and $\mathrm{N}_{2} / \mathrm{N}_{2} \mathrm{H}_{4}$. Reproduced with permission from Ref. [244], ๔ American Chemical Society 2018. (i) UV-vis DRS spectra, (j) corresponding Tauc plots, (k) band structure of the $\mathrm{SrMoO}_{4}$ and the Fe doped $\mathrm{SrMoO}_{4}$. The insert images (i) are the photographs of the $\mathrm{SrMoO}_{4}$ and the $\mathrm{Fe}$ doped $\mathrm{SrMoO}$. Reproduced with permission from Ref. [174], @ Elsevier Ltd. 2019.
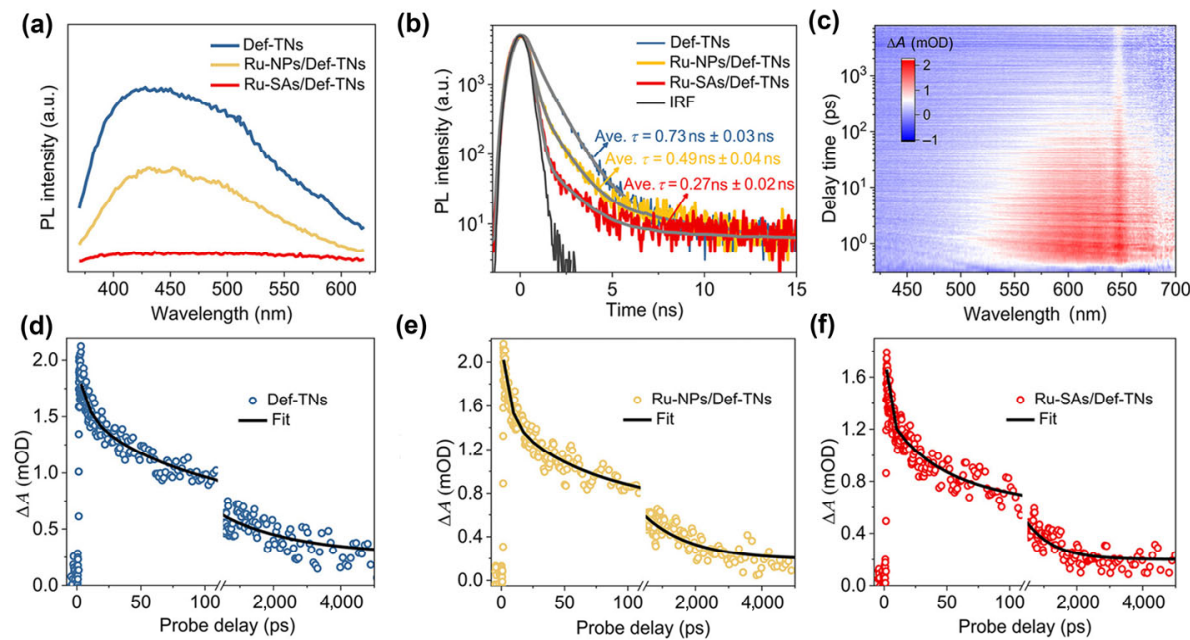

Figure 13 Advanced technologies to characterize charge transfer and separation of defect-engineered catalysts. (a) PL emission spectra and (b) time-resolved PL kinetics (excitation at $320 \mathrm{~nm}$, emission at $420 \mathrm{~nm}$ ) for Def-TNs, Ru-NPs/Def-TNs, and Ru-SAs/Def-TNs. (c) Pseudocolor TA spectra of Ru-SAs/Def-TNs (excitation at $320 \mathrm{~nm}$ ). Ultrafast TA kinetics and the fitting results for (d) Def-TNs, (e) Ru-NPs/Def-TNs, and (f) Ru-SAs/Def-TNs (probing at $630 \mathrm{~nm}$ ). Reproduced with permission from Ref. [254], ๑ American Chemical Society 2020. 
to a great extent [41]. After $\mathrm{N}_{2}$ molecules approach the catalyst surface, adsorption on the surface might occur, either by physisorption or chemisorption. Physisorption of nitrogen, which is purely based on weak forces, e.g., on van der Waals interactions, is commonly exploited in heterogeneous catalysis for surface area measurements according to the BrunnauerEmmett-Teller (BET) method at temperatures near the boiling point of liquid nitrogen [255]. Compared with physical adsorption, chemical adsorption involves electron transfer between the catalyst and nitrogen molecule, which is linked to $\mathrm{N}_{2}$ activation. Defects have been shown to enhance the $\mathrm{N}_{2}$ adsorption on the photocatalyst surface because of the following aspects: (1) the formation of thermodynamically unstable atoms with low coordination induced by defects, favoring $\mathrm{N}_{2}$ adsorption [148]; (2) some surface defects are frequently positively or negatively charged, which is conducive to promote the adsorption of oppositely charged reactant molecules by electrostatic interactions [133]; (3) some defects (i.e., NVs) can selectively adsorb $\mathrm{N}_{2}$ since their size and shape resemble the nitrogen atoms in $\mathrm{N}_{2}$ [256].

Experiments (such as in situ diffuse reflectance infrared Fourier-transform spectroscopy (DRIFTS), temperatureprogrammed desorption (TPD), isotopic labeling measurements) combined with theory (such as DFT calculations) have been employed to verify the roles of defects (OVs, NVs, SVs) in facilitating adsorption and activation of $\mathrm{N}_{2}$ in photocatalytic $\mathrm{N}_{2}$ reduction. As revealed by DRIFTS (Fig. 14(a)), a series of infrared (IR) peaks located at 3,555, 3,360, 2,874, 2,359, 1,624, and $1,557 \mathrm{~cm}^{-1}$ were detected for $\mathrm{N}_{2}$ adsorption on OVs enriched $\mathrm{Bi}_{5} \mathrm{O}_{7} \mathrm{Br}-40$ in the dark for up to $40 \mathrm{~min}$, which were ascribed to $\mathrm{N}-\mathrm{H}$ stretch, adsorbed $-\mathrm{OH}, \mathrm{NH}_{4}{ }^{+}$stretching vibration, adsorbed $\mathrm{CO}_{2}$, adsorbed $\mathrm{N}_{2}$, and adsorbed $\mathrm{NH}_{3}$, respectively [181]. The intensity of these vibration peaks increased with the prolongation of adsorption time. Under visible light, peaks
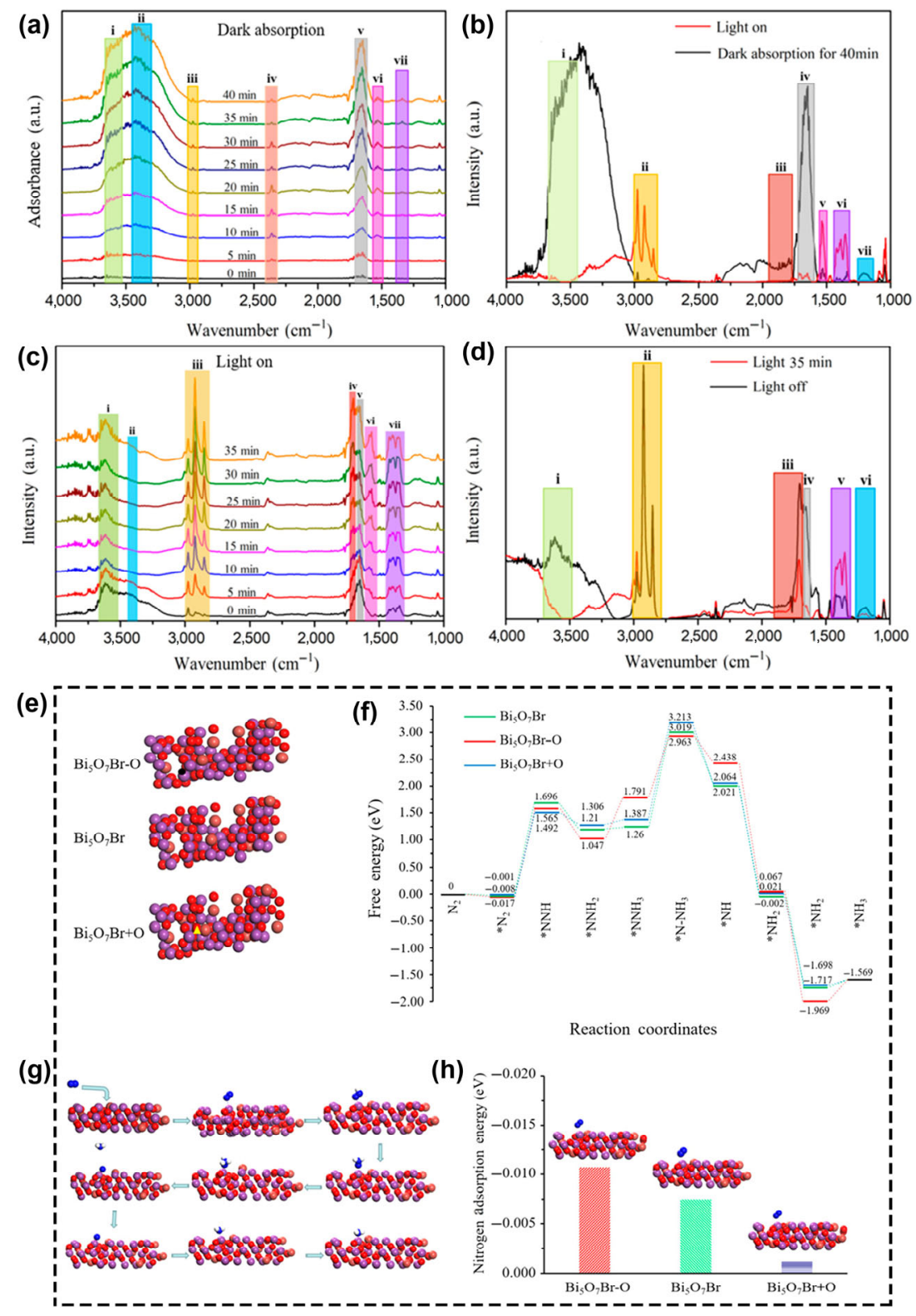

Figure 14 DRIFT spectra and structural models of nitrogen photoreduction reaction on $\mathrm{Bi}_{5} \mathrm{O}_{7} \mathrm{Br}$. In situ infrared spectra of $\mathrm{Bi}_{5} \mathrm{O}_{7} \mathrm{Br}_{-} 40$ (a) after adsorption of $\mathrm{N}_{2}$ in the dark for up to $40 \mathrm{~min}$, (b) after adsorption in the dark for $40 \mathrm{~min}$ and then visible light photoirradiation being turned on, (c) under visible light photoirradiation for up to $35 \mathrm{~min}$, and (d) after visible light photoirradiation for $35 \mathrm{~min}$, after which the light is turned off. (e) Structural models of anoxic $\mathrm{Bi}_{5} \mathrm{O}_{7} \mathrm{Br}-\mathrm{O}$, pristine $\mathrm{Bi}_{5} \mathrm{O}_{7} \mathrm{Br}$, and oxygen-enriched $\mathrm{Bi}_{5} \mathrm{O}_{7} \mathrm{Br}\left(\mathrm{Bi}_{5} \mathrm{O}_{7} \mathrm{Br}+\mathrm{O}\right)$. (f) Reaction energy diagram of nitrogen fixation catalyzed by $\mathrm{Bi}_{5} \mathrm{O}_{7} \mathrm{Br}-\mathrm{O}, \mathrm{Bi}_{5} \mathrm{O}_{7} \mathrm{Br}$, and $\mathrm{Bi}_{5} \mathrm{O}_{7} \mathrm{Br}+\mathrm{O}$. (g) Schematic pathway of nitrogen fixation. (h) Nitrogen adsorption energy (eV) on the surfaces of $\mathrm{Bi} \mathrm{O}_{7} \mathrm{Br}-\mathrm{O}$, $\mathrm{Bi}_{5} \mathrm{O}_{7} \mathrm{Br}$, and $\mathrm{Bi}_{5} \mathrm{O}_{7} \mathrm{Br}+\mathrm{O}$. Reproduced with permission from Ref. [181], (c) American Chemical Society 2020. 
of $3,555,2,874$, and $2,359 \mathrm{~cm}^{-1}$ were extremely weakened, whereas peaks at $3,360,1,624$, and $1,557 \mathrm{~cm}^{-1}$ were enhanced (Fig. 14(b)), indicating promoted adsorption of $\mathrm{N}_{2}$ and the conversion of $\mathrm{N}-\mathrm{H}$ to $\mathrm{NH}_{3}$. With increasing photoirradiation time (up to $35 \mathrm{~min}$ ), the IR signals centered at 3,555 and $2,874 \mathrm{~cm}^{-1}$ enhanced, while the peak at $1,624 \mathrm{~cm}^{-1}$ became weakened (Fig. 14(c)). This originated from the activation and cleavage of $\mathrm{N} \equiv \mathrm{N}$ bond and the subsequent formation of $\mathrm{NH}_{4}{ }^{+}$. Upon switching off the light, the IR signals at 3,555 and $3,360 \mathrm{~cm}^{-1}$ remained nearly unchanged, whereas the peak at $1,557 \mathrm{~cm}^{-1}$ enhanced (Fig. 14(d)). This suggested that the $\mathrm{N}-\mathrm{H}$ bond concentration increased and a large number of $\mathrm{N}_{2}$ molecules were adsorbed on the $\mathrm{Bi}_{5} \mathrm{O}_{7} \mathrm{Br}$ catalyst surface. Based on DFT calculations, $\mathrm{Bi}_{5} \mathrm{O}_{7} \mathrm{Br}-\mathrm{O}$ containing $\mathrm{OVs}$ was found to possess more negative adsorption free energy for the initial $\mathrm{N}_{2}$ adsorption and activation $\left({ }^{\star} \mathrm{N}_{2}\right)$ and larger adsorption free energy of the ${ }^{\star} \mathrm{NH}_{2}$ product, compared with neat $\mathrm{Bi}_{5} \mathrm{O}_{7} \mathrm{Br}$ and pristine $\mathrm{Bi}_{5} \mathrm{O}_{7} \mathrm{Br}+\mathrm{O}$ (Figs. 14(e)-14(h)).

\subsection{Enhancing $\mathrm{N}_{2}$ activation}

It has been proposed that the coordination between $\mathrm{N}_{2}$ and defects such as anion vacancies [253] could promote the dissociation of nitrogen and electron transfer, enhancing $\mathrm{N}_{2}$ transformation. For example, OVs with abundant localized electrons have been shown to act as nitrogen trapping sites that can effectively capture and activate $\mathrm{N}_{2}$ by prolongating the $\mathrm{N} \equiv \mathrm{N}$ triple bond [257]. For defective metal-based semiconductors, adsorbed $\mathrm{N}_{2}$ binds with surrounded metallic atoms to generate a metal- $\mathrm{N}_{2}$ complex. This can activate dinitrogen where $\mathrm{N}_{2}$ molecules donate electrons from their occupied $\sigma$ orbitals to empty $\sigma$ orbitals of the metal. Reversibly, back-donation of electrons from the metal to unoccupied $\pi^{\star}$ orbital of $\mathrm{N}_{2}$ molecules takes place, leading to cleavage of dinitrogen. Such electron back-donation mechanism is likely applicable to metal-free systems by forming coordinated nonmetal- $\mathrm{N}_{2}$ such as carbon or boron.

\section{Defects in photocatalysts for enhanced nitrogen photoreduction}

\subsection{Single strategies}

\subsubsection{Surface defect engineering}

Semiconductor materials have high surface energy and abundant exposed atoms to form dangling bonds, thus causing the formation of surface defects [134]. Surface defect engineering of semiconductors (i.e., surface vacancy and doping) has been employed to modify photocatalysts toward effective photocatalytic
$\mathrm{N}_{2}$ reduction for $\mathrm{NH}_{3}$ synthesis $[38,82]$. In the subsequent section, we will provide discussions on the most common surface defects including OVs, NVs, SVs, CVs, and FVs. A summary of defect-engineered photocatalysts for the $\mathrm{N}_{2}$ reduction is given in Table 1 .

\subsubsection{Oxygen vacancies (anion defects)}

A considerable number of metal oxides, such as Ti-based [191, 248, 258], Bi-based [41, 259, 260], layered-double-hydroxide (LDH) [169], $\mathrm{W}^{6+}$ [245], $\mathrm{Mo}^{6+}[261,262], \mathrm{In}^{3+}[121,263], \mathrm{Ce}^{4+}$ [47] oxides have been reported to be active for the $\mathrm{N}_{2}$ photoreduction. Among these oxides, oxygen-vacancy-rich $\mathrm{TiO}_{2}$ is the most investigated semiconductor material for the $\mathrm{N}_{2}$ photoreduction. A commercially available $\mathrm{TiO}_{2}$ with abundant OVs was successfully fabricated, which provided coordinatively unsaturated $\mathrm{Ti}^{3+}$ species as active sites on OVs [67]. OVs as photoexcited electron traps inherently created surface $\mathrm{Ti}^{3+}$ species that served as adsorption sites for $\mathrm{N}_{2}$ and promoted the photocatalytic $\mathrm{N}_{2}$ reduction to $\mathrm{NH}_{3}$ (Fig. 15(a)). This semiconductor displayed high activity with a solar-to-chemical energy conversion efficiency of $0.02 \%$. Analogously, OVs and fluorine (F)-modified $\mathrm{TiO}_{2}$ photocatalyst could further improve the photocatalytic $\mathrm{N}_{2}$ reduction activity with an $\mathrm{NH}_{3}$ yield rate of $206 \mu \mathrm{mol} \cdot \mathrm{h}^{-1} \cdot \mathrm{g}^{-1}$ [221]. The impressive performance was ascribed to the synergy of OVs and $F$, in which the OVs facilitated $\mathrm{N}_{2}$ chemical adsorption via electron transfer and $\mathrm{F}$ sites altered the $\mathrm{TiO}_{2}$ surface properties from hydrophilic to aerophilic (Fig. 15(b)). A "working-in-tandem" pathway was proposed for $\mathrm{Au}$ nanocrystals and OVs co-modified $\mathrm{TiO}_{2}$ nanosheets $\left(\mathrm{Au} / \mathrm{TiO}_{2}-\mathrm{OV}\right)$ toward photo-driven $\mathrm{N}_{2}$ reduction [158]. The OVs acted as active sites to promote chemisorption and activation of $\mathrm{N}_{2}$ molecules while hot electrons originating from plasmon excitation of the Au nanocrystals facilitated $\mathrm{NH}_{3}$ formation (Figs. 15(c) and $15(\mathrm{~d})$ ). $\mathrm{An} \mathrm{NH}_{3}$ yield rate of $78.6 \mu \mathrm{mol} \cdot \mathrm{h}^{-1} \cdot \mathrm{g}^{-1}$ accompanied by an apparent quantum effciency (AQE) of $0.82 \%$ was achieved at $550 \mathrm{~nm}$, exceeding many reported systems for $\mathrm{N}_{2}$ photoreduction. However, the purity of both $\mathrm{N}_{2}$ and Ar used in this work was not provided. Additionally, the origin and quantity of $\mathrm{NH}_{3}$ formed were not investigated by using ${ }^{15} \mathrm{~N}_{2}$ isotope labeling.

Apart from Ti-based photocatalysts, Bi-based compounds have recently attracted extensive attentions for $\mathrm{N}_{2}$ reduction because of their suitable energy band gap structures and large exposed surface areas $[172,264]$. OV-rich $\mathrm{BiOBr}$ nanosheets with exposed (001) facets (BOB-001-OV) were shown to be active for visible light-driven $\mathrm{N}_{2}$ reduction to $\mathrm{NH}_{3}$. The defect states caused by OVs on the surface of $\mathrm{BiOBr}$ were supposed to accelerate interface charge transfer from the excited nanosheets to $\mathrm{N}_{2}$ adsorbed on OVs [253]. Alternatively, an

Table 1 Summary of recent studies on defect-engineered photocatalysts used for the $\mathrm{N}_{2}$ reduction to $\mathrm{NH}_{3}$

\begin{tabular}{|c|c|c|c|c|c|c|c|c|c|c|c|}
\hline Photocatalyst & $\begin{array}{l}\text { Defect } \\
\text { type }\end{array}$ & Illumination & $\begin{array}{l}{ }^{14} \mathrm{~N}_{2} \\
\text { purity }\end{array}$ & $\begin{array}{l}\text { Reaction } \\
\text { medium }\end{array}$ & $\begin{array}{c}\mathrm{NH}_{3} \text { yield; } \\
\mathrm{AQE}^{\mathrm{a}} / \mathrm{AQY}^{\mathrm{b}}(\%)\end{array}$ & $\begin{array}{l}\text { Quantification } \\
\text { method }\end{array}$ & ${ }^{15} \mathrm{~N}_{2}$ isotope & $\begin{array}{l}\mathrm{N}_{2} \\
\text { purifica- } \\
\text { tion }\end{array}$ & $\begin{array}{c}\text { Control } \\
\text { experiment }\end{array}$ & Stability & $\begin{array}{l}\text { Ref. } \\
\text { (year) }\end{array}$ \\
\hline $\begin{array}{c}\mathrm{BiOBr} \\
\text { nanosheet }\end{array}$ & OVs & $\begin{array}{l}\text { Full-spectrum; } \\
\text { (300 W Xe) }\end{array}$ & No & Water; $25^{\circ} \mathrm{C}$ & $54.70 \mu \mathrm{mol} \cdot \mathrm{g}^{-1} \cdot \mathrm{h}^{-1}$ & Nessler's regent & No & No & Ar-PC & $\begin{array}{c}6 \text { cycles; } \\
12 \mathrm{~h}\end{array}$ & $\begin{array}{l}{[172]} \\
(2018)\end{array}$ \\
\hline $\begin{array}{l}\mathrm{Fe}-\mathrm{BiOBr} \\
\text { nanosheet }\end{array}$ & OVs & $\begin{array}{l}\lambda \geq 420 \mathrm{~nm} ; \\
(300 \mathrm{~W} \mathrm{Xe})\end{array}$ & No & Water; $25^{\circ} \mathrm{C}$ & $382.68 \mu \mathrm{mol} \cdot \mathrm{g}^{-1} \cdot \mathrm{h}^{-1}$ & Nessler's reagent & $\begin{array}{c}\text { Yes (only } \\
\text { qualitatively, not } \\
\text { quantitatively) }\end{array}$ & No & No & 4 cycles & $\begin{array}{l}{[209]} \\
(2020)\end{array}$ \\
\hline $\begin{array}{l}\mathrm{Fe}-\mathrm{BiOCl} \\
\text { nanosheet }\end{array}$ & OVs & $\begin{array}{l}\text { Full-spectrum; } \\
\text { (300 W Xe) }\end{array}$ & No & Water; RT & $\begin{array}{l}1.022 \mathrm{mmol} \cdot \mathrm{g}^{-1} \cdot \mathrm{h}^{-1} \text {; } \\
\text { AQE: } 1.8(420 \mathrm{~nm})\end{array}$ & Indophenol blue & $\begin{array}{c}\text { Yes } \\
\text { (quantitatively) }\end{array}$ & No & Ar-PC & 5 cycles & $\begin{array}{c}{[41]} \\
(2019)\end{array}$ \\
\hline $\begin{array}{c}\mathrm{Bi}_{5} \mathrm{O}_{7} \mathrm{Br} \\
\text { nanotube }\end{array}$ & OVs & $\begin{array}{l}\lambda \geq 400 \mathrm{~nm} ; \\
(300 \mathrm{~W} \mathrm{Xe})\end{array}$ & No & Water; $25^{\circ} \mathrm{C}$ & $\begin{array}{l}1.38 \mathrm{mmol} \cdot \mathrm{h}^{-1} \cdot \mathrm{g}^{-1} \\
\text { AQE: } 2.3(420 \mathrm{~nm})\end{array}$ & Nessler's reagent & $\begin{array}{c}\text { Yes (only } \\
\text { qualitatively, not } \\
\text { quantitatively) }\end{array}$ & No & Ar-PC & $\begin{array}{l}4 \text { cycles; } \\
10 \mathrm{~h}\end{array}$ & $\begin{array}{r}{[180]} \\
(2017)\end{array}$ \\
\hline
\end{tabular}




\begin{tabular}{|c|c|c|c|c|c|c|c|c|c|c|c|}
\hline Photocatalyst & $\begin{array}{l}\text { Defect } \\
\text { type }\end{array}$ & Illumination & $\begin{array}{l}{ }^{14} \mathrm{~N}_{2} \\
\text { purity }\end{array}$ & $\begin{array}{l}\text { Reaction } \\
\text { medium }\end{array}$ & $\begin{array}{c}\mathrm{NH}_{3} \text { yield; } \\
\mathrm{AQE}^{\mathrm{a}} / \mathrm{AQY}^{\mathrm{b}}(\%)\end{array}$ & $\begin{array}{c}\text { Quantification } \\
\text { method }\end{array}$ & ${ }^{15} \mathrm{~N}_{2}$ isotope & $\begin{array}{c}\mathrm{N}_{2} \\
\text { purifica- } \\
\text { tion }\end{array}$ & $\begin{array}{c}\text { Control } \\
\text { experiment }\end{array}$ & Stability & $\begin{array}{l}\text { Ref. } \\
\text { (year) }\end{array}$ \\
\hline $\begin{array}{c}\mathrm{Bi}_{5} \mathrm{O}_{7} \mathrm{Br} \\
\text { nanostructure }\end{array}$ & OVs & $\begin{array}{c}\lambda \geq 400 \mathrm{~nm} ; \\
(300 \mathrm{~W} \mathrm{Xe})\end{array}$ & No & Water; $25^{\circ} \mathrm{C}$ & $12.72 \mathrm{mmol} \cdot \mathrm{g}^{-1} \cdot \mathrm{h}^{-1}$ & Nessler's reagent & No & No & No & No & $\begin{array}{c}{[181]} \\
(2020)\end{array}$ \\
\hline $\begin{array}{c}\mathrm{Bi}_{2} \mathrm{MoO}_{6} \\
\text { sphere }\end{array}$ & OVs & $\begin{array}{c}\lambda \geq 420 \mathrm{~nm} ; \\
(300 \mathrm{~W} \mathrm{Xe})\end{array}$ & $\begin{array}{l}\text { Purified } \\
\text { air }\end{array}$ & Water; RT & $\begin{array}{c}1.3 \mathrm{mmol} \cdot \mathrm{g}^{-1} \cdot \mathrm{h}^{-1} ; \\
\text { AQE: } 0.73(500 \mathrm{~nm})\end{array}$ & Nessler's reagent & No & No & Ar-PC & 13 cycles & $\begin{array}{c}{[148]} \\
(2016)\end{array}$ \\
\hline $\begin{array}{c}\mathrm{Bi}_{2} \mathrm{MoO}_{6} / \\
\mathrm{BiOBr}\end{array}$ & OVs & $\begin{array}{l}\text { Full-spectrum; } \\
\text { (300 W Xe) }\end{array}$ & No & Water; $25^{\circ} \mathrm{C}$ & $90.7 \mu \mathrm{mol} \cdot \mathrm{g}^{-1} \cdot \mathrm{h}^{-1}$ & Nessler's reagent & No & No & No & 6 cycles & $\begin{array}{c}{[259]} \\
(2019)\end{array}$ \\
\hline $\mathrm{H}-\mathrm{Bi}_{5} \mathrm{O}_{7} \mathrm{I}$ & OVs & $300 \mathrm{~W} \mathrm{Xe}$ & No & Water; $25^{\circ} \mathrm{C}$ & $162.48 \mu \mathrm{mol} \cdot \mathrm{g}^{-1} \cdot \mathrm{h}^{-1}$ & Nessler's reagent & No & No & Ar-PC & $\begin{array}{l}5 \text { cycles; } \\
15 \mathrm{~h}\end{array}$ & $\begin{array}{c}{[147]} \\
(2020)\end{array}$ \\
\hline $\begin{array}{l}\mathrm{Bi}_{2} \mathrm{O}_{2} \mathrm{CO}_{3} \\
\text { nanosheet }\end{array}$ & OVs & $\begin{array}{c}\lambda \geq 420 \mathrm{~nm} ; \\
(300 \mathrm{~W} \mathrm{Xe})\end{array}$ & No & $\begin{array}{c}\text { Water/ } \\
\mathrm{Na}_{2} \mathrm{SO}_{3} ; \mathrm{RT}\end{array}$ & $\begin{array}{c}1,178 \\
\mu \mathrm{mol} \cdot \mathrm{L}^{-1} \cdot \mathrm{g}^{-1} \cdot \mathrm{h}^{-1} ; \\
\mathrm{AQE}: 0.07(420 \mathrm{~nm})\end{array}$ & $\begin{array}{l}\text { Nessler's reagent } \\
\text { and ion } \\
\text { chromatograph }\end{array}$ & No & No & No & 4 cycles & $\begin{array}{c}{[130]} \\
(2021)\end{array}$ \\
\hline $\begin{array}{l}\mathrm{B}-\mathrm{C}_{3} \mathrm{~N}_{4} \\
\left(\mathrm{MoO}_{2}\right)\end{array}$ & OVs & $\begin{array}{l}\lambda \geq 400 \mathrm{~nm} ; \\
(300 \mathrm{~W} \mathrm{Xe})\end{array}$ & No & $\begin{array}{c}\text { Water/ } \\
\text { methanol; RT }\end{array}$ & $\begin{array}{c}1.68 \mathrm{mmol} \cdot \mathrm{g}^{-1} \cdot \mathrm{h}^{-1} ; \\
\text { AQE: } 0.62(400 \mathrm{~nm})\end{array}$ & Nessler's reagent & No & No & No & 4 cycles & $\begin{array}{c}{[265]} \\
(2020)\end{array}$ \\
\hline $\begin{array}{c}\mathrm{CuCr}-\mathrm{LDH}^{\mathrm{d}} \\
\text { nanosheet }\end{array}$ & OVs & $\begin{array}{l}\lambda \geq 400 \mathrm{~nm} ; \\
(300 \mathrm{~W} \mathrm{Xe})\end{array}$ & 99.999 & Water; $25^{\circ} \mathrm{C}$ & $\begin{array}{l}57.1 \mu \mathrm{mol} \cdot \mathrm{h}^{-1} \cdot \mathrm{g}^{-1} \\
\text { AQY: } 0.44(380 \mathrm{~nm})\end{array}$ & Nessler's reagent & No & No & Ar-PC & 5 cycles & $\begin{array}{c}{[169]} \\
(2017)\end{array}$ \\
\hline $\begin{array}{c}\mathrm{Cu}^{\delta+}-\mathrm{ZnAl}- \\
\mathrm{LDH} \\
\text { nanosheet }\end{array}$ & OVs & $\begin{array}{c}800 \mathrm{~nm} \geq \lambda \geq \\
200 \mathrm{~nm} ; \\
(300 \mathrm{~W} \mathrm{Xe} \\
\left.5.1 \mathrm{~W} \mathrm{~cm}^{-2}\right)\end{array}$ & 99.999 & Water; $25^{\circ} \mathrm{C}$ & $110 \mu \mathrm{mol} \cdot \mathrm{g}^{-1} \cdot \mathrm{h}^{-1}$ & $\begin{array}{c}\text { Ion } \\
\text { chromatography }\end{array}$ & $\begin{array}{c}\text { Yes (only } \\
\text { qualitatively, not } \\
\text { quantitatively) }\end{array}$ & No & Ar-PC & 8 cycles & $\begin{array}{c}{[177]} \\
(2020)\end{array}$ \\
\hline $\begin{array}{c}\mathrm{FeS}_{2}-\mathrm{FeP}- \\
\mathrm{CeO}_{2}\end{array}$ & OVs & $\begin{array}{l}\text { Full spectrum; } \\
\text { (250 W Hg) }\end{array}$ & No & Water; $25^{\circ} \mathrm{C}$ & $5.6 \mathrm{mmol} \cdot \mathrm{g}^{-1} \cdot \mathrm{h}^{-1}$ & Indophenol blue & No & No & Ar-PC & No & $\begin{array}{c}{[47]} \\
(2019)\end{array}$ \\
\hline $\begin{array}{l}\mathrm{In}_{2} \mathrm{O}_{3} / \mathrm{In}_{2} \mathrm{~S}_{3} \\
\text { microsphere }\end{array}$ & OVs & $\begin{array}{c}(300 \mathrm{~W} \mathrm{Xe}, \\
\left.200 \mathrm{~mW} \cdot \mathrm{cm}^{-2}\right)\end{array}$ & No & Water; $25^{\circ} \mathrm{C}$ & $40.04 \mu \mathrm{mol} \cdot \mathrm{g}^{-1} \cdot \mathrm{h}^{-1}$ & Nessler's regent & No & No & Ar-PC & $\begin{array}{l}5 \text { cycles; } \\
10 \mathrm{~h}\end{array}$ & $\begin{array}{l}{[121]} \\
(2019)\end{array}$ \\
\hline $\begin{array}{c}\operatorname{In}(\mathrm{OH})_{3} / \\
g-\mathrm{C}_{3} \mathrm{~N}_{4}\end{array}$ & OVs & $\begin{array}{c}\lambda \geq 420 \mathrm{~nm} ; \\
(300 \mathrm{~W} \mathrm{Xe}, \\
\left.100 \mathrm{~mW} \cdot \mathrm{cm}^{-2}\right)\end{array}$ & No & $\begin{array}{c}\text { Water/ } \\
\text { triethano- } \\
\text { lamine; } 25^{\circ} \mathrm{C}\end{array}$ & $3.81 \mathrm{Mm} \cdot \mathrm{g}^{-1} \cdot \mathrm{h}^{-1}$ & Nessler's reagent & No & No & Ar-PC & $\begin{array}{l}6 \text { cycles; } \\
30 \mathrm{~h}\end{array}$ & $\begin{array}{c}{[263]} \\
(2020)\end{array}$ \\
\hline $\begin{array}{c}\mathrm{MoO}_{3-x} \\
\text { nanosheet }\end{array}$ & OVs & $\begin{array}{c}\lambda \geq 420 \mathrm{~nm} ; \\
(300 \mathrm{~W} \mathrm{Xe})\end{array}$ & No & Water; $25^{\circ} \mathrm{C}$ & $\begin{array}{c}328 \mu \mathrm{M} \cdot \mathrm{g}_{\mathrm{cat}}^{-1} \cdot \mathrm{h}^{-1} \\
\text { AQE: } 0.31 \\
(808 \mathrm{~nm})\end{array}$ & $\begin{array}{l}\text { Nessler's reagent } \\
\text { and ion } \\
\text { chromatograph }\end{array}$ & No & No & No & 4 cycles & $\begin{array}{l}{[261]} \\
(2020)\end{array}$ \\
\hline $\mathrm{Fe}-\mathrm{SrMoO}_{4}$ & OVs & $\begin{array}{l}\text { Full spectrum; } \\
\text { (300 W Xe) }\end{array}$ & No & Water; $15^{\circ} \mathrm{C}$ & $93.1 \mu \mathrm{M} \cdot \mathrm{g}^{-1} \cdot \mathrm{h}^{-1}$ & $\begin{array}{l}\text { Indophenol blue } \\
\text { and nessler's } \\
\text { reagent }\end{array}$ & No & No & No & 3 cycles & $\begin{array}{c}{[174]} \\
(2019)\end{array}$ \\
\hline $\begin{array}{c}\mathrm{TiO}_{2} \\
\text { nanotubular }\end{array}$ & OVs & $\begin{array}{l}\text { Full spectrum; } \\
\text { (300 W Xe) }\end{array}$ & No & $\begin{array}{c}\text { Water/ } \\
\text { methanol; RT }\end{array}$ & $1.2 \mathrm{mmol} \cdot \mathrm{L}^{-1} \cdot \mathrm{h}^{-1}$ & Nessler's reagent & No & No & Ar-PC & 7 cycles & $\begin{array}{c}{[149]} \\
(2020)\end{array}$ \\
\hline $\mathrm{Au} / \mathrm{TiO}_{2}$ & OVs & $\begin{array}{l}\lambda \geq 420 \mathrm{~nm} ; \\
(300 \mathrm{~W} \mathrm{Xe})\end{array}$ & No & $\begin{array}{l}\text { Water/ } \\
\text { methanol; } \\
25^{\circ} \mathrm{C}\end{array}$ & $\begin{array}{c}78.6 \mu \mathrm{mol} \cdot \mathrm{h}^{-1} \cdot \mathrm{g}^{-1} \\
\text { AQE: } 0.82(550 \mathrm{~nm})\end{array}$ & Indophenol blue & No & No & Ar-PC & $\begin{array}{c}6 \text { cycles; } \\
9 \mathrm{~h}\end{array}$ & $\begin{array}{c}{[158]} \\
(2018)\end{array}$ \\
\hline $\begin{array}{c}\mathrm{Ru}-\mathrm{TiO}_{2} \\
\text { nanosheet }\end{array}$ & OVs & $\begin{array}{l}\text { Full spectrum; } \\
\text { (300 W Xe) }\end{array}$ & No & $\begin{array}{c}\text { Water/ } \\
\text { ethanol; } 25^{\circ} \mathrm{C}\end{array}$ & $56.3 \mu \mathrm{g} \cdot \mathrm{h}^{-1} \cdot \mathrm{g}^{-1}$ & Indophenol blue & No & No & No & 3 cycles & $\begin{array}{l}{[266]} \\
(2019)\end{array}$ \\
\hline $\mathrm{Sb} / \mathrm{TiO}_{2}$ & OVs & $\begin{array}{l}\lambda \geq 420 \mathrm{~nm} ; \\
(300 \mathrm{~W} \mathrm{Xe})\end{array}$ & No & $\begin{array}{c}\text { Water/ } \\
\text { methanol; RT }\end{array}$ & $20.8 \mu \mathrm{mol} \cdot \mathrm{g}^{-1} \cdot \mathrm{h}^{-1}$ & Indophenol blue & No & No & Ar-PC & 8 cycles & $\begin{array}{c}{[166]} \\
(2019)\end{array}$ \\
\hline $\mathrm{Ti}_{3} \mathrm{C}_{2} \mathrm{~T} x / \mathrm{TiO}_{2}$ & OVs & $\begin{array}{c}\text { Full } \\
\text { spectrum; }(\mathrm{Xe}, \\
\left.250 \mathrm{~mW} \cdot \mathrm{cm}^{-2}\right) \\
\lambda=630 \mathrm{~nm} \\
\left(25 \mathrm{~mW} \cdot \mathrm{cm}^{-2}\right)\end{array}$ & 99.999 & Water; $25^{\circ} \mathrm{C}$ & $\begin{array}{c}422 \mu \mathrm{mol} \cdot \mathrm{g}^{-1} \cdot \mathrm{h}^{-1} \\
\text { (full-spectrum); } \\
\text { AQE: } 0.05(630 \mathrm{~nm})\end{array}$ & $\begin{array}{c}\text { Nessler's reagent } \\
\text { and ion } \\
\text { chromatograph }\end{array}$ & No & No & Ar-PC & 10 cycles & $\begin{array}{c}{[267]} \\
(2020)\end{array}$ \\
\hline $\begin{array}{l}\mathrm{WS}_{2} @ \mathrm{TiO}_{2} \\
\quad \text { film }\end{array}$ & OVs & $\begin{array}{l}\text { Simulated } \\
\text { sunlight } \\
\text { (AM1.5) }\end{array}$ & No & $\begin{array}{c}\text { Water/ } \\
\mathrm{Na}_{2} \mathrm{SO}_{3} ; \mathrm{RT}\end{array}$ & $1.39 \mathrm{mmol} \cdot \mathrm{g}^{-1} \cdot \mathrm{h}^{-1}$ & Indophenol blue & No & No & No & $\begin{array}{l}4 \text { cycles; } \\
36 \mathrm{~h}\end{array}$ & $\begin{array}{l}{[248]} \\
(2020)\end{array}$ \\
\hline $\mathrm{WO}_{3}$ & OVs & $\begin{array}{c}\lambda \geq 400 \mathrm{~nm} ; \\
\quad(\mathrm{Xe}, 200 \\
\left.\mathrm{mW} \cdot \mathrm{cm}^{-2}\right)\end{array}$ & 99.999 & Water; $25^{\circ} \mathrm{C}$ & $\begin{array}{l}132 \mu \mathrm{mol} \cdot \mathrm{g}_{\text {cat }^{-1}} \cdot \mathrm{h}^{-1} \\
\text { AQY: } 0.13(420 \mathrm{~nm})\end{array}$ & $\begin{array}{l}\text { Nessler's reagent } \\
\text { and ion } \\
\text { chromatograph }\end{array}$ & $\begin{array}{c}\text { Yes (only } \\
\text { qualitatively, not } \\
\text { quantitatively) }\end{array}$ & No & Ar-PC & 10 cycles & $\begin{array}{l}{[179]} \\
(2019)\end{array}$ \\
\hline Sb nanosheet & $\begin{array}{c}\text { OVs } \\
\text { and } \mathrm{Sb} \\
\text { defect }\end{array}$ & $\begin{array}{l}\lambda \geq 420 \mathrm{~nm} ; \\
(300 \mathrm{~W} \mathrm{Xe})\end{array}$ & 99.999 & $\begin{array}{c}\text { Water/ } \\
\text { methanol; RT }\end{array}$ & $388.5 \mu \mathrm{g}_{\mathrm{NH}_{3}} \cdot \mathrm{g}^{-1} \cdot \mathrm{h}^{-1}$ & Indophenol blue & No & Yes & Ar-PC & 5 cycles & $\begin{array}{c}{[167]} \\
(2020)\end{array}$ \\
\hline $\begin{array}{c}\text { Few-layer } \\
g-\mathrm{C}_{3} \mathrm{~N}_{4}\end{array}$ & NVs & $\begin{array}{c}\text { (500 W Xe, AM } \\
1.5 \mathrm{G}, \\
\left.100 \mathrm{~mW} \cdot \mathrm{cm}^{-2}\right)\end{array}$ & 99.999 & $\begin{array}{l}\text { Water/ } \\
\text { methanol; } \\
25^{\circ} \mathrm{C}\end{array}$ & $8.20 \mathrm{mM} \cdot \mathrm{g}^{-1} \cdot \mathrm{h}^{-1}$ & Nessler's reagent & $\begin{array}{c}\text { Yes (only } \\
\text { qualitatively, not } \\
\text { quantitatively) }\end{array}$ & No & No & 4 cycles & $\begin{array}{l}{[268]} \\
(2020)\end{array}$ \\
\hline $\begin{array}{c}\mathrm{Au} / g-\mathrm{C}_{3} \mathrm{~N}_{4} \\
\text { hollow sphere }\end{array}$ & NVs & $\begin{array}{l}\lambda \geq 420 \mathrm{~nm} ; \\
(300 \mathrm{~W} \mathrm{Xe})\end{array}$ & No & $\begin{array}{c}\text { Water/ } \\
\text { methanol; RT }\end{array}$ & $\begin{array}{l}357.3 \mu \mathrm{mol} \cdot \mathrm{g}_{\mathrm{cat}}{ }^{-1} \cdot \mathrm{h}^{-1} \\
\text { AQY: } 0.64(550 \mathrm{~nm})\end{array}$ & Nessler's reagent & $\begin{array}{c}\text { Yes (only } \\
\text { qualitatively, not } \\
\text { quantitatively) }\end{array}$ & No & No & 4 cycles & $\begin{array}{c}{[96]} \\
(2020)\end{array}$ \\
\hline
\end{tabular}




\begin{tabular}{|c|c|c|c|c|c|c|c|c|c|c|c|}
\hline Photocatalyst & $\begin{array}{l}\text { Defect } \\
\text { type }\end{array}$ & Illumination & $\begin{array}{l}{ }^{14} \mathrm{~N}_{2} \\
\text { purity }\end{array}$ & $\begin{array}{l}\text { Reaction } \\
\text { medium }\end{array}$ & $\begin{array}{c}\mathrm{NH}_{3} \text { yield; } \\
\mathrm{AQE}^{\mathrm{a}} / \mathrm{AQY}^{\mathrm{b}}(\%)\end{array}$ & $\begin{array}{l}\text { Quantification } \\
\text { method }\end{array}$ & ${ }^{15} \mathrm{~N}_{2}$ isotope & $\begin{array}{c}\mathrm{N}_{2} \\
\text { purifica- } \\
\text { tion }\end{array}$ & $\begin{array}{c}\text { Control } \\
\text { experiment }\end{array}$ & Stability & $\begin{array}{l}\text { Ref. } \\
\text { (year) }\end{array}$ \\
\hline $\begin{array}{l}\mathrm{B}-g-\mathrm{C}_{3} \mathrm{~N}_{4} \\
\text { nanosheet }\end{array}$ & NVs & $\begin{array}{l}\lambda \geq 400 \mathrm{~nm} ; \\
(250 \mathrm{~W} \mathrm{Xe} \\
\left.0.5 \mathrm{~W} \cdot \mathrm{cm}^{-2}\right)\end{array}$ & 99.999 & $\begin{array}{c}\text { Water/ } \\
\mathrm{Na}_{2} \mathrm{SO}_{3} ; \mathrm{RT}\end{array}$ & $313.9 \mu \mathrm{mol} \cdot \mathrm{g}^{-1} \cdot \mathrm{h}^{-1}$ & Nessler's reagent & $\begin{array}{c}\text { Yes } \\
\text { (quantitatively) }\end{array}$ & No & Ar-PC & 5 cycles & $\begin{array}{c}{[159]} \\
(2020)\end{array}$ \\
\hline $\begin{array}{c}\text { Cyano group/ } \\
g-\mathrm{C}_{3} \mathrm{~N}_{4}\end{array}$ & NVs & $\begin{array}{l}\lambda>400 \mathrm{~nm} ; \\
(300 \mathrm{~W} \mathrm{Xe}, \\
\left.1.0 \mathrm{~W} \cdot \mathrm{cm}^{-2}\right)\end{array}$ & 99.9 & $\begin{array}{l}\text { Ethylene } \\
\text { glycol; RT }\end{array}$ & $3.42 \mathrm{mmol} \cdot \mathrm{g}^{-1} \cdot \mathrm{h}^{-1}$ & Nessler's reagent & $\begin{array}{c}\text { Yes (only } \\
\text { qualitatively, not } \\
\text { quantitatively) }\end{array}$ & No & Ar-PC & 4 cycles & $\begin{array}{l}{[222]} \\
(2019)\end{array}$ \\
\hline $\mathrm{NC}-g-\mathrm{C}_{3} \mathrm{~N}_{4}$ & NVs & $\begin{array}{c}(300 \mathrm{~W} \mathrm{Xe}, \\
\mathrm{AM} 1.5 \mathrm{G} \\
\left.100 \mathrm{~mW} \cdot \mathrm{cm}^{-2}\right)\end{array}$ & 99.999 & $\begin{array}{c}\text { Water/ } \\
\text { methanol; RT }\end{array}$ & $1.59 \mathrm{mmol} \cdot \mathrm{g}^{-1} \cdot \mathrm{h}^{-1}$ & Nessler's reagent & $\begin{array}{c}\text { Yes (only } \\
\text { qualitatively, not } \\
\text { quantitatively) }\end{array}$ & No & No & No & $\begin{array}{l}{[246]} \\
(2019)\end{array}$ \\
\hline $\mathrm{O}-\mathrm{g}-\mathrm{C}_{3} \mathrm{~N}_{4}$ & NVs & $\begin{array}{l}\lambda \geq 420 \mathrm{~nm} ; \\
(500 \mathrm{~W} \mathrm{Xe})\end{array}$ & No & $\begin{array}{c}\text { Water/ } \\
\text { methanol; RT }\end{array}$ & $118.8 \mathrm{mg} \cdot \mathrm{L}^{-1} \cdot \mathrm{h}^{-1} \cdot \mathrm{g}_{\mathrm{cat}}{ }^{-1}$ & Nessler's reagent & No & No & Ar-PC & 5 cycles & $\begin{array}{c}{[84]} \\
(2020)\end{array}$ \\
\hline $\mathrm{P}-\mathrm{C}_{3} \mathrm{~N}_{4}$ & NVs & $\begin{array}{c}\lambda \geq 420 \mathrm{~nm} \\
(2 \mathrm{~kW} \mathrm{Xe})\end{array}$ & No & Water; $25^{\circ} \mathrm{C}$ & $\begin{array}{c}4.9 \mu \mathrm{mol} ; \\
\text { AQY: } 1(420 \mathrm{~nm})\end{array}$ & $\begin{array}{c}\text { Ion } \\
\text { chromatography }\end{array}$ & $\begin{array}{c}\text { Yes (only } \\
\text { qualitatively, not } \\
\text { quantitatively) }\end{array}$ & No & No & No & $\begin{array}{c}{[52]} \\
(2018)\end{array}$ \\
\hline S- $g-\mathrm{C}_{3} \mathrm{~N}_{4}$ & NVs & $\begin{array}{c}800 \mathrm{~nm} \geq \lambda \geq \\
400 \mathrm{~nm} ; \\
(250 \mathrm{~W} \mathrm{Na})\end{array}$ & No & $\begin{array}{c}\text { Water/ } \\
\text { methanol; RT }\end{array}$ & $6.2 \mathrm{mg} \cdot \mathrm{L}^{-1} \cdot \mathrm{h}^{-1} \cdot \mathrm{g}_{\mathrm{cat}}{ }^{-1}$ & Nessler's reagent & $\begin{array}{c}\text { Yes (only } \\
\text { qualitatively, not } \\
\text { quantitatively) }\end{array}$ & No & No & $\begin{array}{l}5 \text { cycles; } \\
20 \mathrm{~h}\end{array}$ & $\begin{array}{c}{[163]} \\
(2019)\end{array}$ \\
\hline $\begin{array}{c}\qquad g-\mathrm{C}_{3} \mathrm{~N}_{4} / \\
\mathrm{Ag}_{2} \mathrm{CO}_{3} \\
\text { heterojunction }\end{array}$ & NVs & $\begin{array}{c}800 \mathrm{~nm} \geq \lambda \geq \\
400 \mathrm{~nm} ; \\
(250 \mathrm{~W} \mathrm{Na})\end{array}$ & No & $\begin{array}{c}\text { Water/ } \\
\text { methanol; RT }\end{array}$ & $11 \mathrm{mg} \cdot \mathrm{L}^{-1} \cdot \mathrm{h}^{-1} \cdot \mathrm{g}_{\mathrm{cat}}{ }^{-1}$ & Nessler's reagent & $\begin{array}{c}\text { Yes (only } \\
\text { qualitatively, not } \\
\text { quantitatively) }\end{array}$ & No & Ar-PC & $20 \mathrm{~h}$ & $\begin{array}{l}{[269]} \\
(2019)\end{array}$ \\
\hline $\begin{array}{c}\text { MOF-74(Zn) } \\
@ D F-C_{3} \mathrm{~N}_{4}\end{array}$ & NVs & $\begin{array}{l}\lambda \geq 400 \mathrm{~nm} ; \\
(300 \mathrm{~W} \mathrm{Xe})\end{array}$ & No & $\begin{array}{l}\text { Water/ } \\
\text { methanol; } \\
25^{\circ} \mathrm{C}\end{array}$ & $2.32 \mathrm{mmol} \cdot \mathrm{g}^{-1} \cdot \mathrm{h}^{-1}$ & Nessler's reagent & $\begin{array}{c}\text { Yes (only } \\
\text { qualitatively, not } \\
\text { quantitatively) }\end{array}$ & No & No & 5 cycles & $\begin{array}{c}{[270]} \\
(2020)\end{array}$ \\
\hline $\begin{array}{l}\mathrm{GaN} \\
(\mathrm{Ru})\end{array}$ & NVs & $\begin{array}{l}\lambda>400 \mathrm{~nm} ; \\
(300 \mathrm{~W} \mathrm{Xe})\end{array}$ & 99.999 & Water $; 25^{\circ} \mathrm{C}$ & $450 \mu \mathrm{mol} \cdot \mathrm{g}^{-1} \cdot \mathrm{h}^{-1}$ & $\begin{array}{l}\text { GC-MS and } \\
\text { salicylate test }\end{array}$ & $\begin{array}{c}\text { Yes (only } \\
\text { qualitatively, not } \\
\text { quantitatively) }\end{array}$ & No & No & 13 cycles & $\begin{array}{r}{[162]} \\
(2019)\end{array}$ \\
\hline$g-\mathrm{C}_{3} \mathrm{~N}_{4}$ & $\begin{array}{l}\text { Cyano } \\
\text { defects }\end{array}$ & $\begin{array}{c}(500 \mathrm{~W} \mathrm{Xe} \\
\left.7.66 \mathrm{~mW} \cdot \mathrm{cm}^{-2}\right)\end{array}$ & No & $\begin{array}{l}\text { Water/ } \\
\text { ethanol; } 30^{\circ} \mathrm{C}\end{array}$ & $\begin{array}{c}51.65 \mathrm{mg} \cdot \mathrm{L}^{-1} ; \mathrm{AQY}: \\
1.03(420 \mathrm{~nm})\end{array}$ & Nessler's reagent & No & No & No & $12 \mathrm{~h}$ & $\begin{array}{l}{[271]} \\
(2018)\end{array}$ \\
\hline $\begin{array}{c}\text { Holey } g-\mathrm{C}_{3} \mathrm{~N}_{4} \\
\text { nanosheet }\end{array}$ & CVs & $\begin{array}{l}\text { Full spectrum; } \\
\text { (300 W Xe) }\end{array}$ & No & $\begin{array}{l}\text { Water/ } \\
\text { ethylene } \\
\text { glycol; RT }\end{array}$ & $25.54 \mathrm{mg} \cdot \mathrm{L}^{-1} \cdot \mathrm{g}^{-1} \cdot \mathrm{h}^{-1}$ & Nessler's reagent & No & No & No & No & $\begin{array}{l}{[153]} \\
(2020)\end{array}$ \\
\hline $\mathrm{B}-g-\mathrm{C}_{3} \mathrm{~N}_{4}$ & CVs & $\begin{array}{l}\lambda \geq 420 \mathrm{~nm} ; \\
(300 \mathrm{~W} \mathrm{Xe})\end{array}$ & No & $\begin{array}{c}\text { Water/ } \\
\mathrm{Na}_{2} \mathrm{SO}_{3} ; 25^{\circ} \mathrm{C}\end{array}$ & $435.28 \mu \mathrm{mol} \cdot \mathrm{g}^{-1} \cdot \mathrm{h}^{-1}$ & Nessler's reagent & No & No & No & 5 cycles & $\begin{array}{r}{[160]} \\
(2020)\end{array}$ \\
\hline $\mathrm{I}-g-\mathrm{C}_{3} \mathrm{~N}_{4}$ & $\mathrm{CVs}$ & $\begin{array}{c}(300 \mathrm{~W} \mathrm{Xe}, \\
\left.191.2 \mathrm{~mW} \cdot \mathrm{cm}^{-2}\right)\end{array}$ & No & $\begin{array}{c}\text { Water/ } \\
\text { methanol; RT }\end{array}$ & $200.8 \mathrm{mg} \cdot \mathrm{L}^{-1} \cdot \mathrm{g}^{-1}$ & Nessler's reagent & No & No & No & $\begin{array}{c}5 \text { cycles; } \\
15 \mathrm{~h}\end{array}$ & $\begin{array}{l}{[272]} \\
(2020)\end{array}$ \\
\hline $\begin{array}{l}\text { S- } g-\mathrm{C}_{3} \mathrm{~N}_{4} \\
\text { nanosheet }\end{array}$ & $\mathrm{CVs}$ & $\begin{array}{c}\text { Simulated } \\
\text { solar; } \\
\text { (500 W Xe) }\end{array}$ & No & $\begin{array}{c}\text { Water/ } \\
\text { methanol; RT }\end{array}$ & $5.99 \mathrm{mM} \cdot \mathrm{h}^{-1} \cdot \mathrm{g}_{\mathrm{Cat}}{ }^{-1}$ & Nessler's reagent & No & No & Ar-PC & 5 cycles & $\begin{array}{l}{[273]} \\
(2018)\end{array}$ \\
\hline $\mathrm{In}_{2} \mathrm{~S}_{3}$ nanotube & SVs & $\begin{array}{l}\text { Full spectrum; } \\
\text { (300 W Xe) }\end{array}$ & No & Water; $15^{\circ} \mathrm{C}$ & $52.49 \mu \mathrm{mol} \cdot \mathrm{h}^{-1} \cdot \mathrm{g}^{-1}$ & Nessler's reagent & No & No & No & 3 cycles & $\begin{array}{r}{[274]} \\
(2019)\end{array}$ \\
\hline $\begin{array}{l}\text { Ultrathin } \\
\mathrm{MoS}_{2}\end{array}$ & SVs & $\begin{array}{l}\lambda \geq 420 \mathrm{~nm} ; \\
(500 \mathrm{~W} \mathrm{Xe})\end{array}$ & No & Water; $25^{\circ} \mathrm{C}$ & $325 \mu \mathrm{mol} \cdot \mathrm{h}^{-1} \cdot \mathrm{g}^{-1}$ & Indophenol blue & $\begin{array}{c}\text { Yes (only } \\
\text { qualitatively, not } \\
\text { quantitatively) }\end{array}$ & No & No & $10 \mathrm{~h}$ & $\begin{array}{c}{[46]} \\
(2017)\end{array}$ \\
\hline $\mathrm{Mo}_{0.1} \mathrm{Ni}_{0.1} \mathrm{Cd}_{0.8} \mathrm{~S}$ & SVs & $\begin{array}{c}800 \mathrm{~nm} \geq \lambda \geq \\
400 \mathrm{~nm} ; \\
(250 \mathrm{~W} \mathrm{Na})\end{array}$ & 98 & $\begin{array}{c}\text { Water/ } \\
\text { ethanol; } 30^{\circ} \mathrm{C}\end{array}$ & $3.2 \mathrm{mg} \cdot \mathrm{L}^{-1} \cdot \mathrm{h}^{-1} \cdot \mathrm{gcat}^{-1}$ & Nessler's reagent & $\begin{array}{c}\text { Yes } \\
\text { (only qualitatively, } \\
\text { not quantitatively) }\end{array}$ & No & No & $20 \mathrm{~h}$ & $\begin{array}{l}{[275]} \\
(2016)\end{array}$ \\
\hline $\mathrm{Zn}_{0.1} \mathrm{Sn}_{0.1} \mathrm{Cd}_{0.8} \mathrm{~S}$ & SVs & $\begin{array}{c}800 \mathrm{~nm} \geq \lambda \geq \\
400 \mathrm{~nm} ; \\
(250 \mathrm{~W} \mathrm{Na})\end{array}$ & 98 & $\begin{array}{c}\text { Water/ } \\
\text { ethanol; } 30^{\circ} \mathrm{C}\end{array}$ & $4.75 \mathrm{mg} \cdot \mathrm{L}^{-1} \cdot \mathrm{h}^{-1} \cdot \mathrm{g}_{\mathrm{cat}}^{-1}$ & Nessler's reagent & $\begin{array}{c}\text { Yes (only } \\
\text { qualitatively, not } \\
\text { quantitatively) }\end{array}$ & No & No & $20 \mathrm{~h}$ & $\begin{array}{l}{[276]} \\
(2016)\end{array}$ \\
\hline $1 \mathrm{~T}-\mathrm{MoS}_{2} / \mathrm{CdS}$ & SVs & $\begin{array}{c}780 \mathrm{~nm}>\lambda> \\
420 \mathrm{~nm} ; \\
(\mathrm{Xe}, \mathrm{AM} 1.5 \mathrm{G})\end{array}$ & 99.999 & $\begin{array}{c}\text { Water/ } \\
\text { methanol; RT }\end{array}$ & $\begin{array}{c}8220.83 \\
\mu \mathrm{mol} \cdot \mathrm{L}^{-1} \cdot \mathrm{h}^{-1} \cdot \mathrm{g}^{-1} \\
\text { AQE: } 4.424\end{array}$ & Nessler's reagent & No & No & No & 3 cycles & $\begin{array}{l}{[170]} \\
(2020)\end{array}$ \\
\hline $\begin{array}{c}\mathrm{Ru}-\mathrm{CoS} / \\
g-\mathrm{C}_{3} \mathrm{~N}_{4}\end{array}$ & SVs & $\begin{array}{c}\lambda \geq 420 \mathrm{~nm} ; \\
(300 \mathrm{~W} \mathrm{Xe}, \\
\left.200 \mathrm{~mW} \cdot \mathrm{cm}^{-2}\right)\end{array}$ & 99.999 & $\begin{array}{c}\text { Water/ } \\
\text { methanol; RT }\end{array}$ & $\begin{array}{l}0.438 \mathrm{mmol} \cdot \mathrm{g}^{-1} \cdot \mathrm{h}^{-1} \\
\text { AQE: } 1.28(400 \mathrm{~nm})\end{array}$ & Indophenol blue & $\begin{array}{c}\text { Yes (only } \\
\text { qualitatively, not } \\
\text { quantitatively) }\end{array}$ & No & No & 12 cycles & $\begin{array}{r}{[168]} \\
(2019)\end{array}$ \\
\hline $\begin{array}{c}g-\mathrm{C}_{3} \mathrm{~N}_{4} / \\
\mathrm{ZnMoCdS}\end{array}$ & SVs & $\begin{array}{c}800 \mathrm{~nm} \geq \lambda \geq \\
400 \mathrm{~nm} ; \\
(250 \mathrm{~W} \mathrm{Na})\end{array}$ & No & $\begin{array}{l}\text { Water/ } \\
\text { ethanol; } 30^{\circ} \mathrm{C}\end{array}$ & $3.5 \mathrm{mg} \cdot \mathrm{L}^{-1} \cdot \mathrm{h}^{-1} \cdot \mathrm{g}_{\mathrm{cat}}{ }^{-1}$ & Nessler's reagent & No & No & No & $20 \mathrm{~h}$ & $\begin{array}{l}{[277]} \\
(2016)\end{array}$ \\
\hline $\begin{array}{c}\mathrm{C}_{3} \mathrm{~N}_{4} / \mathrm{MoS}_{2} / \\
\mathrm{Mn}_{3} \mathrm{O}_{4}\end{array}$ & SVs & $\begin{array}{l}\lambda \geq 420 \mathrm{~nm} ; \\
(300 \mathrm{~W} \mathrm{Xe})\end{array}$ & No & $\begin{array}{c}\text { Water/ } \\
\mathrm{Na}_{2} \mathrm{SO}_{3} ; \mathrm{RT}\end{array}$ & $\begin{array}{c}185 \mu \mathrm{mol} \cdot \mathrm{h}^{-1} \cdot \mathrm{g}^{-1} \\
\text { AQE: } 1.2(420 \mathrm{~nm})\end{array}$ & Indophenol blue & $\begin{array}{c}\text { Yes (only } \\
\text { qualitatively, not } \\
\text { quantitatively) }\end{array}$ & No & Ar-PC & No & $\begin{array}{r}{[278]} \\
(2021)\end{array}$ \\
\hline
\end{tabular}


(Continued)

\begin{tabular}{|c|c|c|c|c|c|c|c|c|c|c|c|}
\hline Photocatalyst & $\begin{array}{l}\text { Defect } \\
\text { type }\end{array}$ & Illumination & $\begin{array}{l}{ }^{14} \mathrm{~N}_{2} \\
\text { purity }\end{array}$ & $\begin{array}{l}\text { Reaction } \\
\text { medium }\end{array}$ & $\begin{array}{c}\mathrm{NH}_{3} \text { yield; } \\
\mathrm{AQE}^{2} / \mathrm{AQY}^{\mathrm{b}}(\%)\end{array}$ & $\begin{array}{l}\text { Quantification } \\
\text { method }\end{array}$ & ${ }^{15} \mathrm{~N}_{2}$ isotope & $\begin{array}{c}\mathrm{N}_{2} \\
\text { purifica- } \\
\text { tion }\end{array}$ & $\begin{array}{c}\text { Control } \\
\text { experiment }\end{array}$ & Stability & $\begin{array}{l}\text { Ref. } \\
\text { (year) }\end{array}$ \\
\hline $\begin{array}{c}\mathrm{Pr}^{3+}: \mathrm{CeF}_{3} / \\
\text { ATP } \\
\text { (attapulgite) }\end{array}$ & FVs & $\begin{array}{l}\lambda \geq 420 \mathrm{~nm} ; \\
(300 \mathrm{~W} \mathrm{Xe})\end{array}$ & No & $\begin{array}{l}\text { Ethanol; } \\
30^{\circ} \mathrm{C}\end{array}$ & $629.16 \mu \mathrm{mol} \cdot \mathrm{L}^{-1}$ & Nessler's reagent & No & No & No & 5 cycles & $\begin{array}{c}{[171]} \\
(2019)\end{array}$ \\
\hline $\begin{array}{l}\mathrm{YF}_{3}: \mathrm{Sm}^{3+} / \mathrm{ATP} \\
\text { nanocomposite }\end{array}$ & FVs & $\begin{array}{l}\lambda \geq 420 \mathrm{~nm} ; \\
(300 \mathrm{~W} \mathrm{Xe})\end{array}$ & No & $\begin{array}{c}\text { Water/ } \\
\mathrm{Na}_{2} \mathrm{SO}_{3} ; 30^{\circ} \mathrm{C}\end{array}$ & $41.2 \mathrm{mg} \cdot \mathrm{L}^{-1}$ & Nessler's reagent & No & No & No & No & $\begin{array}{c}{[279]} \\
(2020)\end{array}$ \\
\hline
\end{tabular}

${ }^{\mathrm{a}}$ The AQE was calculated [180]. ${ }^{\mathrm{b}}$ The apparent quantum yield (AQY) was calculated [96].

${ }^{\mathrm{c}} \mathrm{Ar}-\mathrm{PC}$ represents photocatalytic experiments performed in Ar. ${ }^{\mathrm{d}} \mathrm{LDH}$ stands for layered-double-hydroxide.

(a)

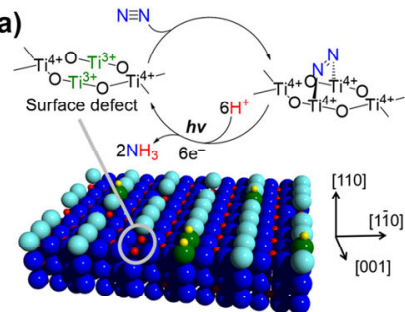

(c)

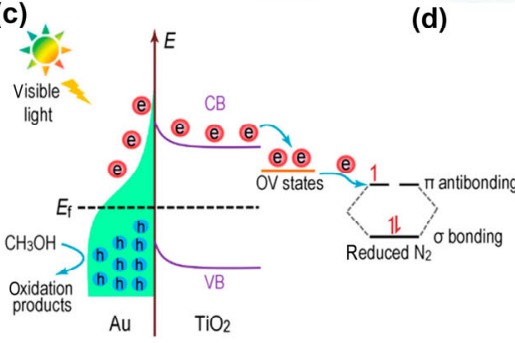

(b)

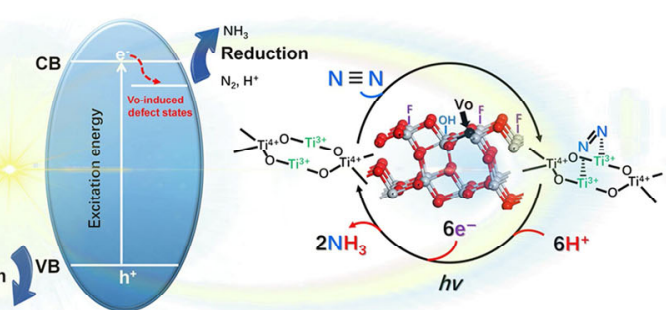

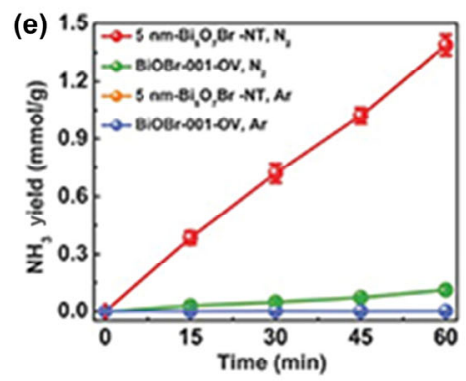

(f)
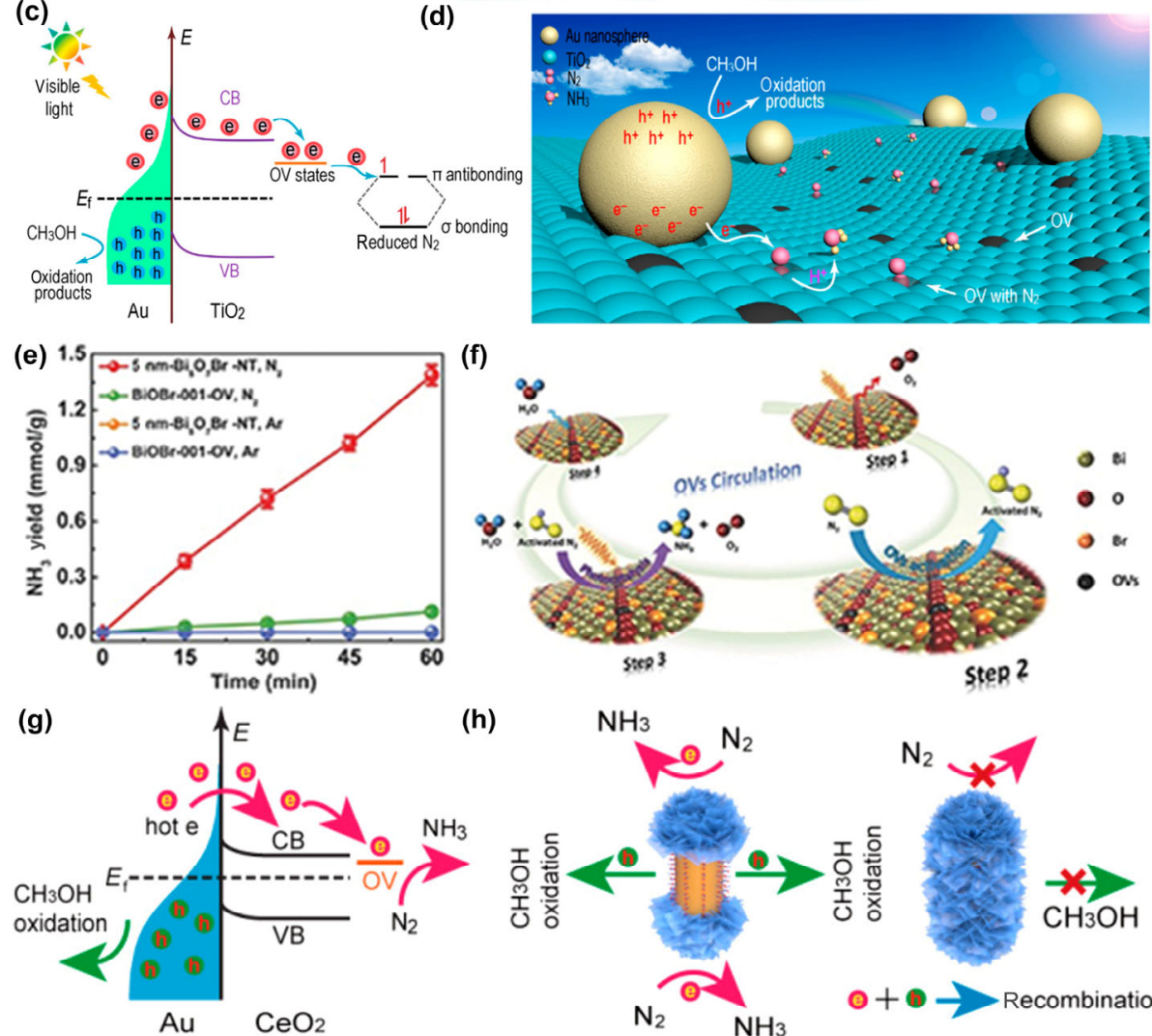

(h)
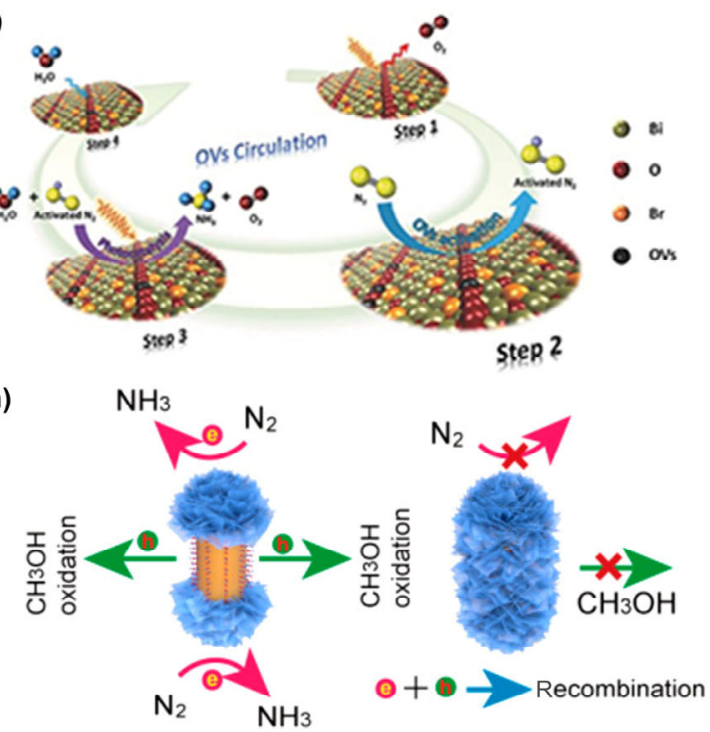

Figure 15 Photocatalytic $\mathrm{N}_{2}$ fixation on photocatalysts with OVs. (a) Proposed photocatalytic cycle for $\mathrm{N}_{2}$ fixation on rutile $\mathrm{TiO}_{2}(110)$ surface. Reproduced with permission from Ref. [67], ( ) American Chemical Society 2017. (b) Photocatalytic $\mathrm{N}_{2}$ fixation mechanism on the surface of hydrophobic treated defective $\mathrm{TiO}_{2}$ with $\mathrm{F}$ and Vo. Reproduced with permission from Ref. [221], () Elsevier Ltd. 2020. (c) Schematic illustrating the plasmonic hot electron generation, injection, $\mathrm{N}_{2}$ reduction processes in the $\mathrm{N}_{2}$ photofixation over $\mathrm{Au} / \mathrm{TiO}_{2}-\mathrm{OV}$ under visible light. (d) Artistic illustration of plasmonic $\mathrm{N}_{2}$ photofixation. Reproduced with permission from Ref. [158], @ American Chemical Society 2018. (e) Quantitative determination of $\mathrm{NH}_{3}$ generated on $\mathrm{Bi}_{5} \mathrm{O}_{7} \mathrm{Br}$ nanotubes and BOB-001-OV nanosheets under visible light $\left(\lambda>400 \mathrm{~nm}\right.$ ) irradiation. (f) Schematic illustration of the photocatalytic $\mathrm{N}_{2}$ fixation model. Reproduced with permission from Ref. [180], ( ) Wiley-VCH Verlag GmbH \& Co. KGaA 2017. (g) Mechanism of $\mathrm{N}_{2}$ photofixation on $\mathrm{Au} / \mathrm{end}-\mathrm{CeO}_{2}$. (h) Comparison of the hot carrier separation behaviors of Au/end- $\mathrm{CeO}_{2}$ nanostructure with that of the core@shell nanostructure. Reproduced with permission from Ref. [280], () American Chemical Society 2019.

$\mathrm{NH}_{3}$ generation rate of up to $1.38 \mathrm{mmol} \cdot \mathrm{h}^{-1} \cdot \mathrm{g}^{-1}$ was achieved on self-assembled $\mathrm{Bi}_{5} \mathrm{O}_{7} \mathrm{Br}$ nanotubes with sufficient $\mathrm{OV}$ s induced under visible light (Figs. 15(e) and 15(f)) [180].

Combining plasmon excitation to afford hot electrons and enhanced $\mathrm{N}_{2}$ adsorption, near infared (NIR)-driven $\mathrm{N}_{2}$ reduction to $\mathrm{NH}_{3}$ was attained over crystalline $\mathrm{V}_{\mathrm{O}}$-rich $\mathrm{CeO}_{2}$ grown at the ends of the gold nanorods ( $\left.\mathrm{Au} / \mathrm{end}-\mathrm{CeO}_{2}\right)$ [280]. $\mathrm{An} \mathrm{NH}_{3}$ yield rate of $114.3 \mu \mathrm{mol} \cdot \mathrm{h}^{-1} \cdot \mathrm{g}^{-1}$ was obtained under $808 \mathrm{~nm}$ laser illumination. The performance was mostly credited to the spatially-separated architecture, in which the Au nanorods absorbed NIR photons to produce plasmon-excited hot electrons and injected them into the $\mathrm{CB}$ of $\mathrm{V}_{\mathrm{O}}$-rich $\mathrm{CeO}_{2}$. This boosted 
broad-spectrum $\mathrm{N}_{2}$ reduction on the OVs sites (Figs. 15(g) and $15(\mathrm{~h})$ ). It is noted that the purity of $\mathrm{N}_{2}$ feed gas in this work was unknown. The source and amount of $\mathrm{NH}_{3}$ evolved were not probed by ${ }^{15} \mathrm{~N}_{2}$ isotope labeling experiments.

\subsubsection{Nitrogen vacancies (anion defects)}

$\mathrm{NVs}$ have primarily been investigated in $g-\mathrm{C}_{3} \mathrm{~N}_{4}$ with abundant nitrogen atoms $[84,160,241,281]$. The type of surface NVs is usually grouped into $\mathrm{N}$ vacancy defects and surface functional groups (i.e., cyano groups and amine), which could effectively improve the photocatalytic $\mathrm{N}_{2}$ reduction to $\mathrm{NH}_{3}[94,282]$. The surface NVs possess similar size and shape with the nitrogen atom in $\mathrm{N}_{2}$, thus facilitating selectively adsorb and activate $\mathrm{N}_{2}$. Elemental analysis (Fig. 16(a)) in combination with XPS (Figs. 16(b) and 16(c)) was employed to estimate the $\mathrm{C} / \mathrm{N}$ molar ratio for $g-\mathrm{C}_{3} \mathrm{~N}_{4}$ and $\mathrm{V}-g$ - $\mathrm{C}_{3} \mathrm{~N}_{4}$ (with $\mathrm{NVs}$ ) and verify the formation of NVs [256]. Based on N 1s and C 1s XP spectra, the peak-area ratio of $\mathrm{N}-\mathrm{C}_{3}$ to $\mathrm{C}-\mathrm{N}-\mathrm{C}$ was found to decrease from 3.25 to 0.76 , suggesting that NVs were primarily located at the tertiary nitrogen lattice sites. The disappearance of threecoordinate nitrogen was accompanied by the gradual formation of two- coordinate carbon $(\mathrm{N}-\mathrm{C}-\mathrm{N})$, further confirming the generation of NVs (Fig. 16(d)). Notably, an $\mathrm{NH}_{4}{ }^{+}$amount of $2.4 \mathrm{mM}$ and an $\mathrm{NH}_{4}^{+}$production rate of $1.24 \mathrm{mmol} \cdot \mathrm{h}^{-1} \cdot \mathrm{g}^{-1}$ were attained over $\mathrm{V}-\mathrm{g}-\mathrm{C}_{3} \mathrm{~N}_{4}$ in the $\mathrm{N}_{2}$ atmosphere under visible light irradiation (Figs. 16(e) and 16(f)). Moreover, when using a mixed gas $\left(\mathrm{N}_{2}, \mathrm{O}_{2}\right.$, and $\mathrm{CO}_{2}$ with the volume ratio of 1:1:1) in place of $\mathrm{N}_{2}$, the amount of $\mathrm{NH}_{4}{ }^{+}$formed remained unchanged. This indicated that the photocatalytic $\mathrm{N}_{2}$ fixation activity of $\mathrm{V}-g-\mathrm{C}_{3} \mathrm{~N}_{4}$ was unlikely interfered by other gases.

Besides $g-\mathrm{C}_{3} \mathrm{~N}_{4}$, NVs were also created in some nitride semiconductors [283, 284]. For example, gallium nitride nanowires (NWs) with NVs were designed and applied for $\mathrm{N}_{2}$ photoreduction [162]. The presence of NVs in GaN nanowires was validated by EPR measurements revealing a peak at approximately 3,450 G. After treating the GaN nanowire photocatalyst with $\mathrm{N}_{2}$, the EPR signal apparently decreased, indicating the interaction between $\mathrm{NVs}$ and $\mathrm{N}_{2}$. The assynthesized GaN NWs with NVs displayed an $\mathrm{NH}_{3}$ yield rate of $340 \mu \mathrm{mol} \cdot \mathrm{g}_{\mathrm{cat}}{ }^{-1} \cdot \mathrm{h}^{-1}$ under visible light ( $>400 \mathrm{~nm}$ ) with good stability and reusability (Fig. $16(\mathrm{~g})$ ). ${ }^{15} \mathrm{~N}_{2}$ isotope labeling experiments were further performed to examine the origin of nitrogen in the formed $\mathrm{NH}_{3}$ (Fig. 16(h)). It was found that when using ${ }^{15} \mathrm{~N}_{2}$ (98\% purity) as a feedstock, ${ }^{14} \mathrm{NH}_{3}$ was still generated as the main product over GaN NWs. ${ }^{15} \mathrm{NH}_{3}$ did not become the main product until the catalyst was evacuated under high temperature and vacuum $\left(>400^{\circ} \mathrm{C}\right.$ under $<5 \times 10^{-2} \mathrm{mbar}$ for $12 \mathrm{~h}$ ). This supported that the ${ }^{14} \mathrm{NH}_{3}$ product was mainly
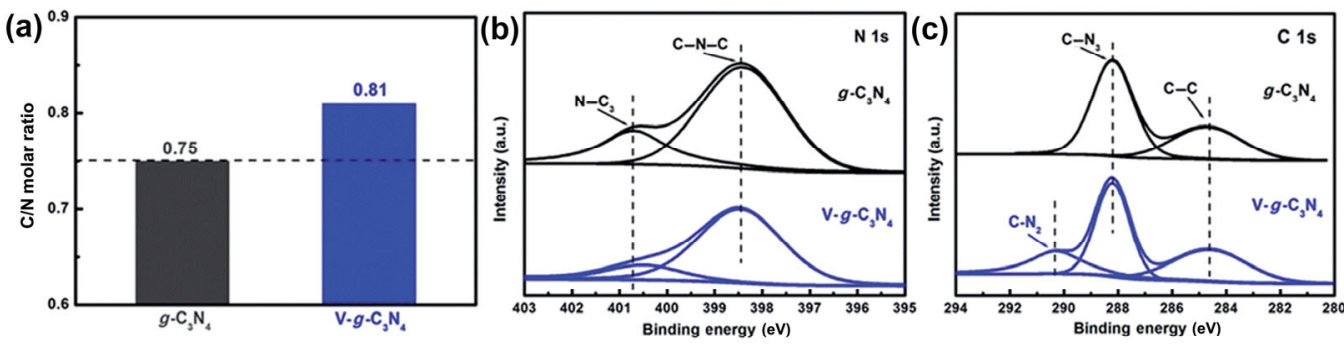

(d)
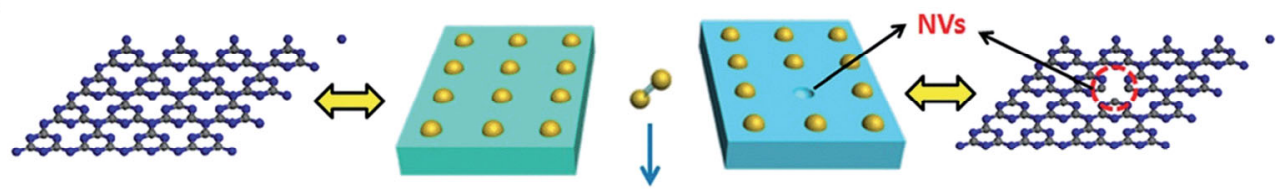

(e)
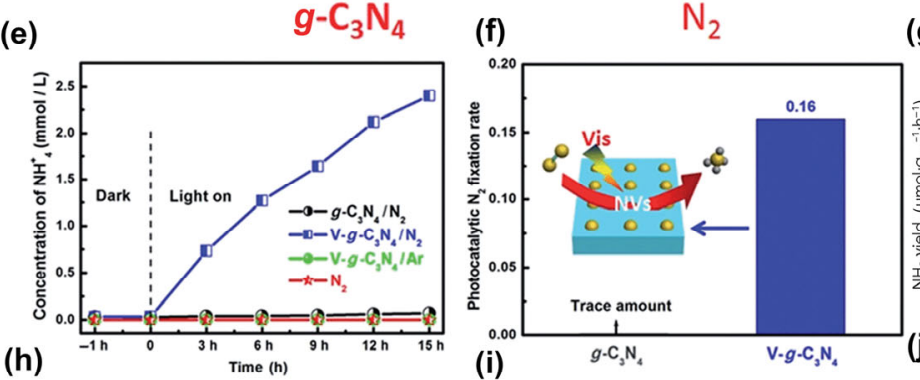

(g) $\mathrm{V}-\mathrm{g}-\mathrm{C}_{3} \mathrm{~N}_{4}$

(h)

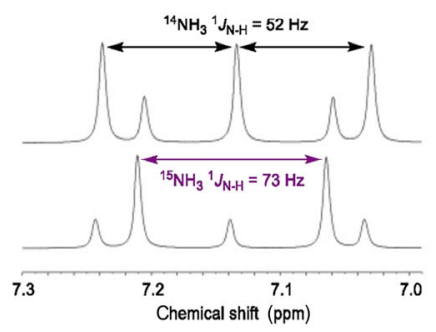

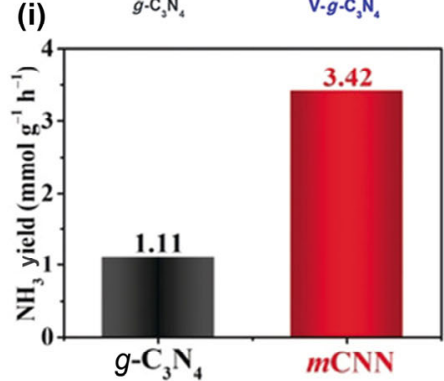

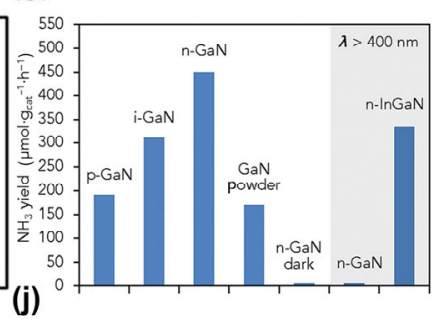

(j)

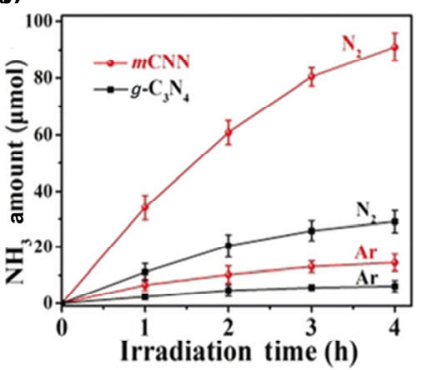

Figure 16 Photocatalytic $\mathrm{N}_{2}$ fixation on photocatalysts with NVs. (a) C/N molar ratio, (b) N 1s XP spectra, (c) C 1s XP spectra, and (d) schematic of $g-\mathrm{C}_{3} \mathrm{~N}_{4}$ and $\mathrm{V}-g-\mathrm{C}_{3} \mathrm{~N}_{4}$. (e) The concentration of generated $\mathrm{NH}_{4}{ }^{+}$in different systems. (f) Photocatalytic $\mathrm{N}_{2}$ fixation rates of $g-\mathrm{C}_{3} \mathrm{~N}_{4}$ and $\mathrm{V}_{-} g-\mathrm{C}_{3} \mathrm{~N}_{4}$. Reproduced with permission from Ref. [256], () The Royal Society of Chemistry 2015. (g) GaN NWs with different dopants under light illumination and with $>400 \mathrm{~nm}$ filter. (h) ${ }^{15} \mathrm{~N}_{2}$-labeling results before (above) and after (below) removing adsorbents on the catalyst. Reproduced with permission from Ref. [162], @ Elsevier Ltd. 2019. (i) $\mathrm{NH}_{3}$ yields. (j) $\mathrm{NH}_{3}$ yield versus irradiation time plots of $g$ - $\mathrm{C}_{3} \mathrm{~N}_{4}$ and $\mathrm{mCNN}$ with $\mathrm{N}_{2}$ and Ar as the feed gases. Reproduced with permission from Ref. [222], () Wiley-VCH Verlag GmbH \& Co. KGaA 2019. 
ascribed to adsorption of atmospheric $\mathrm{N}_{2}$ to the catalyst and not from GaN decomposition.

The surface NVs coupled with extra species including cyano groups and amine can jointly regulate the electronic structure and hence improve photocatalytic efficiency for $\mathrm{N}_{2}$ reduction $[97,271]$. As an example, $g-C_{3} N_{4}$ photocatalyst was modified with cyano groups and also intercalated with $\mathrm{K}^{+}(\mathrm{mCNN})$, which provided a high $\mathrm{NH}_{3}$ yield of $3.42 \mathrm{mmol} \cdot \mathrm{g}^{-1} \cdot \mathrm{h}^{-1}$ under visible-light irradiation (Fig. 16(i)) [222]. When Ar was applied as the feed gas, the quantity of $\mathrm{NH}_{3}$ also increased with the extension of irradiation time but the value was substantially reduced compared to the process using $\mathrm{N}_{2}$ feed gas (Fig. 16(j)). This observation suggested that under Ar, the nitrogen source in the formed $\mathrm{NH}_{3}$ stemmed from the photocatalyst. ${ }^{15} \mathrm{~N}_{2}$ isotope labeling analysis was carried out. The ratio of the collective integral area of ${ }^{15} \mathrm{NH}_{4}{ }^{+}$peaks centered at chemical shifts of $d=6.88$ and $7.06 \mathrm{ppm}$ after 4 and $8 \mathrm{~h}$ of reaction was 1.65 showing continuous ${ }^{15} \mathrm{NH}_{4}{ }^{+}$production, whereas the ratio of the collective integral area of ${ }^{14} \mathrm{NH}_{4}{ }^{+}$peaks centered at chemical shifts of $d=6.84,6.97$, and 7.10 ppm after 4 and $8 \mathrm{~h}$ of reaction was 1.07, indicating that the generation of ${ }^{14} \mathrm{NH}_{4}{ }^{+}$ discontinued. This result suggested that the utilizable $\mathrm{N}$ from mCNN for $\mathrm{NH}_{3}$ formation was exhausted after some time.

\subsubsection{Sulfur vacancies (anion defects)}

Introducing SVs onto photocatalyst surfaces can adjust the electronic structure of sulfides, which is conducive to enhance the photocatalytic $\mathrm{N}_{2}$ reduction [278]. Until now, sulfides such as $\mathrm{In}_{2} \mathrm{~S}_{3}$ [274], $\mathrm{MoS}_{2}$ [46], $\mathrm{Mo}_{0.1} \mathrm{Ni}_{0.1} \mathrm{Cd}_{0.8} \mathrm{~S}$ [275], $\mathrm{ZnMoCdS}$ [277], $\mathrm{Zn}_{0.1} \mathrm{Sn}_{0.1} \mathrm{Cd}_{0.8} \mathrm{~S}$ [276], and $\mathrm{Zn}_{0.11} \mathrm{Sn}_{0.12} \mathrm{Cd}_{0.88} \mathrm{~S}_{1.12}$ [285] have been demonstrated to be capable of catalyzing ambient photochemical $\mathrm{N}_{2}$ reduction to $\mathrm{NH}_{3}$. For example, $\mathrm{CdS}$ nanorods modified with SVs-rich O-doped 1T- $\mathrm{MoS}_{2}$ nanosheets (denoted as SV-1T-MoS ) (as a cocatalyst) could effectively catalyze photochemical $\mathrm{N}_{2}$ reduction [170]. The optimized composites presented a remarkable $\mathrm{NH}_{3}$ rate as high as $8,220.83 \mu \mathrm{mol} \cdot \mathrm{L}^{-1} \cdot \mathrm{h}^{-1} \cdot \mathrm{g}^{-1}$ under simulated solar light irradiation (Fig. 17(a)). The outstanding photocatalytic activity was speculated to result from the synergy of SVs, O-doping, and more metallic 1T phase, which extended visible light absorption and also promoted the separation and migration of photogenerated electrons (Fig. 17(b)). Nevertheless, the purity of $\mathrm{N}_{2}$ used in this work was not provided. In addition, ${ }^{15} \mathrm{~N}_{2}$ isotope labeling experiments were not conducted to confirm the origin of $\mathrm{NH}_{3}$ formed. An $\mathrm{Ru}-\mathrm{Co}$ bimetal center at the interface of $\mathrm{Ru} / \mathrm{CoS}_{x}$ with S-vacancy on graphitic carbon nitride nanosheets $\left(\mathrm{Ru}-\mathrm{V}_{\mathrm{s}}-\mathrm{CoS} / \mathrm{CN}\right)$ was designed for $\mathrm{N}_{2}$ reduction, delivering an $\mathrm{NH}_{3}$ yield rate of $0.438 \mathrm{mmol} \cdot \mathrm{g}^{-1} \cdot \mathrm{h}^{-1}$ with an apparent quantum efficiency of $1.28 \%$ at $400 \mathrm{~nm}$ and solar-toammonia efficiency of $0.042 \%$ in pure water (Fig. 17(c)) [168]. The two $\mathrm{N}$ atoms in $\mathrm{N}_{2}$ were posited to be bridged to the $\mathrm{Ru}-\mathrm{Co}$ center. The asymmetrical electron donation from $\mathrm{Ru}$ and Co atoms to the $\mathrm{N}_{2}$ adsorbate polarized the $\mathrm{N} \equiv \mathrm{N}$ bond to double bond order. The Schottky barrier between Ru and $\mathrm{CoS}_{\mathrm{x}}$ endowed an interface with plasmonic electron transfer from $\mathrm{CoS}_{x}$ to $\mathrm{Ru}$, favoring hydrogenation of the $\mathrm{Ru}$-end bound $\mathrm{N}$ at the Ru-Co center (Fig. 17(d)).

\subsubsection{Carbon vacancies (anion defects)}

$\mathrm{CVs}$ are the most common anion vacancy present in carbonbased materials [286]. Like OVs, NVs, and SVs, manipulation of CVs enables tuning of the electronic structure of materials. Meanwhile, CVs can act as active sites to enhance adsorption and activation of $\mathrm{N}_{2}$ [153]. For instance, integration of CVs and iodine doping led to lowered band gap and enhanced separation efficiency of the photo-generated charge carriers over $g-\mathrm{C}_{3} \mathrm{~N}_{4}$, promoting the $\mathrm{N}_{2}$ reduction to $\mathrm{NH}_{3}$ with an $\mathrm{NH}_{3}$ yield rate of $200.8 \mathrm{mg} \cdot \mathrm{L}^{-1} \cdot \mathrm{g}_{\text {cat. }}{ }^{-1}$ under simulated sunlight irradiation within $3 \mathrm{~h}, 2.8$ times as high as that of bulk $g-\mathrm{C}_{3} \mathrm{~N}_{4}$ (Figs. 18(a) and 18(b)) [272]. The CVs on the surface of $g-\mathrm{C}_{3} \mathrm{~N}_{4}$ were proposed as active centers for $\mathrm{N}_{2}$ adsorption and $\mathrm{N} \equiv \mathrm{N}$ triple bond activation, affording an $\mathrm{NH}_{3}$ production rate of up to $54 \mathrm{mmol} \cdot \mathrm{L}^{-1}$ within $100 \mathrm{~min}$ (Fig. 18(c)) [287].

\subsubsection{Fluorine vacancy (anion defects)}

FVs are recognized as an effective anion defect while they are rarely discussed especially for photocatalytic $\mathrm{N}_{2}$ reduction. $\mathrm{Pr}^{3+}: \mathrm{CeF}_{3}$ supported on one-dimensional ATP mineral was
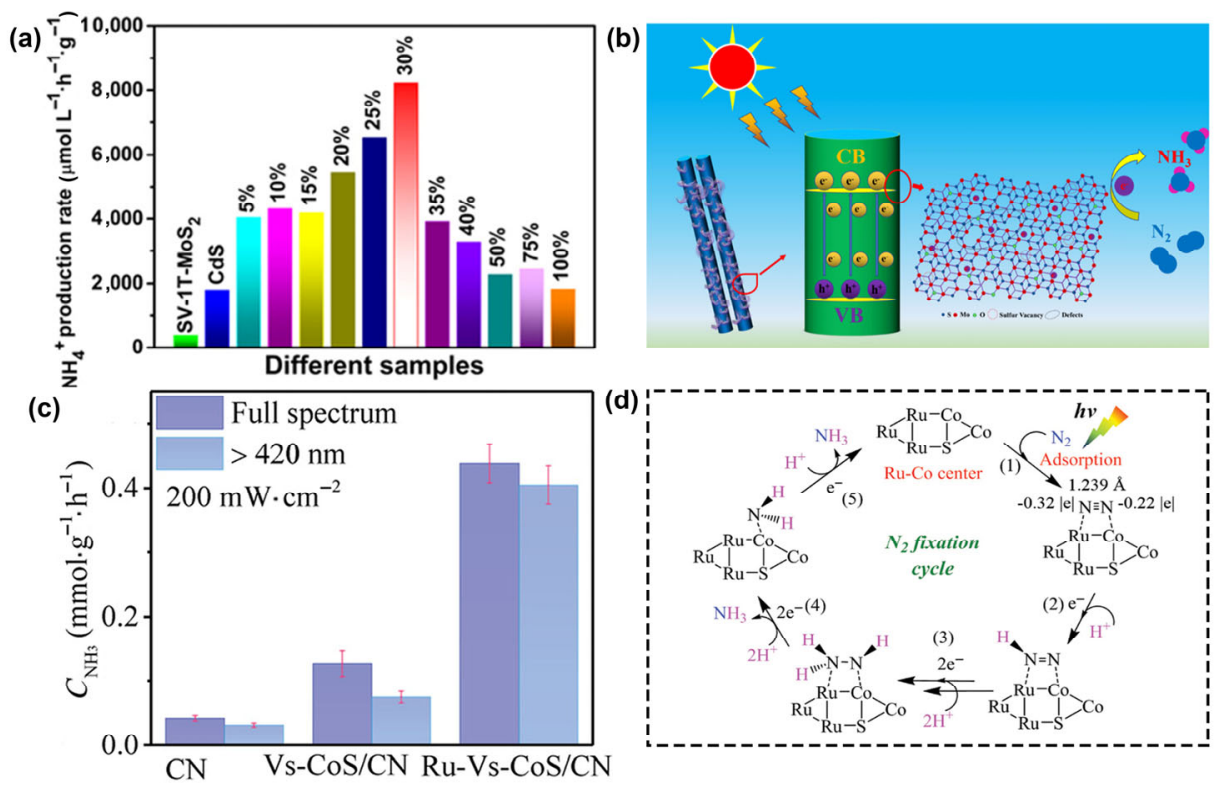

Figure 17 The $\mathrm{N}_{2}$ photoreduction on catalysts with SVs. (a) Photocatalytic $\mathrm{NH}_{3}$ production rates over neat SV-1T-MoS 2 , CdS, and SV-1T-MoS $/$ CdS composites with different amounts of SV-1T-MoS 2 . (b) Schematic illustration of the photoexcited carrier transfer in SV-1T-MoS $2 / \mathrm{CdS}$. Reproduced with permission from Ref. [170], () American Chemical Society 2020. (c) Photocatalytic $\mathrm{NH}_{3}$ production rates of $\mathrm{CN}, \mathrm{Vs}-\mathrm{CoS} / \mathrm{CN}$, and Ru-Vs-CoS/CN. (d) Proposed photocatalytic $\mathrm{N}_{2}$ reduction pathway on $\mathrm{Ru}-\mathrm{V}_{s}-\mathrm{CoS} / \mathrm{CN}$. Reproduced with permission from Ref. [168], ๑ Wiley-VCH Verlag GmbH \& Co. KGaA 2019. 

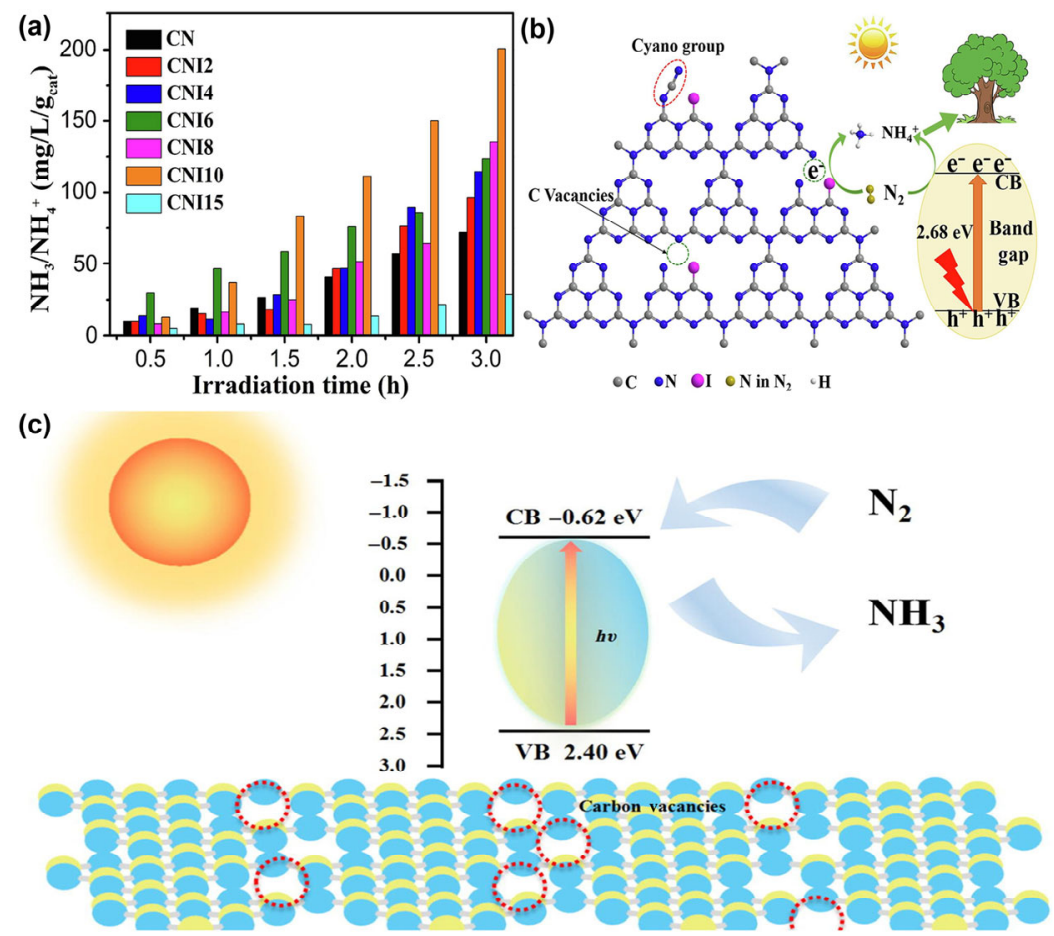

Figure 18 CVs of catalysts for photocatalytic $\mathrm{N}_{2}$ fixation. (a) The photocatalytic nitrogen fixation over $\mathrm{CN}$ and CNIX under simulated sunlight irradiation. (b) The possible process of photocatalytic nitrogen fixation over CNI10. Reproduced with permission from Ref. [272], @ Elsevier Ltd. 2020. (c) Photocatalytic mechanism diagram of $g$ - $\mathrm{C}_{3} \mathrm{~N}_{4}$ with CVs. Reproduced with permission from Ref. [287], () Elsevier Ltd. 2019.

demonstrated to be active for $\mathrm{N}_{2}$ photoreduction [171]. The prominent activity was attributed to the abundant FVs which served as active sites to facilitate $\mathrm{N}_{2}$ adsorption and weaken the $\mathrm{N} \equiv \mathrm{N}$ triple bond during the photocatalytic reaction. Moreover, FVs were postulated to act as a mediator to facilitate the formation of a Z-scheme structure [279]. $\mathrm{Yb}^{3+}$ and $\mathrm{Tm}^{3+}$ co-doping of $\mathrm{LaF}_{3}$ anchored on palygorskite (Pal) $\left(\mathrm{LaF}_{3}: \mathrm{Yb}^{3+}, \mathrm{Tm}^{3+} / \mathrm{Pal}\right)$ was shown to promote the photocatalytic $\mathrm{N}_{2}$ reduction [288]. An $\mathrm{NH}_{3}$ formation rate of $5.7 \mathrm{mg} \cdot \mathrm{L}^{-1}$ within $3 \mathrm{~h}$ was attained even under NIR light irradiation. The good photocatalytic performance was supposed to arise from the upconversion capability of $\mathrm{LaF}_{3}: \mathrm{Yb}^{3+} \mathrm{Tm}_{3+}$, which converted NIR into visible and UV light, drastically increasing the utilization of sunlight. Furthermore, the indirect Z-scheme heterostructure comprising $\mathrm{LaF}_{3}: \mathrm{Yb}^{3+}, \mathrm{Tm}^{3+}$ and $\mathrm{Pal}$ could be effectively mediated by FVs to promote photogenerated carrier separation and migration and also retain the redox capacity.

\subsubsection{Cation defects}

In addition to anion vacancies, metal cation vacancies can also affect the physicochemical and electronic properties of metal compounds, originating from their specific orbital distribution with characteristic electronic configurations [289]. Introduction of cation vacancies can change the semiconductor conductivity from $n$-type to $\mathrm{p}$-type and facilitate the separation of photogenerated carriers. Compared with anion vacancies, clarification of the role of metal cation vacancies is more challenging given their high formation energy and seldomly reported experimental protocols [59]. $\mathrm{Ni}_{12} \mathrm{P}_{5} / \mathrm{ZnIn}_{2} \mathrm{~S}_{4}$ hybrids with zinc vacancies $(\mathrm{ZnVs})$ were fabricated and used as a dualfunctional photoredox catalyst with holes to oxidize benzyl alcohol and electrons to reduce $\mathrm{N}_{2}$ [290]. The as-prepared $\mathrm{Ni}_{12} \mathrm{P}_{5} / \mathrm{ZnIn}_{2} \mathrm{~S}_{4}$ heterostructures with $\mathrm{ZnVs}$ showed promising capability for photocatalytic $\mathrm{N}_{2}$ fixation coupled with benzyl alcohol oxidation. Recently, a Ti-based metal organic framework $\mathrm{Ti}_{8} \mathrm{O}_{8}(\mathrm{OH})_{4}(\mathrm{BDC})_{6}$ (MIL-125 (Ti)) was firstly constructed and employed for photocatalytic $\mathrm{N}_{2}$ fixation [210]. Ligand functionalization was demonstrated to extend light harvesting of the metal organic framework (MOF) to visible region of up to $550 \mathrm{~nm}$ (Fig. 19(a)). The electron transfer from ligand to metal induced $\mathrm{Ti}^{3+}$ species in the form of $\mathrm{Ti}_{8}$ clusters with defect sites as proved by EPR analysis (Fig. 19(b)). Enriched photogenerated electrons were observed to inject from the $\mathrm{Ti}^{3+}$ to $\mathrm{N}_{2}$ by time-resolved photoluminescence decay measurements (Fig. 19(c)). Furthermore, integration of Ti sites and aminefunctionalized linkers enabled an enhanced ammonia evolution rate of $12.3 \mu \mathrm{mol} \cdot \mathrm{g}^{-1} \cdot \mathrm{h}^{-1}$ (Fig. 19 (d)). ${ }^{15} \mathrm{~N}_{2}$ isotopic labeling experiments confirmed the true reduction of $\mathrm{N}_{2}$ (Fig. 19(e)). It was envisioned that electrons were transferred from the organic ligand to $\mathrm{Ti}^{4+}$ forming $\mathrm{Ti}^{3+}$, while the $\mathrm{Ti}_{8}$ clusters with defect sites adsorbed and activated $\mathrm{N}_{2}$ molecules to yield $\mathrm{NH}_{3}$ and then reacted with $\mathrm{Ti}^{3+}$ to reproduce $\mathrm{Ti}^{4+}$ under visible light irradiation (Fig. 19(f)).

\subsubsection{Synergism of cation and anion defects}

It is discovered that multifold defects, such as cation and anion defects, cation and coordinatively unsaturated metal atoms, exhibit synergistic effects for the photocatalytic $\mathrm{N}_{2}$ reduction to $\mathrm{NH}_{3}[148,291]$. The synergistic effects not only extend the range of light response and promote efficient separation and migration of photogenerated electron-hole pairs, but also enhance the adsorption and activation of $\mathrm{N}_{2}$ molecules [292]. For instance, two-dimensional oxidized $\mathrm{Sb}$ nanosheets with $\mathrm{Sb}$ and OVs were reported through controlled liquid exfoliation of bulk Sb [167]. The 2D defective Sb contributed to an $\mathrm{NH}_{3}$ formation rate of $388.5 \mu \mathrm{g}_{\mathrm{NH}_{3}} \cdot \mathrm{h}^{-1} \cdot \mathrm{g}_{\text {cat. }}{ }^{-1}$, nearly 8 times higher than that for bulk Sb. Further DFT calculations revealed that the anion-cation vacancy pairs ( $\mathrm{Sb}$ and $\mathrm{OVs}$ ) acted as abundant surface catalytic sites, which significantly promoted the formation of ${ }^{*} \mathrm{NNH}$, thereby facilitating the photocatalytic $\mathrm{N}_{2}$ reduction. Single-unit-cell $\mathrm{Bi}_{3} \mathrm{O}_{4} \mathrm{Br}$ nanosheets with " $\mathrm{Bi}-\mathrm{O}$ " vacancy pairs were synthesized and applied for $\mathrm{N}_{2}$ photoreduction (Figs. 20(a) and 20(b)) [173]. A number of point defects associated with Bi vacancies were observed on defect-rich 

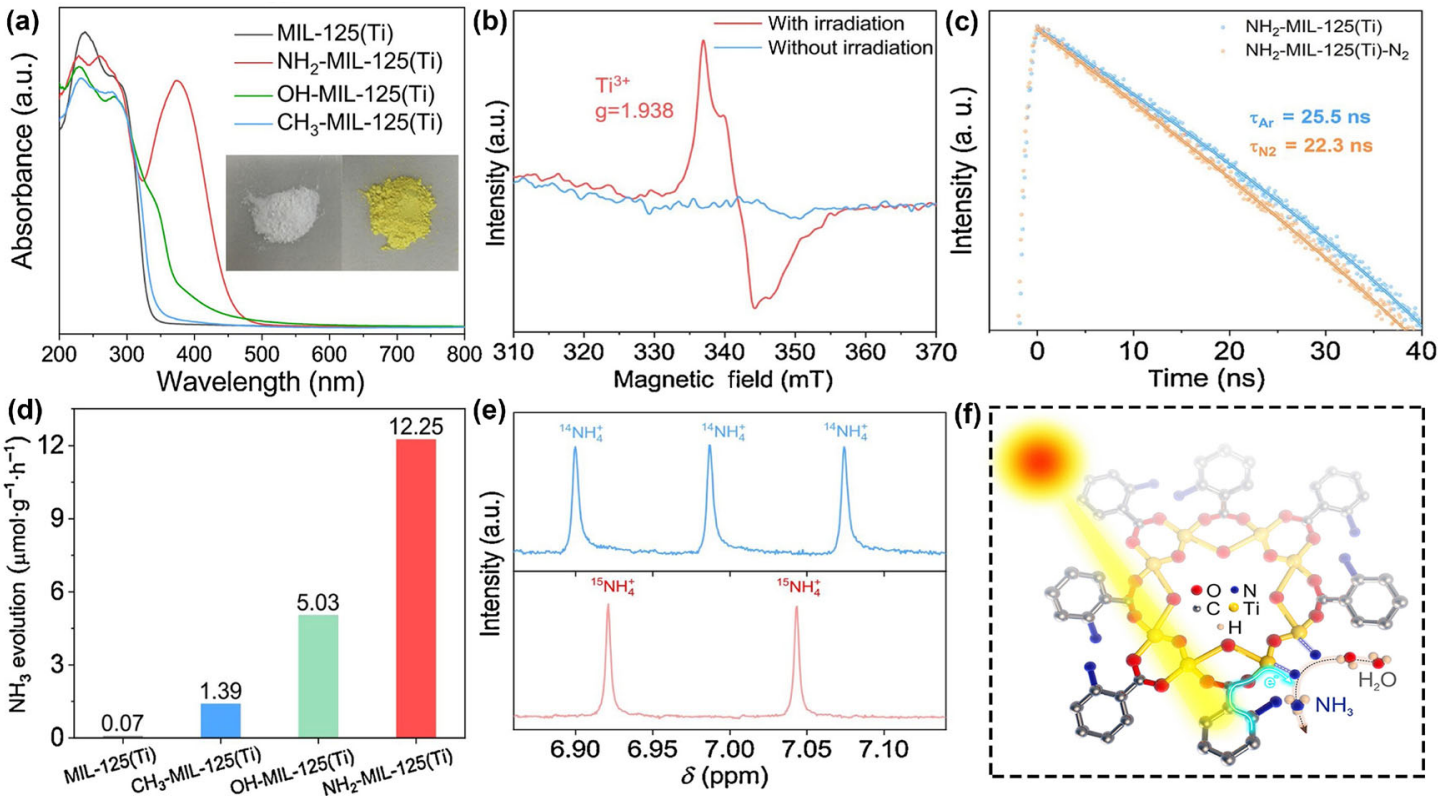

Figure 19 Ti defect on $\mathrm{NH}_{2}$-MIL-125 (Ti) and photocatalytic $\mathrm{N}_{2}$ fixation over MIL-125 (Ti). (a) UV-vis spectra of MIL-125 (Ti), NH$-\mathrm{MIL}-125$ (Ti), OH-MIL-125 (Ti) and $\mathrm{CH}_{3}$-MIL-125 (Ti). (b) Low-temperature EPR spectra of $\mathrm{NH}_{2}-\mathrm{MIL}-125$ (Ti) before and after light irradiation. (c) Time-resolved photoluminescence decay curves of $\mathrm{NH}_{2}$-MIL-125 (Ti) under $\mathrm{Ar}$ and $\mathrm{N}_{2}$ atmosphere. (d) Production yield rates of ammonia over photocatalysts for $15 \mathrm{~h}$. (e) ${ }^{1} \mathrm{H}$ NMR spectra of the products obtained in different reaction atmospheres. (f) Proposed mechanism for the photocatalytic $\mathrm{N}_{2}$ fixation over $\mathrm{NH}_{2}$-MIL-125 (Ti). Reproduced with permission from Ref. [210], @ Elsevier Ltd. 2020.

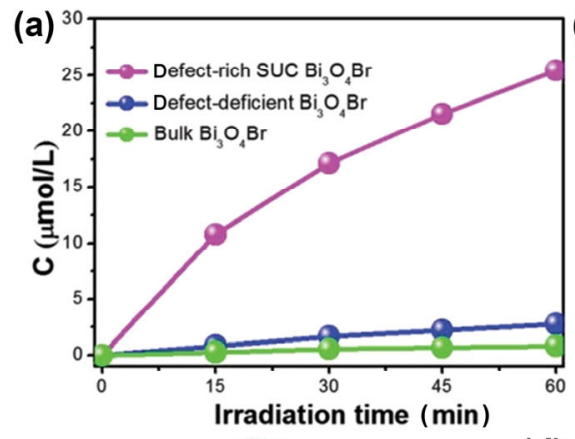

(c)

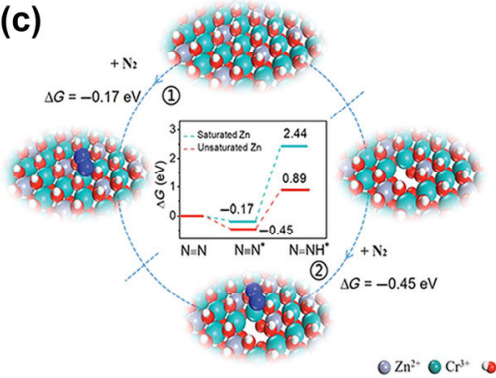

(d) (b)
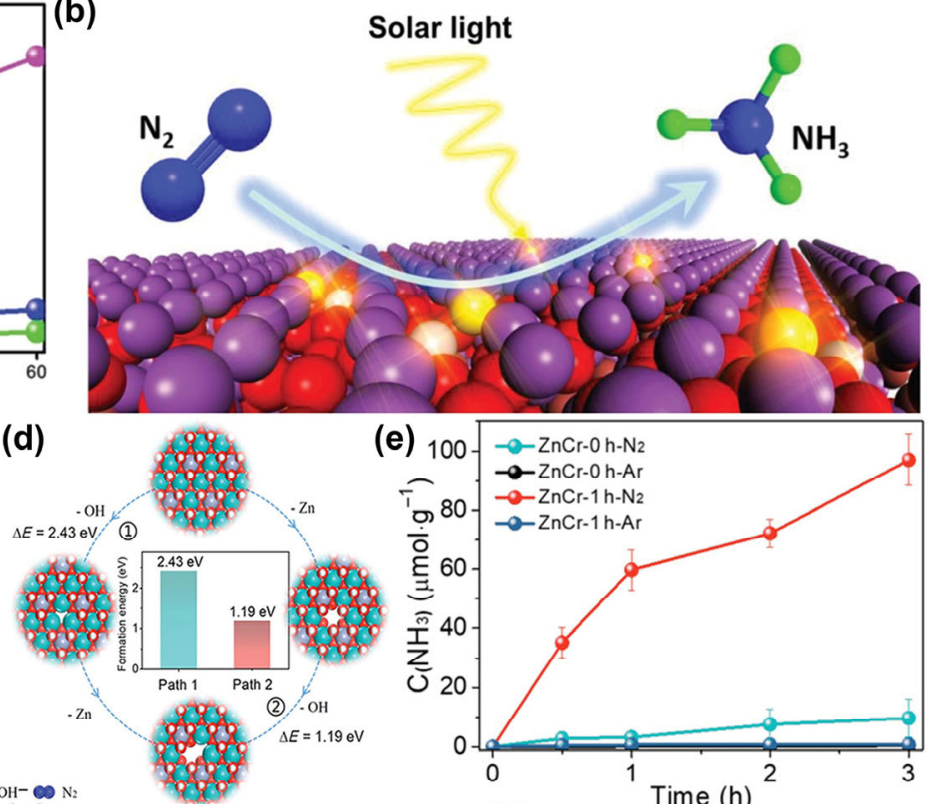

(e) $100-2-0-$ Zncr-oh-N

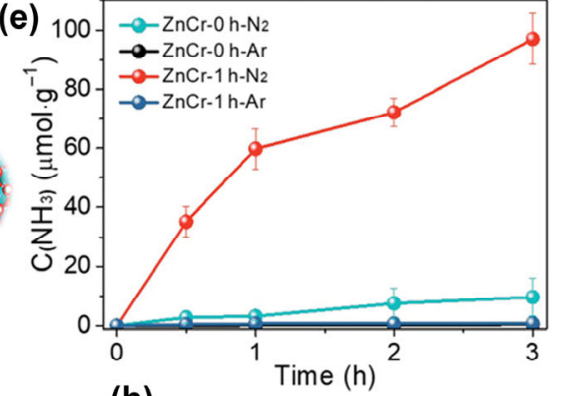

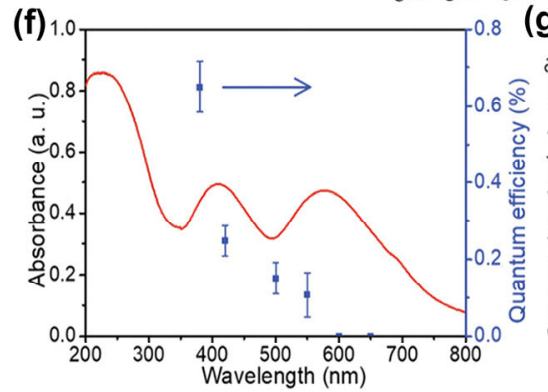
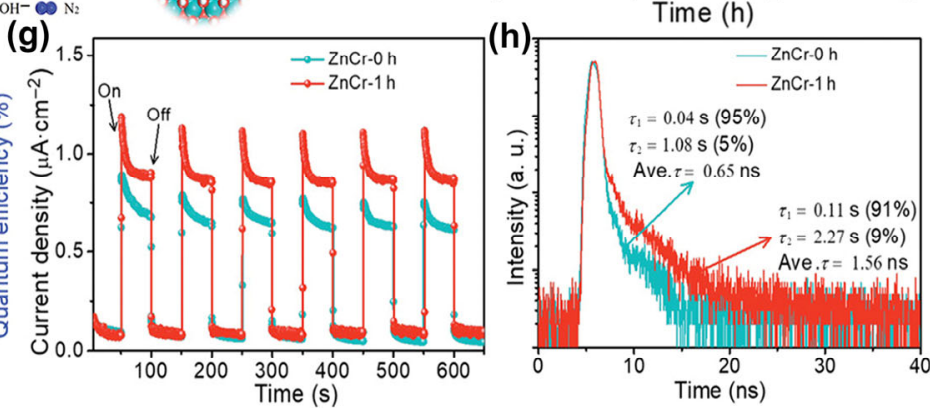

Figure 20 Synergistic effects of multifold defects for the photocatalytic $\mathrm{N}_{2}$ reduction to $\mathrm{NH}_{3}$. (a) Concentration of generated $\mathrm{NH}_{3}$ versus irradiation time. (b) Schematic illustration of the photocatalytic $\mathrm{N}_{2}$ fixation over defect-rich SUC $\mathrm{Bi}_{3} \mathrm{O}_{4} \mathrm{Br}$. Reproduced with permission from Ref. [173], ๑ Wiley-VCH Verlag $\mathrm{GmbH} \&$ Co. KGaA 2019. (c) DFT predicted activity for $\mathrm{N}_{2}$ adsorption and hydrogenation on different types of ZnCr-LDH surfaces. (d) Formation energy of Vo in defect-free $\mathrm{ZnCr}-\mathrm{LDH}$ and $\mathrm{ZnCr}-\mathrm{LDH}$ with zinc vacancies. (e) Concentration of generated $\mathrm{NH}_{3}$ in $\mathrm{Ar}$ and $\mathrm{N}_{2}$ atmospheres over $\mathrm{ZnCr}-0 \mathrm{~h}$ and $\mathrm{ZnCr}-1 \mathrm{~h}$ under UV-vis irradiation. (f) Apparent quantum efficiency for $\mathrm{N}_{2}$ photofixation over etched $\mathrm{ZnCr}-1 \mathrm{~h}$. The absorbance spectrum is shown for comparison. (g) Periodic on/off photocurrent responses for $\mathrm{ZnCr}-0 \mathrm{~h}$ and etched $\mathrm{ZnCr}-1 \mathrm{~h}$. (h) Time-resolved photoluminescence decay curves for $\mathrm{ZnCr}-0 \mathrm{~h}$ and etched ZnCr-1 h. Reproduced with permission from Ref. [165], ๑ Wiley-VCH Verlag GmbH \& Co. KGaA 2020. 
$\mathrm{Bi}_{3} \mathrm{O}_{4} \mathrm{Br}$. The $\mathrm{Bi}_{3} \mathrm{O}_{4} \mathrm{Br}$ nanosheets with " $\mathrm{Bi}-\mathrm{O}$ " vacancy pairs were active for photocatalytic $\mathrm{N}_{2}$ reduction with an $\mathrm{NH}_{3}$ yield rate of $50.8 \mu \mathrm{mol} \cdot \mathrm{g}^{-1} \cdot \mathrm{h}^{-1}$, more than 9.2 and 30.9 times compared to the defect-deficient $\mathrm{Bi}_{3} \mathrm{O}_{4} \mathrm{Br}$ and bulk $\mathrm{Bi}_{3} \mathrm{O}_{4} \mathrm{Br}$, respectively (Fig. 20(a)). The enhanced photocatalytic activity was supposed to be related with the increased charge separation efficiency based on density of state (DOS) calculations and ultrafast transient absorption (TA) spectroscopy. DFT calculations uncovered that the defective structure of $\mathrm{Bi}_{3} \mathrm{O}_{4} \mathrm{Br}$ could enhance the adsorption of $\mathrm{N}_{2}$. Furthermore, by virtue of ${ }^{15} \mathrm{~N}_{2}$ isotope labeling experiments, it was verified that the evolved $\mathrm{NH}_{3}$ stemmed from the actual reduction of $\mathrm{N}_{2}$. Likewise, $\mathrm{ZnCr}-\mathrm{LDH}$ nanosheets with OVs were fabricated [165]. The nanosheets contained abundant coordinately unsaturated metal active sites (zinc vacancies) with OVs which served as the sites for $\mathrm{N}_{2}$ chemisorption. Unsaturated $\mathrm{Zn}$ sites were calculated to have a more negative adsorption free energy value $(-0.45 \mathrm{eV})$ than saturated $\mathrm{Zn}$ sites $(-0.17 \mathrm{eV}$ ) (Fig. 20(c)), suggesting that the unsaturated $\mathrm{Zn}$ sites promoted both $\mathrm{N}_{2}$ adsorption and activation. DFT calculations further illustrated that the unsaturated $\mathrm{Zn}$ sites could be more easily generated after introducing zinc vacancies (Fig. 20(d)). Consequently, the $\mathrm{ZnCr}-1 \mathrm{~h}$ nanosheets rich in oxygen and cation vacancies provided an $\mathrm{NH}_{3}$ yield rate of $33.19 \mu \mathrm{mol} \cdot \mathrm{g}^{-1} \cdot \mathrm{h}^{-1}$ (Fig. 20(e)) with quantum efficiency of $0.95 \%$ at $380 \mathrm{~nm}$ (Fig. 20(f)). In addition to enhanced adsorption and activation of $\mathrm{N}_{2}$ due to the oxygen and cation vacancies as revealed by XAFS and DFT calculations, separation, and migration of photogenerated carriers were also promoted evidenced by photocurrent and TR-PL measurements (Figs. 20(g) and 20(h)).

\subsubsection{Heteroatom doping}

Heteroatom doping has emerged as another effective and feasible strategy for enhancing the $\mathrm{N}_{2}$ reduction. The introduction of foreign atoms with different physical (such as types, concentrations, and distribution locations, etc.) and chemical properties (such as atom radius, electron density, and chemical valence, etc.) can modulate the local electronic structure and electronic properties of semiconductor materials [293-296]. Heteroatom doping can be mainly divided into metal element doping and nonmetal element doping, depending on the types of dopants [82].

\subsubsection{Metal doping}

Metal doping mainly focuses on transition metals (TMs) because TM species can bind with $\mathrm{N}_{2}$ at low temperatures. The nature of the interaction between the TMs and $\mathrm{N}_{2}$ primarily depends on the "acceptance-donation" of electrons, where the combination of empty and occupied d orbitals plays an indispensable role [297, 298]. The TM center can accept the lone pair of electrons of $\mathrm{N}_{2}$ through the empty d orbital [299]. The backdonation of $\mathrm{d}$ electrons from the TMs to $\mathrm{N}_{2}$ can strengthen the N-TM bonds and also simultaneously weaken the $\mathrm{N} \equiv \mathrm{N}$ bonds, facilitating effective $\mathrm{N}_{2}$ binding and activation [300]. TMs such as Fe, Mo, Mn, etc. have been widely employed as dopants to enhance $\mathrm{N}_{2}$ reduction [301-303]. For example, doping of ultrathin $\mathrm{W}_{18} \mathrm{O}_{49}$ nanowires by Mo atoms showed efficiency in improving photocatalytic $\mathrm{N}_{2}$ reduction [66]. EPR spectroscopy revealed co-existence of coordinatively unsaturated $\mathrm{Mo}\left(\mathrm{Mo}^{5+}\right)$ and oxygen defects in the samples (Figs. 21(a) and 21(b)). The optimized Mo- $\mathrm{W}_{18} \mathrm{O}_{49}$ with 1 mol.\% Mo was observed to possess effective photocatalytic $\mathrm{N}_{2}$ reduction activity with an $\mathrm{NH}_{3}$ production rate of $195.5 \mu \mathrm{mol}^{\circ} \mathrm{g}_{\text {cat. }}{ }^{-1} \cdot \mathrm{h}^{-1}$ under full spectrum (Fig. 21(c)). Two aspects associated with such high performance were inferred: (1) elevation of defect-band center toward the Fermi level, thus preserving the energy of photoexcited electrons for $\mathrm{N}_{2}$ reduction (Fig. 21(d)); (2) polarization of chemisorbed $\mathrm{N}_{2}$ molecules and acceleration of electron transfer from coordinatively unsaturated Mo sites to $\mathrm{N}_{2}$ adsorbates, hence boosting dissociation of $\mathrm{N} \equiv \mathrm{N}$ bonds through proton coupling (Figs. 21(e) and 21(f)). Despite this efficiency, the true origin of $\mathrm{NH}_{3}$ formed was not examined by performing ${ }^{15} \mathrm{~N}_{2}$ isotope labeling. Analogously, Mn-doped $\mathrm{W}_{18} \mathrm{O}_{49}$ microspheres $\left(\mathrm{Mn}-\mathrm{W}_{18} \mathrm{O}_{49}\right)$ were synthesized as a photocatalyst for $\mathrm{N}_{2}$ reduction [304]. The $\mathrm{Mn}^{2+}$ ions were supposed to replace some $\mathrm{W}$ sites in the $\mathrm{W}_{18} \mathrm{O}_{49}$ lattice and intervene the formation of microsphere-like structure. The $3.0 \%$ Mn-doped $\mathrm{W}_{18} \mathrm{O}_{49}$ exhibited an optimal $\mathrm{N}_{2}$ reduction activity affording an $\mathrm{NH}_{3}$ production rate of $97.9 \mu \mathrm{mol} \cdot \mathrm{g}^{-1} \cdot \mathrm{h}^{-1}$ under Xe-lamp's full spectrum irradiation (Fig. 21(g)). It appears that $\mathrm{Mn}^{2+}$-doping extended light response range (Fig. 21(h)) and promoted photoinduced charge separation and migration. Meanwhile, the dopant served as chemisorption and activation centers of $\mathrm{N}_{2}$ and $\mathrm{H}_{2} \mathrm{O}$ molecules, boosting the transfer of photogenerated electrons to adsorbed $\mathrm{N}_{2}$ molecules (Fig. 21(i)). Alternatively, Fe was incorporated into $\mathrm{Bi}_{2} \mathrm{MoO}_{6}$ to enhance the $\mathrm{NH}_{3}$ production rate from $28.2 \mu \mathrm{mol} \cdot \mathrm{g}^{-1} \cdot \mathrm{h}^{-1}$ to $106.5 \mu \mathrm{mol} \cdot \mathrm{g}^{-1} \cdot \mathrm{h}^{-1}$ under visible light irradiation (Fig. 21(j)) [305]. The enhanced photocatalytic activity was mainly ascribed to lowering of surface work function after Fe doping, thereby facilitating transport of photoinduced charges and prolonging the lifetime of photogenerated carriers (Figs. 21(k) and 21(l)).

\subsubsection{Nonmetal doping}

Nonmetal doping provides a promising and efficient method to boost the $\mathrm{N}_{2}$ reduction by extending light response range and accelerating carrier transport [306, 307]. C doping was shown to narrow the bandgaps of anatase titanium oxide nanosheets and also facilitate the generation of highconcentration $\mathrm{Ti}^{3+}$ sites, thereby promoting the photocatalytic $\mathrm{N}_{2}$ reduction for $\mathrm{NH}_{3}$ synthesis (Fig. 22) [308]. An optimal $\mathrm{C}_{4}-\mathrm{TiO}_{x}$ with a $\mathrm{Ti}^{3+} / \mathrm{Ti}^{4+}$ ratio of $72.1 \%$ was obtained and showed an $\mathrm{NH}_{3}$ production rate of $109.3 \mu \mathrm{mol} \cdot \mathrm{g}^{-1} \cdot \mathrm{h}^{-1}$ and an apparent quantum efficiency of $1.1 \%$ at $400 \mathrm{~nm}$ (Fig. 22(b)). Likewise, doping of oxygen vacancy-rich anatase nanoplatelets by $\mathrm{S}\left(\mathrm{V}_{\mathrm{O}}-\mathrm{S}\right.$-rich $\left.\mathrm{TiO}_{2-x} \mathrm{~S}_{y}\right)$ was demonstrated to improve ammonia yield rate under visible-NIR irradiation [309]. The as-made $\mathrm{V}_{\mathrm{O}} \mathrm{S}$-rich $\mathrm{TiO}_{2-x} \mathrm{~S}_{y}$ exhibited a narrowed bandgap of $1.18 \mathrm{eV}$ and stronger light trapping that extended from UV light to the near-infrared (NIR) region (Fig. 22(d)). This was attributed to the co-presence of oxygen vacancies and sulfur dopants. Upon further increasing the concentrations of oxygen vacancy and sulfur anion, the $\mathrm{N}_{2}$ adsorption energy was markedly enhanced from -0.76 to $-2.1 \mathrm{eV}$, indicating that the $\mathrm{N}_{2}$ adsorption on $\mathrm{V}_{\mathrm{O}}-\mathrm{S}$-rich $\mathrm{TiO}_{2-x} \mathrm{~S}_{y}$ was energetically more favorable than that on $\mathrm{V}_{\mathrm{O}}-\mathrm{S}$-poor $\mathrm{TiO}_{2-x} \mathrm{~S}_{y}$ (Fig. 22(e)). The effects of OVs and sulfur anion dopants on the bandgap and adsorption energy of $\mathrm{N}_{2}$ molecule on different $\mathrm{TiO}_{2-x} \mathrm{~S}_{y^{-}}(101)$ surfaces are summarized in Fig. 22(f). These results assuredly suggest that the synergistic effect of OVs and sulfur dopants could extend the light absorption, narrow the bandgap of titania, and also promote the adsorption of inert $\mathrm{N}_{2}$, contributing to improved photocatalytic $\mathrm{N}_{2}$ reduction.

Additionally, nonmetal doping can help improve the stability of photocatalytic materials for $\mathrm{N}_{2}$ reduction. For instance, B-doped $g-\mathrm{C}_{3} \mathrm{~N}_{4}$ (BCN) with $\mathrm{B}-\mathrm{N}-\mathrm{C}$ coordination was synthesized [159]. Based on redshift of UV-vis peaks and strong PL quenching as well as enhanced photocurrent, it was speculated that B-doping both effectively improved the visible-light absorption and inhibited the recombination of 

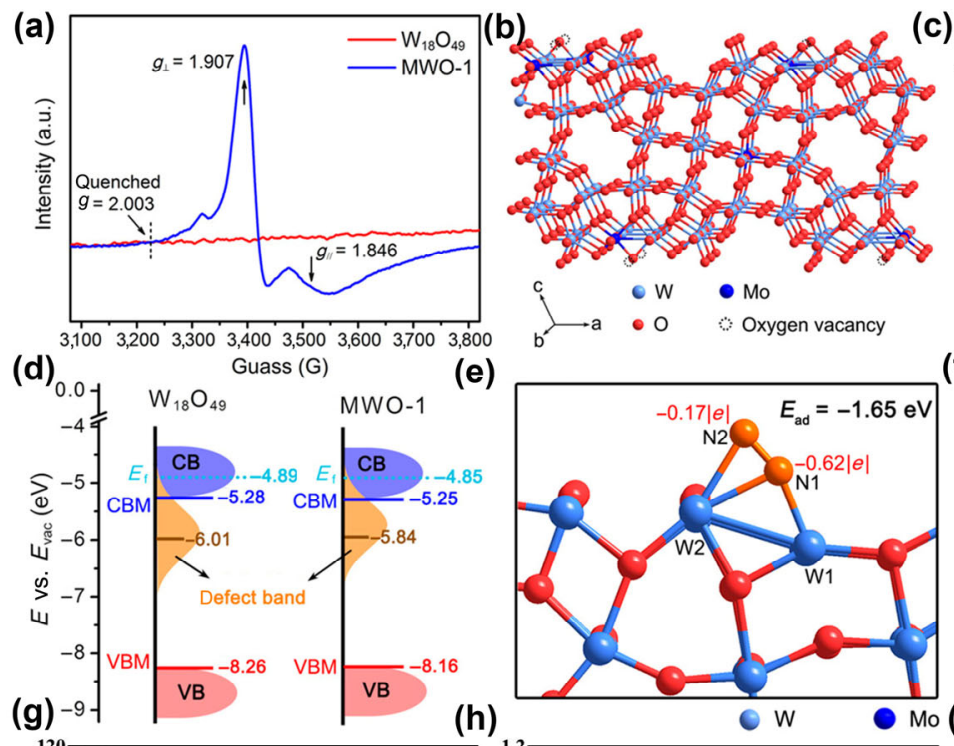

(e)
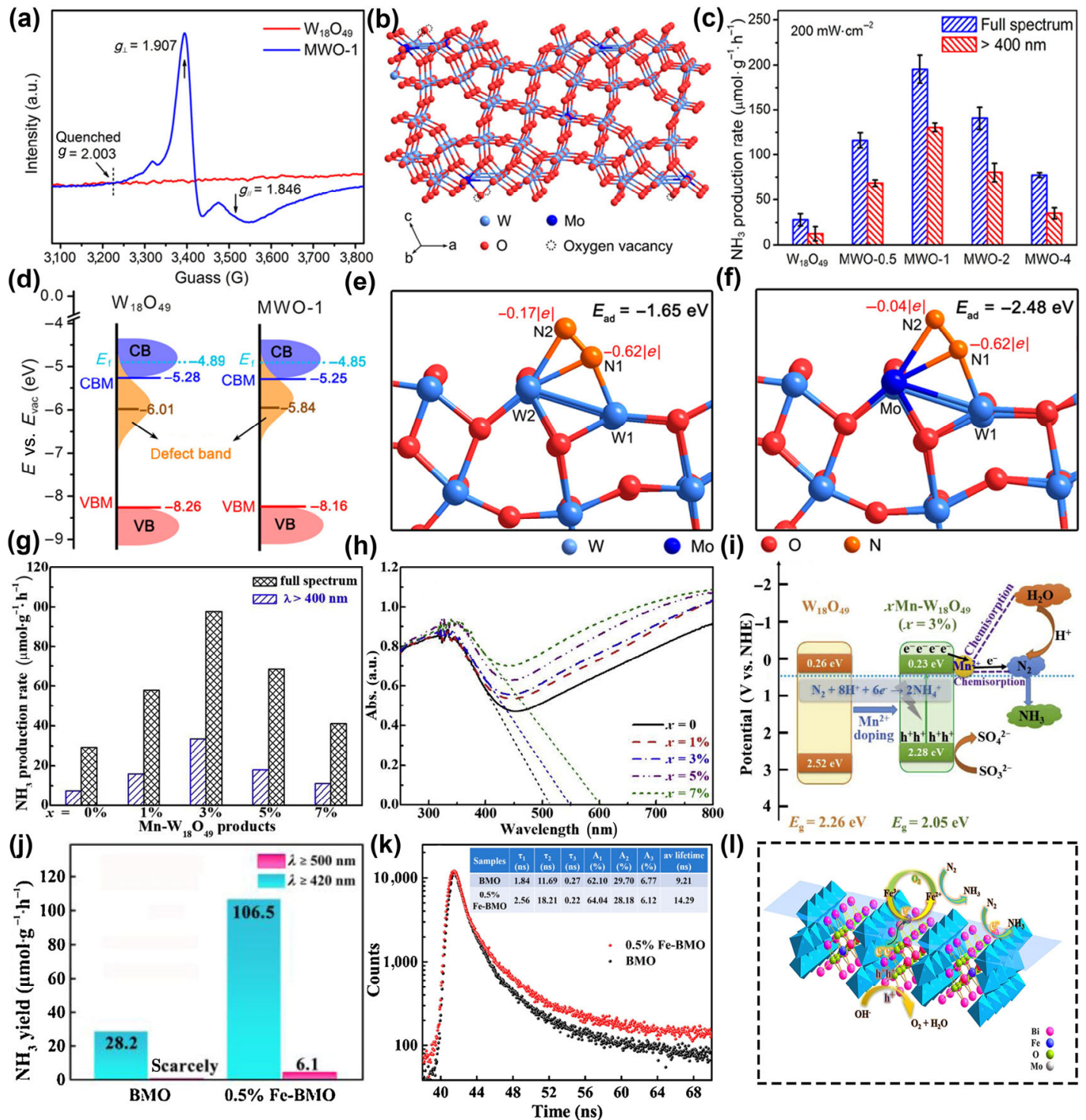

Figure 21 Transition metal ion doped catalyst for photocatalytic $\mathrm{N}_{2}$ fixation. (a) EPR spectra at $140 \mathrm{~K}$. (b) Structural illustration for the lattice of defect-rich Mo-doped $\mathrm{W}_{18} \mathrm{O}_{49}$. (c) Photocatalytic ammonia production rates over $\mathrm{W}_{18} \mathrm{O}_{49}$, MWO-0.5, MWO-1, MWO-2, and MWO-4 UTNWs in the first $2 \mathrm{~h}$. (d) Schematic illustration for the electronic band structures of $\mathrm{W}_{18} \mathrm{O}_{49}$ and MWO-1 UTNWs. The optimized adsorption configurations of $\mathrm{N}_{2}$ molecules with their corresponding charge distribution on the surface of (e) defect-rich $\mathrm{W}_{18} \mathrm{O}_{49}$ and (f) Mo-doped $\mathrm{W}_{18} \mathrm{O}_{49}$ models. Reproduced with permission from Ref. [66], () American Chemical Society 2018. (g) The average $\mathrm{NH}_{3}$ production activity of the obtained $x \mathrm{Mn}^{-} \mathrm{W}_{18} \mathrm{O}_{49}$ products under full spectrum or visible light $\left(\lambda>400 \mathrm{~nm}\right.$ ) illumination for $2 \mathrm{~h}$. (h) UV-vis DRS of the $x \mathrm{Mn}-\mathrm{W}_{18} \mathrm{O}_{49}$ products. (i) Possible mechanisms of $\mathrm{N}_{2}$ photofixation over $\mathrm{Mn}-\mathrm{W}_{18} \mathrm{O}_{49}$. Reproduced with permission from Ref. [304], ( ) Elsevier Ltd. 2019. (j) Photocatalytic nitrogen fixation under visible light irradiation $(\lambda>$ $500 \mathrm{~nm}$ ) on $\mathrm{Bi}_{2} \mathrm{MoO}_{6}$ and $0.5 \% \mathrm{Fe}-\mathrm{Bi}_{2} \mathrm{MoO}_{6}$. (k) Time-resolved fluorescence decay spectra of $\mathrm{Bi}_{2} \mathrm{MoO}_{6}$ and $0.5 \% \mathrm{Fe}^{-} \mathrm{Bi}_{2} \mathrm{MoO}_{6}$. (l) Schematic diagram of the photocatalysis process over $0.5 \% \mathrm{Fe}_{-} \mathrm{Bi}_{2} \mathrm{MoO}_{6}$ under visible light irradiation. Reproduced with permission from Ref. [305], ๑ Elsevier Ltd. 2019.

photogenerated electron-hole pairs in $g-C_{3} \mathrm{~N}_{4}$ (Figs. 22(g)-22(i)). The as-synthesized $\mathrm{BCN}$ delivered an $\mathrm{NH}_{3}$ yield rate of $27.3 \mu \mathrm{g} \cdot \mathrm{h}^{-1} \cdot \mathrm{mg}_{\text {cat. }^{-1}}$ (Fig. 22(j)). The exposed active $\mathrm{N}$ atoms in $g-\mathrm{C}_{3} \mathrm{~N}_{4}$ nanosheets were posited to participate in the $\mathrm{NH}_{3}$ formation during the $\mathrm{N}_{2}$ reduction process. These exposed $\mathrm{N}$ atoms were stabilized by forming $\mathrm{B}-\mathrm{N}-\mathrm{C}$ coordination in $g-\mathrm{C}_{3} \mathrm{~N}_{4}$ nanosheets, as confirmed by ${ }^{15} \mathrm{~N}_{2}$ isotopic labeling experiments (Figs. 22(k) and 22(l)). Incorporation of S into $g$ - ${ }_{3} \mathrm{~N}_{4}$ porous nanosheets (SCNNSs) with $\mathrm{CVs}$ was reported to enhance $\mathrm{N}_{2}$ reduction [273]. The adsorption energy of SCNNSs-550 was calculated to be $-0.665 \mathrm{eV}, 1.99$ times as high as that of bulk SCN $(-0.335 \mathrm{eV})$. This suggests that sulfur doping and CVs provided abundant active sites, thus promoting the $\mathrm{N}_{2}$ adsorption and activation.

\subsubsection{Single atom catalysts}

Single-atom catalysts (SACs), defined as a kind of supported catalyst that only contains a single metal site isolated from each other as the catalytic active center [310], display distinct catalytic activities because of low-coordination environment of the metal center, quantum size effects, and metal-support interactions. SACs could be proposed as a general "defect" definition [38, 311]. A single atom is commonly assumed to be a "defect" of the substrate material, where new chemical bonds would be formed between the atoms and substrate material, significantly regulating their electronic structures, SACs show promise in accelerating photocatalytic $\mathrm{N}_{2}$ reduction [54, 312-315].

Single $\mathrm{Cu}$ atoms were anchored on the defects of carbon nitride nanosheets $(\mathrm{Cu}-\mathrm{CN})$ and used as photocatalysts for $\mathrm{N}_{2}$ reduction [316]. Based on EPR measurements, isolated valence electrons were found to be easily excited to generate free electrons under photo-illumination, which originated from the abundant defects or edge amino group. The single $\mathrm{Cu}$ sites 

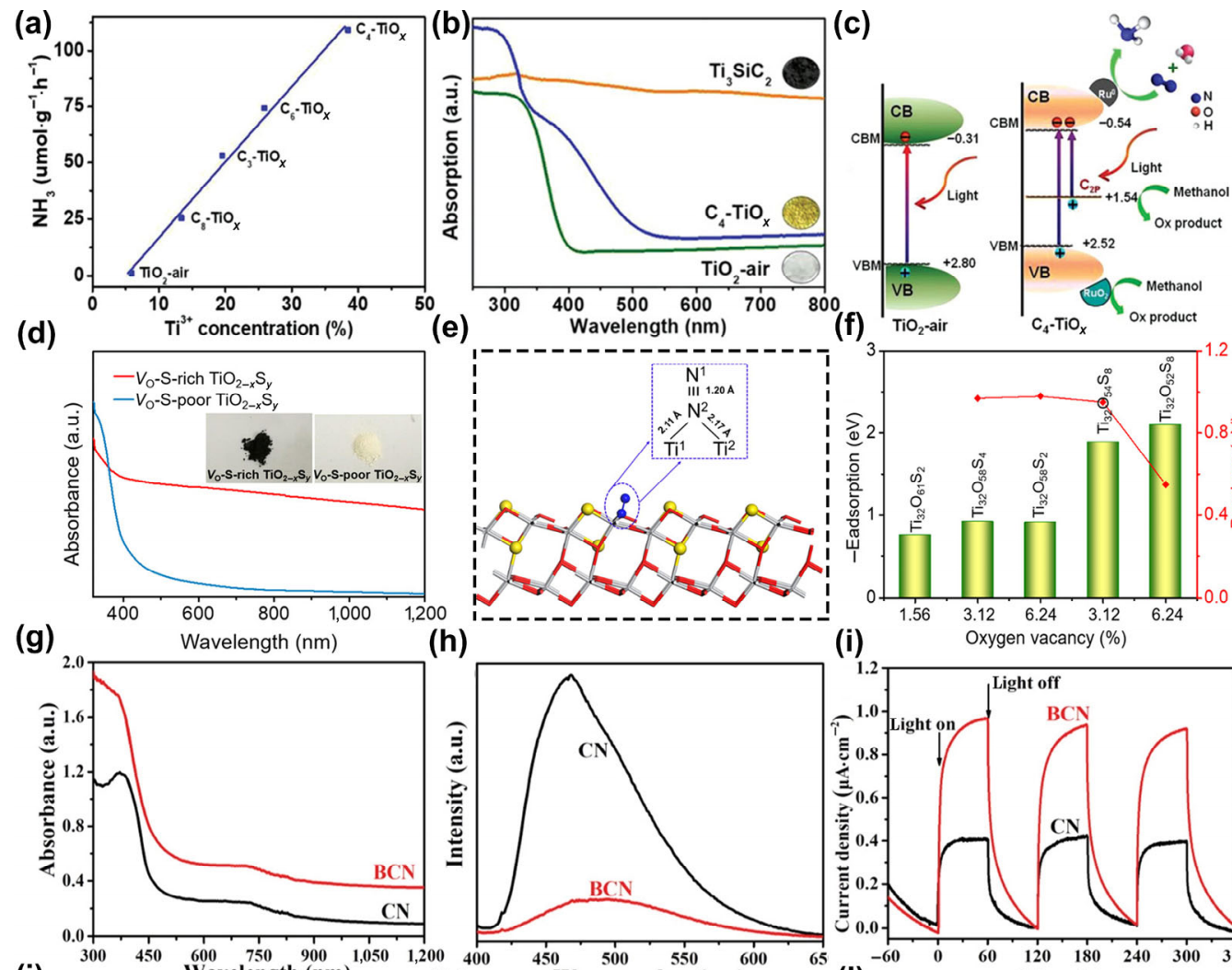

(h)
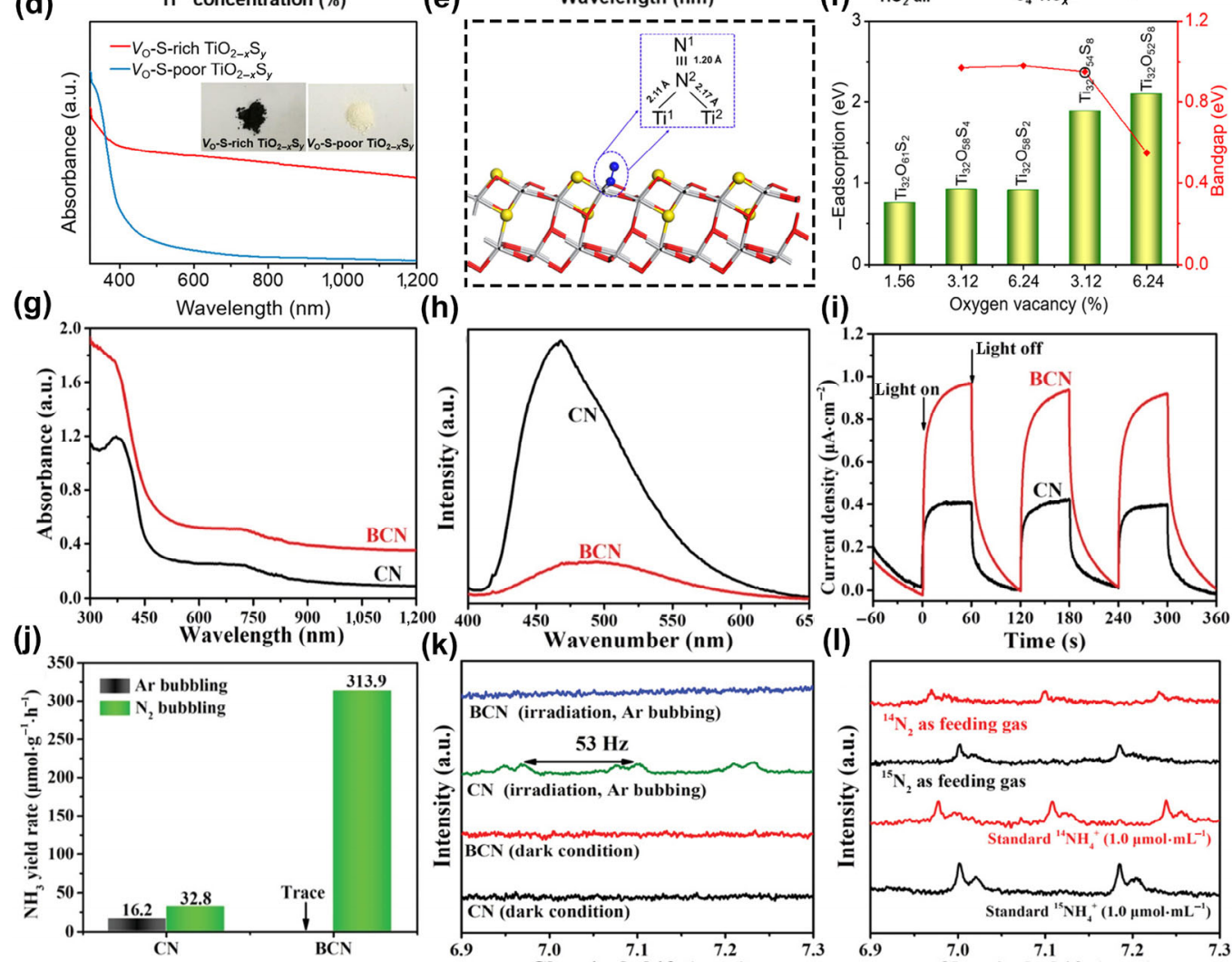

(i)
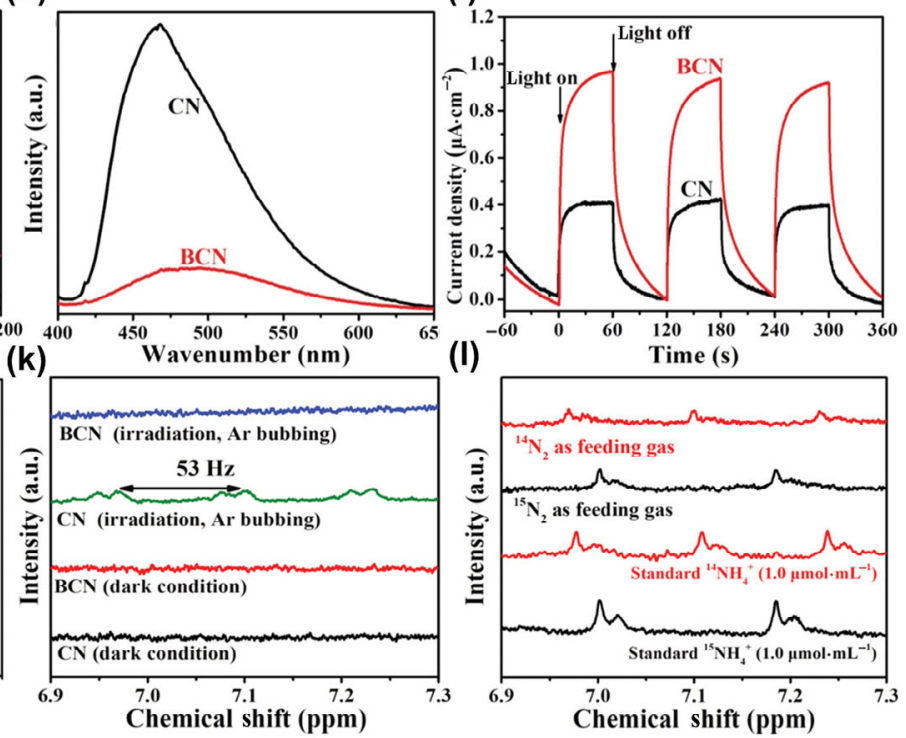

Figure 22 Non-metal doped catalysts and their performances on photocatalytic $\mathrm{N}_{2}$ reduction for $\mathrm{NH}_{3}$ synthesis. (a) Correlation of $\mathrm{Ti}^{3+}$ concentration with the yield of $\mathrm{NH}_{3}$. (b) UV-vis absorption spectra and photographs of $\mathrm{Ti}_{3} \mathrm{SiC}_{2}, \mathrm{TiO}_{2}$-air, and $\mathrm{C}_{4}-\mathrm{TiO}_{x}$. (c) Electronic band structure of $\mathrm{TiO}_{2}$-air and $\mathrm{C}_{4}-\mathrm{TiO}_{x}$, and mechanism for photocatalytic $\mathrm{NH}_{3}$ production on $\mathrm{Ru} / \mathrm{RuO}_{2}$ nanoparticle-loaded $\mathrm{C}_{4}-\mathrm{TiO}_{x}$ under visible-light illumination. Reproduced with permission from Ref. [308], ( ) Wiley-VCH Verlag GmbH \& Co. KGaA 2021. (d) Diffuse reflectance absorption spectra of Vo-S-rich and Vo-S-poor $\mathrm{TiO}_{2-x} \mathrm{~S}_{y}$ nanoplatelets. (e) The pristine surface model with $\mathrm{N}_{2}$ (end-on structure) adsorbed at $\mathrm{Ti}_{32} \mathrm{O}_{52} \mathrm{~S}_{8}$. (f) The synergistic effect of different contents of OVs and sulfur anion dopants on the bandgap and adsorption energy. Reproduced with permission from Ref. [309], () American Chemical Society 2021. (g) UV-vis DRS spectra, (h) steady-state PL spectra, (i) transient photocurrent responses, and (j) photocatalytic $\mathrm{NH}_{3}$ yield rates of $\mathrm{CN}$ and $\mathrm{BCN}$. (k) ${ }^{1} \mathrm{H}$ NMR spectra of $\mathrm{CN}$ and $\mathrm{BCN}$ in $\mathrm{Na}_{2} \mathrm{SO}_{3}$ solution under dark condition or irradiation with Ar bubbling. (l) ${ }^{1} \mathrm{H}$ NMR spectra of photocatalytic produced ${ }^{14} \mathrm{NH}_{4}{ }^{+}$or ${ }^{15} \mathrm{NH}_{4}{ }^{+}$from ${ }^{14} \mathrm{~N}_{2}$ and ${ }^{15} \mathrm{~N}_{2}$ feeding gases, and corresponding standards (1.0 $\mu \mathrm{mol} \cdot \mathrm{mL}^{-1}$ ). Reproduced with permission from Ref. [159], (c) Wiley-VCH Verlag GmbH \& Co. KGaA 2020.

afforded an $\mathrm{NH}_{3}$ production rate of $186 \mu \mathrm{mol} \cdot \mathrm{g}^{-1} \cdot \mathrm{h}^{-1}$ under visible light irradiation with a quantum efficiency reaching $1.01 \%$ at $420 \mathrm{~nm}$ monochromatic light illumination. The good performance was hypothesized to result from the suppression of recombination of photogenerated excitons and efficient separation of the photoexcited electron-hole pairs. Single $\mathrm{Ru}$ atoms were recently decorated on $\mathrm{TiO}_{2}$ nanosheets rich in OVs for photocatalytic $\mathrm{N}_{2}$ reduction (Fig. 23(a)) [266]. Isolated $\mathrm{Ru}$ atoms were shown to effectively promote ammonia generation with a yield rate of $56.3 \mu \mathrm{g} \cdot \mathrm{g}^{-1} \cdot \mathrm{h}^{-1}$ (Fig. 23(b)). Experiments in combination with DFT calculations revealed that atomically dispersed $\mathrm{Ru}$ greatly promoted chemisorption of $\mathrm{N}_{2}$, and improved charge carrier separation, hence enhancing $\mathrm{N}_{2}$ photoreduction to $\mathrm{NH}_{3}$ (Fig. 23(c)).

Single $\mathrm{B}$ atoms attached to $\mathrm{g}-\mathrm{C}_{3} \mathrm{~N}_{4}$ (on H-vacancy; a kind of $\mathrm{C}$ vacancy) were predicted as a potential metal-free photocatalyst for $\mathrm{N}_{2}$ reduction [317]. The main group IIIA $\mathrm{B}$ atoms were proposed to serve as catalytic sites for $\mathrm{N}_{2}$ bonding and an N-B-N active center was formed within $g-\mathrm{C}_{3} \mathrm{~N}_{4}$ for photocatalytic $\mathrm{N}_{2}$ reduction (Figs. 23(d) and 23(e)). It was envisioned that $\mathrm{N}_{2}$ couldbond with $\mathrm{B}$ on $g-\mathrm{C}_{3} \mathrm{~N}_{4}$ either by side-on or end-on mode, corresponding to an adsorption energy of -1.04 and $-1.28 \mathrm{eV}$, respectively. The charge density difference revealed that the single $\mathrm{B}$ atom functioned through electron acceptance or backdonation within the $\mathrm{B}-\mathrm{N}_{2}$ configuration, akin to TMs (Figs. 23(f) and 23(g)). Additionally, the decoration of B on $g-\mathrm{C}_{3} \mathrm{~N}_{4}$ lowered the band gap of $g-\mathrm{C}_{3} \mathrm{~N}_{4}$ and enhanced the visible light and infrared light harvesting (Fig. 23(h)).

\subsection{Combined strategies}

Relative to a single protocol, a combination of different design schemes casts considerable potentials for jointly/collaboratively improving the photocatalytic $\mathrm{N}_{2}$ reduction activity. This area has stimulated heightened research interest. 

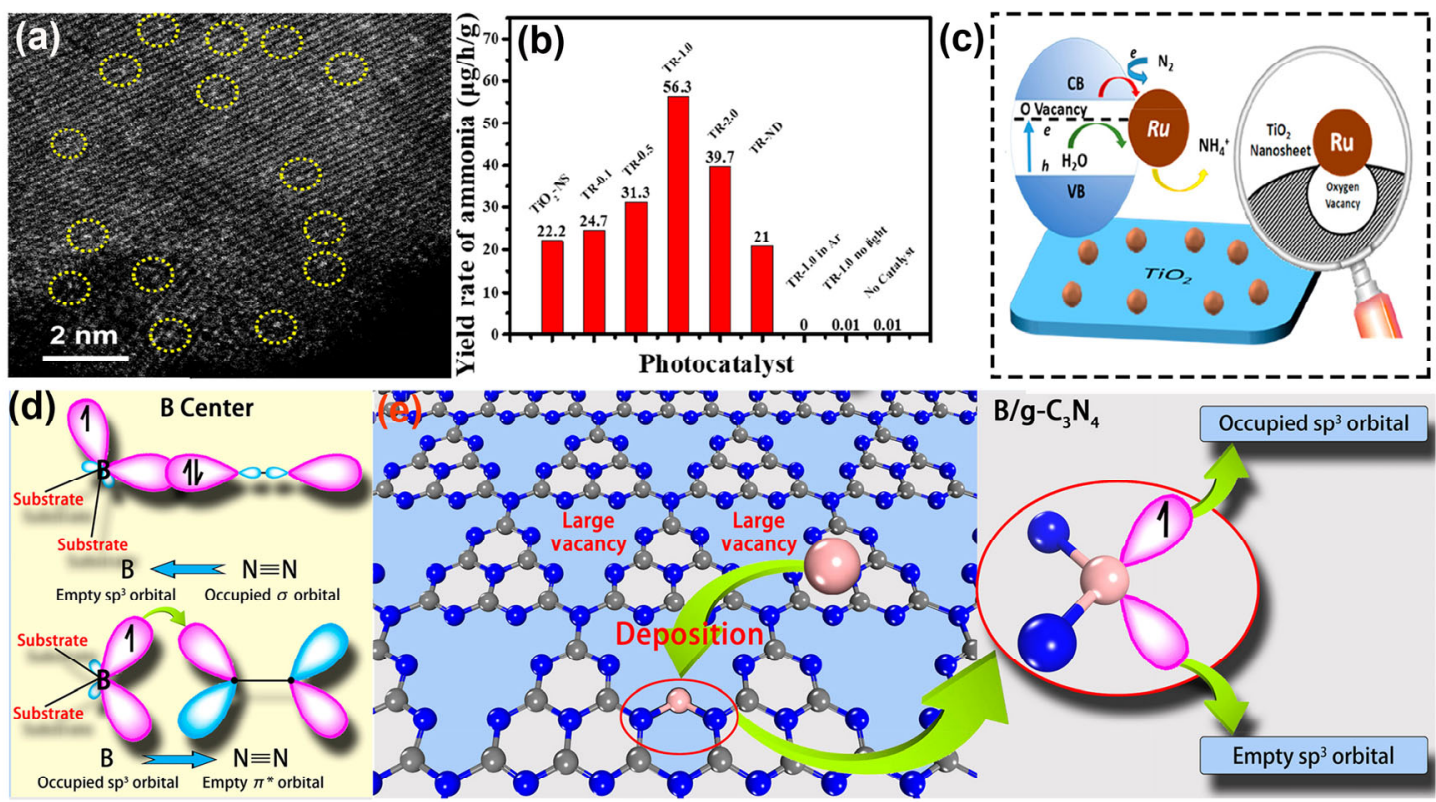

$\mathrm{B} / \mathrm{g}-\mathrm{C}_{3} \mathrm{~N}_{4}$

Bied $s p^{3}$ orbital Empty $t$
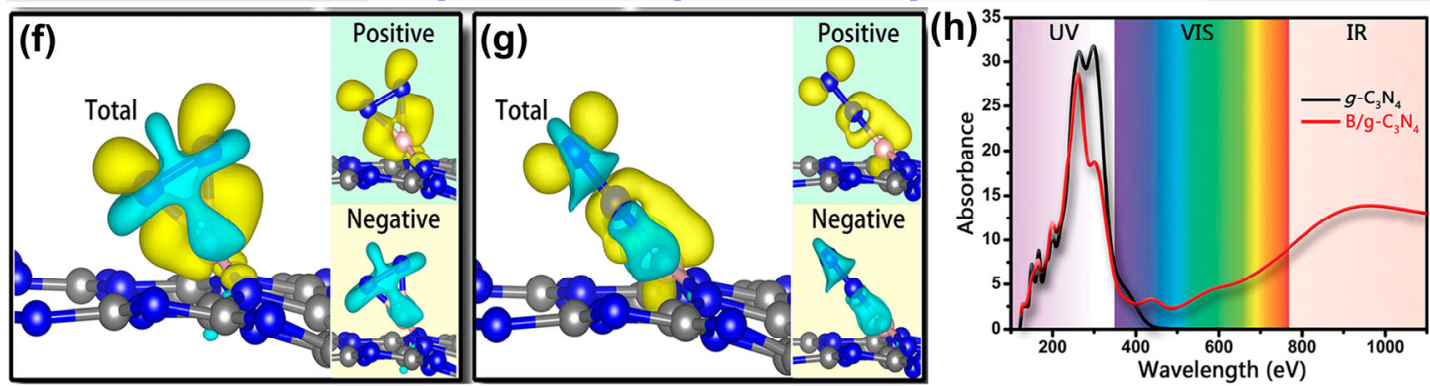

Figure 23 SACs for photocatalytic $\mathrm{N}_{2}$ fixation. (a) HAADF-STEM image of TR-1.0. (b) The yield rates of ammonia over different catalyst. (c) Mechanistic diagram of $\mathrm{N}_{2}$ photoreduction over single $\mathrm{Ru}$ site loaded $\mathrm{TiO}_{2}$ nanosheets with oxygen vacancies. Reproduced with permission from Ref. [266], (C) American Chemical Society 2019. (d) $\mathrm{N}_{2}$ binding motifs to the B atom which is stabilized on the substrate. (e) Design concept of as a photocatalyst for $\mathrm{N}_{2}$ fixation. Difference charge densities of $\mathrm{B} / g-\mathrm{C}_{3} \mathrm{~N}_{4}$ with the adsorption of $\mathrm{N}_{2}$ via (f) side-on and ( $\mathrm{g}$ ) end-on patterns, where the isosurface value is set to be $0.005 \mathrm{e} / \AA^{3}$. (h) Optical adsorption spectra of pure $g-C_{3} \mathrm{~N}_{4}$ and B/g- $\mathrm{C}_{3} \mathrm{~N}_{4}$. Reproduced with permission from Ref. [317], () American Chemical Society 2018.

\subsubsection{Coupling defect engineering and morphology control}

The morphology of semiconductors plays a critical role in their photocatalytic performance. Nanostructuring by controlling the desired morphologies (e.g., particle size, shape, geometrical feature, and surface texture) can maximize the exposure of active sites, accelerate carrier transportation and migration, being beneficial to photocatalysis [80]. Defect engineering in combination with morphology control allows one to further improve photocatalytic $\mathrm{N}_{2}$ reduction activity, taking full advantages of joint/synergistic effects [260]. Such concept has been demonstrated by construction of light-switchable oxygen vacancies in ultrafine $\mathrm{Bi}_{5} \mathrm{O}_{7} \mathrm{Br}$ nanotubes, which realized active and stable photocatalytic $\mathrm{N}_{2}$ reduction [180]. The enhanced photocatalytic activity was postulated to stem from a synergy of oxygen vacancies and ultrafine nanotubes, which provided large surface areas and simultaneously promoted efficient separation and migration of photogenerated carriers, in addition to enhanced $\mathrm{N}_{2}$ adsorption and activation.

\subsubsection{Coupling defect engineering and amorphization}

Amorphization can introduce dangling bonds and unsaturated coordination sites in semiconductors, endowing active sites for $\mathrm{N}_{2}$ reduction reactions [318]. Combining defect engineering and amorphization can strikingly modulate the electronic structure of photocatalysts, thereby promoting $\mathrm{N}_{2}$ adsorption and activation. However, the stability and longevity of such catalysts remain to be addressed.

\subsubsection{Coupling defect engineering and cocatalyst}

Incorporation of suitable cocatalysts can improve the photocatalytic efficiency by lowering activation energy or overpotential, facilitating electron-hole pairs separation, and increasing the photocatalyst stability [319]. Defect engineering along with cocatalyst modification has been extensively employed to further boost the $\mathrm{N}_{2}$ reduction photocatalysis [168].

\subsubsection{Coupling defect engineering and heterojunction construction}

Formation of a heterostructure can extend spectral range of light absorption, and also induce a built-in electric field to facilitate the separation and migration of electron-hole pairs, favoring photocatalysis [320]. Integration of defect engineering and heterostructuring can present a strong synergistic effect to drastically enhance the $\mathrm{N}_{2}$ photoreduction [321].

\subsubsection{Coupling defect engineering and external field}

Aside from the inherent driving force of photocatalysis, introduction of an external field can provide additional energy to promote light generation and charge separation and migration, thereby improving the overall catalytic efficiency [322]. This emerging scheme has been recently combined with defect engineering in photocatalytic $\mathrm{N}_{2}$ reduction. A remarkably high $\mathrm{NH}_{3}$ yield rate exceeding $1.93 \mathrm{mg} \cdot \mathrm{L}^{-1} \cdot \mathrm{h}^{-1}$ was attained over defective $\mathrm{BaTiO}_{3}$ under an applied magnetic field [323]. Such significant enhancement was mainly attributed to boosted $\mathrm{N}_{2}$ adsorption by oxygen vacancies and suppression of photoexcited 
carriers recombination arising from an electromagnetic synergistic effect between the internal electric field of the photocatalyst and an external magnetic field.

\section{Summary, challenges, and future perspectives in defect-engineered $\mathrm{N}_{2}$ photocatalysis}

Defect engineering of a semiconductor facilitates $\mathrm{N}_{2}$ photocatalysis by virtue of extending the range of light response, promoting the efficient separation and migration of photogenerated electrons-hole pairs, and improving the $\mathrm{N}_{2}$ adsorption and activation, all of which are the critical steps in $\mathrm{N}_{2}$ reduction to $\mathrm{NH}_{3}$. Although significant and encouraging progress has been acquired in $\mathrm{N}_{2}$ photocatalysis in the past five years, the attained solar energy conversion efficiency (SCE) of $\mathrm{N}_{2}$ photoreduction is still less than $1 \%$, far below the minimum standard of $10 \%$ needed to realize industrialization [324]. The $\mathrm{NH}_{3}$ yield rates of certain photocatalysts have increased from $\mu \mathrm{mol} \cdot \mathrm{g}^{-1} \cdot \mathrm{h}^{-1}$ to $\mathrm{mmol} \cdot \mathrm{g}^{-1} \cdot \mathrm{h}^{-1}$, which is however still much below the requirements for practical applications. There are a number of scientific and technological challenges that need to be overcome to accomplish large-scale application of defectengineered $\mathrm{N}_{2}$ photocatalysis.

Only by accurately controlling the type, concentration, and location of defects can one rationally design and construct defect-engineered photocatalysts. However, the existing synthetic methods are incapable of achieving the defect control at such a high level [217]. In situ creation of OVs on the catalyst surface (such as caused by light irradiation method) during the photoreduction process is considered as a feasible and promising strategy [180]. Introduction of specific defects with different concentrations could be achieved by accurate amounts of heteroatom doping into photocatalysts. Controllable production and tuning of defects require more future research efforts. It is known that excessive amounts of defects in a photocatalyst lead to reunion of excited carriers. To avoid such issue, it is important to precisely quantify the concentration of defects. Equally importantly, the cooperative mechanisms among multiple defects and role of each individual defect in $\mathrm{N}_{2}$ photocatalysis remain to be elucidated.

The stability of engineered defects is an essential key factor for $\mathrm{N}_{2}$ photocatalysis [325]. Some surface anion defects (such as OVs) are readily oxidized, resulting in perturbation of $\mathrm{N}_{2}$ molecule activation. To alleviate this issue, several strategies can be adopted: (1) modification of the semiconductor material with an acceptor-type dopant [214, 326-328]; (2) anchoring of single atoms by defects in the support [329, 330]; (3) constructing heterostructures or core-shell structure [331]; (4) ultraviolet light-induced regeneration [332].

To date, major endeavors toward defect-engineered $\mathrm{N}_{2}$ photocatalysis have been made on traditional semiconductors. Some emerging photocatalytic materials with defects such as MOFs and covalent organic frameworks (COFs) have not been fully explored for photocatalytic $\mathrm{N}_{2}$ reduction. Meanwhile, the design of cation defects and further combined defects and investigation of their roles in $\mathrm{N}_{2}$ reduction are rarely conducted, which deserves further studies. To synergistically promote $\mathrm{N}_{2}$ photocatalysis, integration of multiple design strategies (e.g., defect engineering and other modification strategies such as creation of Z-scheme heterostructures to separate ammonia production and water oxidation sites in space) is preferred. Additionally, combination of defect engineering and external fields (e.g., microwaves, mechanical stress, temperature gradient, electric field, magnetic field, and coupled fields) is another promising strategy to further boost photocatalytic $\mathrm{N}_{2}$ reduction reactions [322].

Although a range of techniques have been reported to probe defects (e.g., HRTEM, XRD, SE, etc.), most of them are limited to qualitative characterization and cannot quantitatively determine the defect concentrations. To gain insight into the defect structure-performance relationships for the $\mathrm{N}_{2}$ reduction process, it is urgently desired to exploit and develop more advanced in situ/operando characterization techniques which is however still in its early stage. In situ electrochemical tip-enhanced Raman technique (EC-TERS) enables imaging of changes in the surface defect structure of photocatalysts. We expect that this emerging technique may provide a platform for real-time monitoring of defect state and its concentration during the $\mathrm{N}_{2}$ reduction process in the near future after some technical advances.

The impurity composition of $\mathrm{N}_{2}$ supply must be specified. Highly pure $\mathrm{N}_{2}$ and Ar with purity over $99.999 \%$ are strongly suggested for use in the $\mathrm{N}_{2}$ photoreduction. Before starting the $\mathrm{N}_{2}$ photoreduction, the $\mathrm{N}_{2}$ feed gas and photocatalysts should be subjected to purification treatments to exclude artifacts from exogenous nitrogen contaminants $\left(\mathrm{NH}_{3}\right.$, nitrate/nitrite, and nitrous oxide). Particularly, for photocatalysts that either contain structural/lattice nitrogen or are synthesized from nitrates or ammonium precursors, ${ }^{15} \mathrm{~N}_{2}$ isotope labeling should be performed to verify genuine $\mathrm{N}_{2}$ reduction. Currently, the spectrophotometric methods including indophenol blue and Nessler's reagent spectrophotometry are commonly used for quantification of $\mathrm{NH}_{3}$. However, the accuracy of these spectrophotometric methods is usually interfered with several factors, such as $\mathrm{pH}$, ionic strength, and sacrificial reagents. Isotope labeling experiments to analyze and confirm mechanistic studies have been applied too rarely up to now. To provide unequivocal evidences for photocatalytic $\mathrm{N}_{2}$ reduction to ammonia and obtain reliable $\mathrm{NH}_{3}$ yield, quantitative isotope measurements by making essential use of ${ }^{15} \mathrm{~N}_{2}$ along with multiple control experiments are required. It is also necessary to develop more selective, precise, and in situ methods for $\mathrm{NH}_{3}$ determination.

Although theoretical simulations are a powerful approach for study of defect-engineered photocatalysts, the simulated model cannot predict the true structure of the catalyst. Greater advances are expected through the collective knowledge and insights to be gained from fundamental research that integrates experiments and theory. Development of in situ/operando techniques will help build up more valid theoretical models and deepen clarification of reaction pathways, degradation modes as well as catalytic structure-property relationships specific to given materials, further guiding new direction for catalyst design.

\section{Acknowledgements}

This work was supported by the National Natural Science Foundation of China (No. 21972010); Beijing Natural Science Foundation (No. 2192039); the Foundation of Key Laboratory of Low-Carbon Conversion Science \& Engineering, Shanghai Advanced Research Institute, the Chinese Academy of Sciences (No. KLLCCSE-201901, SARI, CAS); Beijing University of Chemical Technology (XK180301, XK1804-2).

Funding note: Open Access funding enabled and organized by Projekt DEAL.

Open Access This article is licensed under a Creative Commons Attribution 4.0 International License, which permits use, sharing, adaptation, distribution and reproduction in any medium or 
format, as long as you give appropriate credit to the original author(s) and the source, provide a link to the Creative Commons licence, and indicate if changes were made.

The images or other third party material in this article are included in the article's Creative Commons licence, unless indicated otherwise in a credit line to the material. If material is not included in the article's Creative Commons licence and your intended use is not permitted by statutory regulation or exceeds the permitted use, you will need to obtain permission directly from the copyright holder.

To view a copy of this licence, visit http://creativecommons.org/licenses/by/4.0/.

\section{References}

[1] Chen, J. G.; Crooks, R. M.; Seefeldt, L. C.; Bren, K. L.; Bullock, R. M.; Darensbourg, M. Y.; Holland, P. L.; Hoffman, B.; Janik, M. J.; Jones, A. K. et al. Beyond fossil fuel-driven nitrogen transformations. Science 2018, 360, eaar6611.

[2] Medford, A. J.; Hatzell, M. C. Photon-driven nitrogen fixation: Current progress, thermodynamic considerations, and future outlook. ACS Catal. 2017, 7, 2624-2643.

[3] Foster, S. L.; Bakovic, S. I. P.; Duda, R. D.; Maheshwari, S.; Milton, R. D.; Minteer, S. D.; Janik, M. J.; Renner, J. N.; Greenlee, L. F. Catalysts for nitrogen reduction to ammonia. Nat. Catal. 2018, 1 , 490-500.

[4] Hoffman, B. M.; Lukoyanov, D.; Yang, Z. Y.; Dean, D. R.; Seefeldt, L. C. Mechanism of nitrogen fixation by nitrogenase: The next stage. Chem. Rev. 2014, 114, 4041-4062.

[5] Choi, J.; Suryanto, B. H. R.; Wang, D. B.; Du, H. L.; Hodgetts, R. Y.; Ferrero Vallana, F. M.; MacFarlane, D. R.; Simonov, A. N. Identification and elimination of false positives in electrochemical nitrogen reduction studies. Nat. Commun. 2020, 11, 5546.

[6] Service, R. F. Liquid sunshine. Science 2018, 361, 120-123.

[7] Guo, J. P.; Chen, P. Catalyst: $\mathrm{NH}_{3}$ as an energy carrier. Chem 2017, 3, 709-712.

[8] Chen, G. F.; Cao, X. R.; Wu, S. Q.; Zeng, X. Y.; Ding, L. X.; Zhu, M.; Wang, H. H. Ammonia electrosynthesis with high selectivity under ambient conditions via a $\mathrm{Li}^{+}$incorporation strategy. J. Am. Chem. Soc. 2017, 139, 9771-9774.

[9] Iwamoto, M.; Akiyama, M.; Aihara, K.; Deguchi, T. Ammonia synthesis on wool-like $\mathrm{Au}, \mathrm{Pt}, \mathrm{Pd}, \mathrm{Ag}$, or $\mathrm{Cu}$ electrode catalysts in nonthermal atmospheric-pressure plasma of $\mathrm{N}_{2}$ and $\mathrm{H}_{2}$. ACS Catal. 2017, 7, 6924-6929.

[10] Singh, A. R.; Rohr, B. A.; Schwalbe, J. A.; Cargnello, M.; Chan, K.; Jaramillo, T. F.; Chorkendorff, I.; Nørskov, J. K. Electrochemical ammonia synthesis-the selectivity challenge. ACS Catal. 2017, 7, 706-709.

[11] MacFarlane, D. R.; Cherepanov, P. V.; Choi, J.; Suryanto, B. H. R.; Hodgetts, R. Y.; Bakker, J. M.; Ferrero Vallana, F. M.; Simonov, A. N. A roadmap to the ammonia economy. Joule 2020, 4, 1186-1205.

[12] Leigh, G. J. Fixing nitrogen any which way. Science 1998, 279, 506-507.

[13] Spatzal, T.; Aksoyoglu, M.; Zhang, L. M.; Andrade, S. L. A.; Schleicher, E.; Weber, S.; Rees, D. C.; Einsle, O. Evidence for interstitial carbon in nitrogenase femo cofactor. Science 2011, 334, 940.

[14] Tanifuji, K.; Ohki, Y. Metal-sulfur compounds in $\mathrm{N}_{2}$ reduction and nitrogenase-related chemistry. Chem. Rev. 2020, 120, 5194-5251.

[15] Chica, B.; Ruzicka, J.; Kallas, H.; Mulder, D. W.; Brown, K. A.; Peters, J. W.; Seefeldt, L. C.; Dukovic, G.; King, P. W. Defining intermediates of nitrogenase MoFe protein during $\mathrm{N}_{2}$ reduction under photochemical electron delivery from CdS quantum dots. $J$. Am. Chem. Soc. 2020, 142, 14324-14330.

[16] Lancaster, K. M.; Roemelt, M.; Ettenhuber, P.; Hu, Y. L.; Ribbe, M. W.; Neese, F.; Bergmann, U.; DeBeer, S. X-ray emission spectroscopy evidences a central carbon in the nitrogenase iron-molybdenum cofactor. Science 2011, 334, 974-977.

[17] Rao, L.; Xu, X.; Adamo, C. Theoretical investigation on the role of the central carbon atom and close protein environment on the nitrogen reduction in Mo nitrogenase. ACS Catal. 2016, 6, 1567-1577.
[18] Hu, Y. L.; Ribbe, M. W. Decoding the nitrogenase mechanism: The homologue approach. Acc. Chem. Res. 2010, 43, 475-484.

[19] Brown, K. A.; Harris, D. F.; Wilker, M. B.; Rasmussen, A.; Khadka, N.; Hamby, H.; Keable, S.; Dukovic, G.; Peters, J. W.; Seefeldt, L. C. et al. Light-driven dinitrogen reduction catalyzed by a CdS: Nitrogenase MoFe protein biohybrid. Science 2016, 352, 448-450.

[20] Wang, L.; Xia, M. K.; Wang, H.; Huang, K. F.; Qian, C. X.; Maravelias, C. T.; Ozin, G. A. Greening ammonia toward the solar ammonia refinery. Joule 2018, 2, 1055-1074.

[21] Schlögl, R. Ammonia synthesis. In Handbook of Heterogeneous Catalysis. Ertl, G.; Knözinger, H.; Weitkamp, J., Eds.; Wiley: Weinheim, 2008; pp 2501-2575.

[22] Kandemir, T.; Schuster, M. E.; Senyshyn, A.; Behrens, M.; Schlögl, R. The haber-bosch process revisited: On the real structure and stability of "ammonia iron" under working conditions. Angew. Chem., Int. Ed. 2013, 52, 12723-12726.

[23] Liu, H. Z. Ammonia synthesis catalyst 100 years: Practice, enlightenment and challenge. Chin. J. Catal. 2014, 35, 1619-1640.

[24] Martín, A. J.; Shinagawa, T.; Pérez-Ramírez, J. Electrocatalytic reduction of nitrogen: From haber-bosch to ammonia artificial leaf. Chem 2019, 5, 263-283.

[25] Smith, B. E. Nitrogenase reveals its inner secrets. Science 2002, 297, $1654-1655$.

[26] Wang, Q. R.; Guo, J. P.; Chen, P. Recent progress towards mildcondition ammonia synthesis. J. Energy Chem. 2019, 36, 25-36.

[27] Shi, R.; Zhang, X. R.; Waterhouse, G. I. N.; Zhao, Y. X.; Zhang, T. R. The journey toward low temperature, low pressure catalytic nitrogen fixation. Adv. Energy Mater. 2020, 10, 2000659.

[28] Zheng, J. Y.; Jiang, L.; Lyu, Y.; Jian, S. P.; Wang, S. Y. Green synthesis of nitrogen-to-ammonia fixation: Past, present, and future. Energy Environ. Mater., in press, DOI: 10.1002/eem2.12192.

[29] Xu, T.; Ma, B. Y.; Liang, J.; Yue, L. C.; Liu, Q.; Li, T. S.; Zhao, H. T.; Luo, Y. L.; Lu, S. Y.; Sun, X. P. Recent progress in metal-free electrocatalysts toward ambient $\mathrm{N}_{2}$ reduction reaction. Acta Phys. Chim. Sin. 2021, 37, 2009043.

[30] Xue, X. L.; Chen, R. P.; Yan, C. Z.; Zhao, P. Y.; Hu, Y.; Zhang, W. J.; Yang, S. Y.; Jin, Z. Review on photocatalytic and electrocatalytic artificial nitrogen fixation for ammonia synthesis at mild conditions: Advances, challenges and perspectives. Nano Res. 2019, 12, 1229-1249.

[31] Zhang, Y.; Du, H. T.; Ma, Y. J.; Ji, L.; Guo, H. R.; Tian, Z. Q.; Chen, H. Y.; Huang, H.; Cui, G. W.; Asiri, A. M. et al. Hexagonal boron nitride nanosheet for effective ambient $\mathrm{N}_{2}$ fixation to $\mathrm{NH}_{3}$. Nano Res. 2019, 12, 919-924.

[32] Liang, X. Y.; Deng, X. X.; Guo, C.; Wu, C. M. L. Activity origin and design principles for atomic vanadium anchoring on phosphorene monolayer for nitrogen reduction reaction. Nano Res. 2020, 13, 2925-2932.

[33] Li, R. G. Photocatalytic nitrogen fixation: An attractive approach for artificial photocatalysis. Chin. J. Catal. 2018, 39, 1180-1188.

[34] Li, B. F.; Hu, Y. Z.; Shen, Z. W.; Ji, Z. Y.; Yao, L.; Zhang, S.; Zou, Y. T.; Tang, D. Y.; Qing, Y.; Wang, S. Q. et al. Photocatalysis driven by near-infrared light: Materials design and engineering for environmentally friendly photoreactions. ACS EST Eng. 2021, 1, 947-964.

[35] Wang, S. Y.; Ichihara, F.; Pang, H.; Chen, H.; Ye, J. H. Nitrogen fixation reaction derived from nanostructured catalytic materials. Adv. Funct. Mater. 2018, 28, 1803309.

[36] Zhu, D.; Zhang, L. H.; Ruther, R. E.; Hamers, R. J. Photo-illuminated diamond as a solid-state source of solvated electrons in water for nitrogen reduction. Nat. Mater. 2013, 12, 836-841.

[37] Zhang, G. Q.; Sewell, C. D.; Zhang, P. X.; Mi, H. W.; Lin, Z. Q. Nanostructured photocatalysts for nitrogen fixation. Nano Energy 2020, 71,104645 .

[38] Cheng, M.; Xiao, C.; Xie, Y. Photocatalytic nitrogen fixation: The role of defects in photocatalysts. J. Mater. Chem. A 2019, 7, 19616-19633.

[39] Mao, C. L.; Wang, J. X.; Zou, Y. J.; Li, H.; Zhan, G. M.; Li, J.; Zhao, J. C.; Zhang, L. Z. Anion (O, N, C, and S) vacancies promoted photocatalytic nitrogen fixation. Green Chem. 2019, 21, 2852-2867.

[40] Schrauzer, G. N.; Guth, T. D. Photolysis of water and photoreduction of nitrogen on titanium dioxide. J. Am. Chem. Soc. 1977, 99, 7189-7193. 
[41] Zhang, N.; Li, L. G.; Shao, Q.; Zhu, T.; Huang, X. Q.; Xiao, X. H. Fe-doped biocl nanosheets with light-switchable oxygen vacancies for photocatalytic nitrogen fixation. ACS Appl. Energy Mater. 2019, 2, 8394-8398.

[42] Rong, X. S.; Chen, H. F.; Rong, J.; Zhang, X. Y.; Wei, J.; Liu, S.; Zhou, X. T.; Xu, J. C.; Qiu, F. X.; Wu, Z. R. An all-solid-state Z-scheme $\mathrm{TiO}_{2} / \mathrm{ZnFe}_{2} \mathrm{O}_{4}$ photocatalytic system for the $\mathrm{N}_{2}$ photofixation enhancement. Chem. Eng. J. 2019, 371, 286-293.

[43] Nazemi, M.; El-Sayed, M. A. Plasmon-enhanced photo(electro)chemical nitrogen fixation under ambient conditions using visible light responsive hybrid hollow $\mathrm{Au}-\mathrm{Ag}_{2} \mathrm{O}$ nanocages. Nano Energy 2019, 63, 103886.

[44] Zhang, S.; Zhao, Y. X.; Shi, R.; Zhou, C.; Waterhouse, G. I. N.; Wang, Z.; Weng, Y. X.; Zhang, T. R. Sub-3 nm ultrafine $\mathrm{Cu}_{2} \mathrm{O}$ for visible light driven nitrogen fixation. Angew. Chem., Int. Ed. 2021, 60, 2554-2560.

[45] Huang, Y. W.; Zhu, Y. S.; Chen, S. J.; Xie, X. Q.; Wu, Z. J.; Zhang, N. Schottky junctions with Bi cocatalyst for taming aqueous phase $\mathrm{N}_{2}$ reduction toward enhanced solar ammonia production. Adv. Sci. 2021, 8, 2003626.

[46] Sun, S. M.; Li, X. M.; Wang, W. Z.; Zhang, L.; Sun, X. Photocatalytic robust solar energy reduction of dinitrogen to ammonia on ultrathin $\mathrm{MoS}_{2}$. Appl. Catal. B: Environ. 2017, 200, 323-329.

[47] Sultana, S.; Mansingh, S.; Parida, K. M. Phosphide protected $\mathrm{FeS}_{2}$ anchored oxygen defect oriented $\mathrm{CeO}_{2} \mathrm{NS}$ based ternary hybrid for electrocatalytic and photocatalytic $\mathrm{N}_{2}$ reduction to $\mathrm{NH}_{3}$. J. Mater. Chem. A 2019, 7, 9145-9153.

[48] Wang, Z. H.; Hu, X.; Liu, Z. Z.; Zou, G. J.; Wang, G. N.; Zhang, K. Recent developments in polymeric carbon nitride-derived photocatalysts and electrocatalysts for nitrogen fixation. ACS Catal. 2019, 9, 10260-10278.

[49] Liu, S. Z.; Wang, S. B.; Jiang, Y.; Zhao, Z. Q.; Jiang, G. Y.; Sun, Z. Y. Synthesis of $\mathrm{Fe}_{2} \mathrm{O}_{3}$ loaded porous $\mathrm{g}_{-} \mathrm{C}_{3} \mathrm{~N}_{4}$ photocatalyst for photocatalytic reduction of dinitrogen to ammonia. Chem. Eng. J. 2019, 373, 572-579.

[50] Qin, J. Z.; Hu, X.; Li, X. Y.; Yin, Z. F.; Liu, B. J.; Lam, K. H. 0D/2D $\mathrm{AgInS}_{2} /$ mxene Z-scheme heterojunction nanosheets for improved ammonia photosynthesis of $\mathrm{N}_{2}$. Nano Energy 2019, 61, 27-35.

[51] Wang, S.; Li, B.; Li, L.; Tian, Z. Q.; Zhang, Q. J.; Chen, L.; Zeng, X. C. Highly efficient $\mathrm{N}_{2}$ fixation catalysts: Transition-metal carbides $\mathrm{M}_{2} \mathrm{C}$ (MXenes). Nanoscale 2020, 12, 538-547.

[52] Shiraishi, Y.; Shiota, S.; Kofuji, Y.; Hashimoto, M.; Chishiro, K.; Hirakawa, H.; Tanaka, S.; Ichikawa, S.; Hirai, T. Nitrogen fixation with water on carbon-nitride-based metal-free photocatalysts with $0.1 \%$ solar-to-ammonia energy conversion efficiency. ACS Appl. Energy Mater. 2018, 1, 4169-4177.

[53] Li, M. Q.; Huang, H.; Low, J.; Gao, C.; Long, R.; Xiong, Y. J. Recent progress on electrocatalyst and photocatalyst design for nitrogen reduction. Small Methods 2019, 3, 1800388.

[54] Zhou, P.; Chao, Y. G.; Lv, F.; Lai, J. P.; Wang, K.; Guo, S. J. Designing noble metal single-atom-loaded two-dimension photocatalyst for $\mathrm{N}_{2}$ and $\mathrm{CO}_{2}$ reduction via anion vacancy engineering. Sci. Bull. 2020, 65, 720-725.

[55] Chen, X. Z.; Li, N.; Kong, Z. Z.; Ong, W. J.; Zhao, X. J. Photocatalytic fixation of nitrogen to ammonia: State-of-the-art advancements and future prospects. Mater. Horiz. 2018, 5, 9-27.

[56] Oshikiri, T.; Ueno, K.; Misawa, H. Plasmon-induced ammonia synthesis through nitrogen photofixation with visible light irradiation. Angew. Chem., Int. Ed. 2014, 53, 9802-9805.

[57] Xiong, J.; Song, P.; Di, J.; Li, H. M. Atomic-level active sites steering in ultrathin photocatalysts to trigger high efficiency nitrogen fixation. Chem. Eng. J. 2020, 402, 126208.

[58] Nowotny, J.; Alim, M. A.; Bak, T.; Idris, M. A.; Ionescu, M.; Prince, K.; Sahdan, M. Z.; Sopian, K.; Mat Teridi, M. A.; Sigmund, W. Defect chemistry and defect engineering of $\mathrm{TiO}_{2}$-based semiconductors for solar energy conversion. Chem. Soc. Rev. 2015, 44, 8424-8442.

[59] Yan, D. F.; Li, Y. X.; Huo, J.; Chen, R.; Dai, L. M.; Wang, S. Y. Defect chemistry of nonprecious-metal electrocatalysts for oxygen reactions. Adv. Mater. 2017, 29, 1606459.

[60] Tong, X. J.; Cao, X.; Han, T.; Cheong, W. C.; Lin, R.; Chen, Z.; Wang, D. S.; Chen, C.; Peng, Q.; Li, Y. D. Convenient fabrication of $\mathrm{BiOBr}$ ultrathin nanosheets with rich oxygen vacancies for photocatalytic selective oxidation of secondary amines. Nano Res. 2019, 12, 1625-1630.

[61] Tan, X. N.; Zhang, J. L.; Tan, D. X.; Shi, J. B.; Cheng, X. Y.; Zhang, F. Y.; Liu, L. F.; Zhang, B. X.; Su, Z. Z.; Han, B. X. Ionic liquids produce heteroatom-doped $\mathrm{Pt} / \mathrm{TiO}_{2}$ nanocrystals for efficient photocatalytic hydrogen production. Nano Res. 2019, 12, 1967-1972.

[62] Fugate, E. A.; Biswas, S.; Clement, M. C.; Kim, M.; Kim, D.; Asthagiri, A.; Baker, L. R. The role of phase impurities and lattice defects on the electron dynamics and photochemistry of $\mathrm{CuFeO}_{2}$ solar photocathodes. Nano Res. 2019, 12, 2390-2399.

[63] Li, H.; Li, W. J.; Li, W.; Chen, M. F.; Snyders, R.; Bittencourt, C.; Yuan, Z. H. Engineering crystal phase of polytypic $\mathrm{CuInS}_{2}$ nanosheets for enhanced photocatalytic and photoelectrochemical performance. Nano Res. 2020, 13, 583-590.

[64] Shi, Q. Q.; Qin, Z. X.; Yu, C. L.; Waheed, A.; Xu, H.; Gao, Y.; Abroshan, H.; Li, G. Experimental and mechanistic understanding of photo-oxidation of methanol catalyzed by $\mathrm{CuO} / \mathrm{TiO}_{2}$-spindle nanocomposite: Oxygen vacancy engineering. Nano Res. 2020, 13, 939-946.

[65] Li, H.; Mao, C. L.; Shang, H.; Yang, Z. P.; Ai, Z. H.; Zhang, L. Z. New opportunities for efficient $\mathrm{N}_{2}$ fixation by nanosheet photocatalysts. Nanoscale 2018, 10, 15429-15435.

[66] Zhang, N.; Jalil, A.; Wu, D. X.; Chen, S. M.; Liu, Y. F.; Gao, C.; Ye, W.; Qi, Z. M.; Ju, H. X.; Wang, C. M. et al. Refining defect states in $\mathrm{W}_{18} \mathrm{O}_{49}$ by mo doping: A strategy for tuning $\mathrm{N}_{2}$ activation towards solar-driven nitrogen fixation. J. Am. Chem. Soc. 2018, 140, 9434-9443.

[67] Hirakawa, H.; Hashimoto, M.; Shiraishi, Y.; Hirai, T. Photocatalytic conversion of nitrogen to ammonia with water on surface oxygen vacancies of titanium dioxide. J. Am. Chem. Soc. 2017, 139, 10929-10936.

[68] Wang, Z.; Fan, C. C.; Shen, Z. X.; Hua, C. Q.; Hu, Q. F.; Sheng, F.; Lu, Y. H.; Fang, H. Y.; Qiu, Z. Z.; Lu, J. et al. Defects controlled hole doping and multivalley transport in snse single crystals. Nat. Commun. 2018, 9, 47.

[69] Liu, Z. C.; Huang, T.; Chang, H. H.; Wang, F. X.; Wen, J.; Sun, H. D.; Hossain, M.; Xie, Q. J.; Zhao, Y.; Wu, Y. P. Computational design of single mo atom anchored defective boron phosphide monolayer as a high-performance electrocatalyst for the nitrogen reduction reaction. Energy Environ. Mater. 2021, 4, 255-262.

[70] Gao, L. L.; Tang, C. Y.; Liu, J. C.; He, L. L.; Wang, H. B.; Ke, Z. J.; Li, W. Q.; Jiang, C. Z.; He, D.; Cheng, L. et al. Oxygen vacancyinduced electron density tuning of $\mathrm{Fe}_{3} \mathrm{O}_{4}$ for enhanced oxygen evolution catalysis. Energy Environ. Mater., 2021, 4, 392-398.

[71] Zhang, N.; Gao, C.; Xiong, Y. J. Defect engineering: A versatile tool for tuning the activation of key molecules in photocatalytic reactions. J. Energy Chem. 2019, 37, 43-57.

[72] Shi, R.; Zhao, Y. X.; Waterhouse, G. I. N.; Zhang, S.; Zhang, T. R. Defect engineering in photocatalytic nitrogen fixation. ACS Catal. 2019, 9, 9739-9750.

[73] Kitano, M.; Inoue, Y.; Yamazaki, Y.; Hayashi, F.; Kanbara, S.; Matsuishi, S.; Yokoyama, T.; Kim, S. W.; Hara, M.; Hosono, H. Ammonia synthesis using a stable electride as an electron donor and reversible hydrogen store. Nat. Chem. 2012, 4, 934-940.

[74] Hao, Q.; Liu, C. W.; Jia, G. H.; Wang, Y.; Arandiyan, H.; Wei, W.; $\mathrm{Ni}$, B. J. Catalytic reduction of nitrogen to produce ammonia by bismuth-based catalysts: State of the art and future prospects. Mater. Horiz. 2020, 7, 1014-1029.

[75] Roberts, M. W. Development of the industrial relevance of catalysis and its physiochemical basis (1860-1940). Catal. Lett. 2000, 67, $5-13$.

[76] Strongin, D. R.; Somorjai, G. A. The effects of potassium on ammonia synthesis over iron single-crystal surfaces. J. Catal. 1988, 109, 51-60.

[77] Hinrichsen, O.; Rosowski, F.; Muhler, M.; Ertl, G. The microkinetics of ammonia synthesis catalyzed by cesium-promoted supported ruthenium. Chem. Eng. Sci. 1996, 51, 1683-1690.

[78] Dahl, S.; Logadottir, A.; Egeberg, R. C.; Larsen, J. H.; Chorkendorff, I.; Törnqvist, E.; Nørskov, J. K. Role of steps in $\mathrm{N}_{2}$ activation on $\mathrm{Ru}(0001)$. Phys. Rev. Lett. 1999, 83, 1814-1817.

[79] Dahl, S.; Törnqvist, E.; Jacobsen, C. J. H. Dissociative adsorption of dinitrogen on a multipromoted iron-based ammonia synthesis catalyst: 
Linking properties of catalysts and single-crystal surfaces. J. Catal. 2001, 198, 97-102.

[80] Shen, H. D.; Peppel, T.; Strunk, J.; Sun, Z. Y. Photocatalytic reduction of $\mathrm{CO}_{2}$ by metal-free-based materials: Recent advances and future perspective. Sol. RRL 2020, 4, 1900546.

[81] Li, J.; Li, H.; Zhan, G. M.; Zhang, L. Z. Solar water splitting and nitrogen fixation with layered bismuth oxyhalides. Acc. Chem. Res. 2017, 50, 112-121.

[82] Chen, X.; Li, J. Y.; Tang, Z. R.; Xu, Y. J. Surface-defect-engineered photocatalyst for nitrogen fixation into value-added chemical feedstocks. Catal. Sci. Technol. 2020, 10, 6098-6110.

[83] Huang, Y. W.; Zhang, N.; Wu, Z. J.; Xie, X. Q. Artificial nitrogen fixation over bismuth-based photocatalysts: Fundamentals and future perspectives. J. Mater. Chem. A 2020, 8, 4978-4995.

[84] Huang, T.; Pan, S. G.; Shi, L. L.; Yu, A. P.; Wang, X.; Fu, Y. S. Hollow porous prismatic graphitic carbon nitride with nitrogen vacancies and oxygen doping: A high-performance visible light-driven catalyst for nitrogen fixation. Nanoscale 2020, 12, 1833-1841.

[85] Zhang, J. N.; Hu, W. P.; Cao, S.; Piao, L. Recent progress for hydrogen production by photocatalytic natural or simulated seawater splitting. Nano Res. 2020, 13, 2313-2322.

[86] Jiao, X. C.; Zheng, K.; Liang, L.; Li, X. D.; Sun, Y. F.; Xie, Y. Fundamentals and challenges of ultrathin 2D photocatalysts in boosting $\mathrm{CO}_{2}$ photoreduction. Chem. Soc. Rev. 2020, 49, 6592-6604.

[87] Li, H.; Li, J.; Ai, Z. H.; Jia, F. L.; Zhang, L. Z. Oxygen vacancymediated photocatalysis of BiOCl: Reactivity, selectivity, and perspectives. Angew. Chem., Int. Ed. 2018, 57, 122-138.

[88] van der Ham, C. J. M.; Koper, M. T. M.; Hetterscheid, D. G. H. Challenges in reduction of dinitrogen by proton and electron transfer. Chem. Soc. Rev. 2014, 43, 5183-5191.

[89] Jia, H. P.; Quadrelli, E. A. Mechanistic aspects of dinitrogen cleavage and hydrogenation to produce ammonia in catalysis and organometallic chemistry: Relevance of metal hydride bonds and dihydrogen. Chem. Soc. Rev. 2014, 43, 547-564.

[90] Hu, C. Y.; Chen, X.; Jin, J. B.; Han, Y.; Chen, S. M.; Ju, H. X.; Cai, J.; Qiu, Y. R.; Gao, C.; Wang, C. M. et al. Surface plasmon enabling nitrogen fixation in pure water through a dissociative mechanism under mild conditions. J. Am. Chem. Soc. 2019, 141, 7807-7814.

[91] Lukoyanov, D.; Dikanov, S. A.; Yang, Z. Y.; Barney, B. M.; Samoilova, R. I.; Narasimhulu, K. V.; Dean, D. R.; Seefeldt, L. C.; Hoffman, B. M. Endor/hyscore studies of the common intermediate trapped during nitrogenase reduction of $\mathrm{N}_{2} \mathrm{H}_{2}, \mathrm{CH}_{3} \mathrm{~N}_{2} \mathrm{H}$, and $\mathrm{N}_{2} \mathrm{H}_{4}$ support an alternating reaction pathway for $\mathrm{N}_{2}$ reduction. J. Am. Chem. Soc. 2011, 133, 11655-11664.

[92] Shipman, M. A.; Symes, M. D. Recent progress towards the electrosynthesis of ammonia from sustainable resources. Catal. Today 2017, 286, 57-68.

[93] Sun, Z. Y.; Talreja, N.; Tao, H. C.; Texter, J.; Muhler, M.; Strunk, J.; Chen, J. F. Catalysis of carbon dioxide photoreduction on nanosheets: Fundamentals and challenges. Angew. Chem., Int. Ed. 2018, 57, 7610-7627.

[94] Li, X. M.; Sun, X.; Zhang, L.; Sun, S. M.; Wang, W. Z. Efficient photocatalytic fixation of $\mathrm{N}_{2}$ by $\mathrm{KOH}$-treated $\mathrm{g}_{-} \mathrm{C}_{3} \mathrm{~N}_{4}$. J. Mater. Chem. A 2018, 6, 3005-3011.

[95] Zhao, W. R.; Xi, H. P.; Zhang, M.; Li, Y. J.; Chen, J. S.; Zhang, J.; $\mathrm{Zhu}, \mathrm{X}$. Enhanced quantum yield of nitrogen fixation for hydrogen storage with in situ-formed carbonaceous radicals. Chem. Commun. 2015, 51, 4785-4788

[96] Guo, Y. Z.; Yang, J. H.; Wu, D. H.; Bai, H. Y.; Yang, Z.; Wang, J. F.; Yang, B. C. Au nanoparticle-embedded, nitrogen-deficient hollow mesoporous carbon nitride spheres for nitrogen photofixation. $J$. Mater. Chem. A 2020, 8, 16218-16231.

[97] Cao, S. H.; Chen, H.; Jiang, F.; Wang, X. Nitrogen photofixation by ultrathin amine-functionalized graphitic carbon nitride nanosheets as a gaseous product from thermal polymerization of urea. Appl. Catal. B: Environ. 2018, 224, 222-229.

[98] Dimitrijevic, N. M.; Vijayan, B. K.; Poluektov, O. G.; Rajh, T.; Gray, K. A.; He, H. Y.; Zapol, P. Role of water and carbonates in photocatalytic transformation of $\mathrm{CO}_{2}$ to $\mathrm{CH}_{4}$ on titania. J. Am. Chem. Soc. 2011, 133, 3964-3971.

[99] Zhao, Y. X.; Shi, R.; Bian, X. A. N.; Zhou, C.; Zhao, Y. F.; Zhang, S.; Wu, F.; Waterhouse, G. I. N.; Wu, L. Z.; Tung, C. H. et al. Ammonia detection methods in photocatalytic and electrocatalytic experiments: How to improve the reliability of $\mathrm{NH}_{3}$ production rates? $A d v$. Sci. 2019, 6, 1802109.

[100] Gao, X.; Wen, Y. J.; Qu, D.; An, L.; Luan, S. L.; Jiang, W. S.; Zong, X. P.; Liu, X. Y.; Sun, Z. C. Interference effect of alcohol on nessler's reagent in photocatalytic nitrogen fixation. ACS Sustain. Chem. Eng. 2018, 6, 5342-5348.

[101] Yuan, S. J.; Chen, J. J.; Lin, Z. Q.; Li, W. W.; Sheng, G. P.; Yu, H. Q. Nitrate formation from atmospheric nitrogen and oxygen photocatalysed by nano-sized titanium dioxide. Nat. Commun. 2013, 4, 2249.

[102] Liu, Y. W.; Cheng, M.; He, Z. H.; Gu, B. C.; Xiao, C.; Zhou, T. F.; Guo, Z. P.; Liu, J. D.; He, H. Y.; Ye, B. J. et al. Pothole-rich ultrathin $\mathrm{WO}_{3}$ nanosheets that trigger $\mathrm{N} \equiv \mathrm{N}$ bond activation of nitrogen for direct nitrate photosynthesis. Angew. Chem., Int. Ed. 2019, 58, 731-735.

[103] Shiraishi, Y.; Hashimoto, M.; Chishiro, K.; Moriyama, K.; Tanaka, S.; Hirai, T. Photocatalytic dinitrogen fixation with water on bismuth oxychloride in chloride solutions for solar-to-chemical energy conversion. J. Am. Chem. Soc. 2020, 142, 7574-7583.

[104] Ren, W. J.; Mei, Z. W.; Zheng, S. S.; Li, S. N.; Zhu, Y. M.; Zheng, J. X.; Lin, Y.; Chen, H. B.; Gu, M.; Pan, F. et al. Wavelengthdependent solar $\mathrm{N}_{2}$ fixation into ammonia and nitrate in pure water. Research 2020, 2020, 3750314.

[105] Yang, J. H.; Bai, H. Y.; Guo, Y. Z.; Zhang, H.; Jiang, R. B.; Yang, B. C.; Wang, J. F.; Yu, J. C. Photodriven disproportionation of nitrogen and its change to reductive nitrogen photofixation. Angew. Chem., Int. Ed. 2021, 60, 927-936.

[106] George, S.; Pokhrel, S.; Ji, Z. X.; Henderson, B. L.; Xia, T.; Li, L. J.; Zink, J. I.; Nel, A. E.; Mädler, L. Role of Fe doping in tuning the band gap of $\mathrm{TiO}_{2}$ for the photo-oxidation-induced cytotoxicity paradigm. J. Am. Chem. Soc. 2011, 133, 11270-11278.

[107] Teranishi, M.; Naya, S. I.; Tada, H. In situ liquid phase synthesis of hydrogen peroxide from molecular oxygen using gold nanoparticleloaded titanium (IV) dioxide photocatalyst. J. Am. Chem. Soc. 2010, $132,7850-7851$

[108] Ran, M. X.; Cui, W.; Li, K. L.; Chen, L.; Zhang, Y. X.; Dong, F.; Sun, Y. J. Light-induced dynamic stability of oxygen vacancies in $\mathrm{BiSbO}_{4}$ for efficient photocatalytic formaldehyde degradation. Energy Environ. Mater., in press, DOI: 10.1002/eem2.12176.

[109] Shen, H. D.; Choi, C.; Masa, J.; Li, X.; Qiu, J. S.; Jung, Y.; Sun, Z. Y. Electrochemical ammonia synthesis: Mechanistic understanding and catalyst design. Chem, 2021, 7, 1708-1754.

[110] Ivančič, I.; Degobbis, D. An optimal manual procedure for ammonia analysis in natural waters by the indophenol blue method. Water Res. 1984, 18, 1143-1147.

[111] Yuen, S. H.; Pollard, A. G. Determination of nitrogen in agricultural materials by the nessler reagent. II. - Micro-determinations in plant tissue and in soil extracts. J. Sci. Food Agric. 1954, 5, 364-369.

[112] Nielander, A. C.; McEnaney, J. M.; Schwalbe, J. A.; Baker, J. G.; Blair, S. J.; Wang, L.; Pelton, J. G.; Andersen, S. Z.; EnemarkRasmussen, K.; Čolić, V. et al. A versatile method for ammonia detection in a range of relevant electrolytes via direct nuclear magnetic resonance techniques. ACS Catal. 2019, 9, 5797-5802.

[113] Zaffaroni, R.; Ripepi, D.; Middelkoop, J.; Mulder, F. M. Gas chromatographic method for in situ ammonia quantification at parts per billion levels. ACS Energy Lett. 2020, 5, 3773-3777.

[114] Liu, Y. C.; Asset, T.; Chen, Y. C.; Murphy, E.; Potma, E. O.; Matanovic, I.; Fishman, D. A.; Atanassov, P. Facile all-optical method for in situ detection of low amounts of ammonia. iScience 2020, 23, 101757.

[115] Duan, G. Y.; Ren, Y.; Tang, Y.; Sun, Y. Z.; Chen, Y. M.; Wan, P. Y.; Yang, X. J. Improving the reliability and accuracy of ammonia quantification in electro- and photochemical synthesis. ChemSusChem 2020, 13, 88-96.

[116] Yang, C. C.; Yu, Y. H.; van der Linden, B.; Wu, J. C. S.; Mul, G. Artificial photosynthesis over crystalline $\mathrm{TiO}_{2}$-based catalysts: Fact or fiction? J. Am. Chem. Soc. 2010, 132, 8398-8406.

[117] Moustakas, N. G.; Strunk, J. Photocatalytic $\mathrm{CO}_{2}$ reduction on $\mathrm{TiO}_{2}$-based materials under controlled reaction conditions: Systematic insights from a literature study. Chem. Eur. J. 2018, 24, 1273912746 . 
[118] Andersen, S. Z.; Čolić, V.; Yang, S.; Schwalbe, J. A.; Nielander, A. C.; McEnaney, J. M.; Enemark-Rasmussen, K.; Baker, J. G.; Singh, A. R.; Rohr, B. A. et al. A rigorous electrochemical ammonia synthesis protocol with quantitative isotope measurements. Nature 2019, 570, 504-508.

[119] Greenlee, L. F.; Renner, J. N.; Foster, S. L. The use of controls for consistent and accurate measurements of electrocatalytic ammonia synthesis from dinitrogen. ACS Catal. 2018, 8, 7820-7827.

[120] Minteer, S. D.; Christopher, P.; Linic, S. Recent developments in nitrogen reduction catalysts: A virtual issue. ACS Energy Lett. 2019, 4, 163-166.

[121] Xu, H. C.; Wang, Y.; Dong, X. L.; Zheng, N.; Ma, H. C.; Zhang, X. F. Fabrication of $\operatorname{In}_{2} \mathrm{O}_{3} / \mathrm{In}_{2} \mathrm{~S}_{3}$ microsphere heterostructures for efficient and stable photocatalytic nitrogen fixation. Appl. Catal. B: Environ. 2019, 257, 117932.

[122] Li, L. Q.; Tang, C.; Yao, D. Z.; Zheng, Y.; Qiao, S. Z. Electrochemical nitrogen reduction: Identification and elimination of contamination in electrolyte. ACS Energy Lett. 2019, 4, 2111-2116.

[123] Comer, B. M.; Liu, Y. H.; Dixit, M. B.; Hatzell, K. B.; Ye, Y. F.; Crumlin, E. J.; Hatzell, M. C.; Medford, A. J. The role of adventitious carbon in photo-catalytic nitrogen fixation by titania. J. Am. Chem. Soc. 2018, 140, 15157-15160.

[124] Li, D. H.; Li, J. J.; Jin, Q. W.; Ren, Z. P.; Sun, Y. W.; Zhang, R. Q.; Zhai, Y. P.; Liu, Y. G. Photocatalytic reduction of $\mathrm{Cr}$ (VI) on nanosized red phosphorus under visible light irradiation. J. Colloid Interface Sci. 2019, 537, 256-261.

[125] Cui, X. Y.; Tang, C.; Zhang, Q. A review of electrocatalytic reduction of dinitrogen to ammonia under ambient conditions. Adv. Energy Mater. 2018, 8, 1800369.

[126] Battino, R.; Rettich, T. R.; Tominaga, T. The solubility of nitrogen and air in liquids. J. Phys. Chem. Ref. Data 1984, 13, 563-600.

[127] Ali, M.; Zhou, F. L.; Chen, K.; Kotzur, C.; Xiao, C. L.; Bourgeois, L.; Zhang, X. Y.; MacFarlane, D. R. Nanostructured photoelectrochemical solar cell for nitrogen reduction using plasmonenhanced black silicon. Nat. Commun. 2016, 7, 11335.

[128] Tang, C.; Qiao, S. Z. How to explore ambient electrocatalytic nitrogen reduction reliably and insightfully. Chem. Soc. Rev. 2019, 48, 3166-3180.

[129] Hu, L.; Xing, Z.; Feng, X. F. Understanding the electrocatalytic interface for ambient ammonia synthesis. ACS Energy Lett. 2020, $5,430-436$.

[130] Feng, Y. L.; Zhang, Z. S.; Zhao, K.; Lin, S. L.; Li, H.; Gao, X. Photocatalytic nitrogen fixation: Oxygen vacancy modified novel micro-nanosheet structure $\mathrm{Bi}_{2} \mathrm{O}_{2} \mathrm{CO}_{3}$ with band gap engineering. $J$. Colloid Interface Sci. 2021, 583, 499-509.

[131] Yan, D. F.; Li, H.; Chen, C.; Zou, Y. Q.; Wang, S. Y. Defect engineering strategies for nitrogen reduction reactions under ambient conditions. Small Methods 2019, 3, 1800331.

[132] Li, G. W.; Blake, G. R.; Palstra, T. T. M. Vacancies in functional materials for clean energy storage and harvesting: The perfect imperfection. Chem. Soc. Rev. 2017, 46, 1693-1706.

[133] Bai, S.; Zhang, N.; Gao, C.; Xiong, Y. J. Defect engineering in photocatalytic materials. Nano Energy 2018, 53, 296-336.

[134] Zhou, W.; Fu, H. G. Defect-mediated electron-hole separation in semiconductor photocatalysis. Inorg. Chem. Front. 2018, 5, $1240-1254$.

[135] Kong, M.; Li, Y. Z.; Chen, X.; Tian, T. T.; Fang, P. F.; Zheng, F.; Zhao, X. J. Tuning the relative concentration ratio of bulk defects to surface defects in $\mathrm{TiO}_{2}$ nanocrystals leads to high photocatalytic efficiency. J. Am. Chem. Soc. 2011, 133, 16414-16417.

[136] Li, L. D.; Yan, J. Q.; Wang, T.; Zhao, Z. J.; Zhang, J.; Gong, J. L.; Guan, N. J. Sub-10 nm rutile titanium dioxide nanoparticles for efficient visible-light-driven photocatalytic hydrogen production. Nat. Commun. 2015, 6, 5881 .

[137] Mao, Y. S.; Wang, P. F.; Li, L. N.; Chen, Z. W.; Wang, H. T.; Li, Y.; Zhan, S. H. Unravelling the synergy between oxygen vacancies and oxygen substitution in $\mathrm{BiO}_{2-x}$ for efficient molecular-oxygen activation. Angew. Chem., Int. Ed. 2020, 59, 3685-3690.

[138] Feng, H. F.; Xu, Z. F.; Ren, L.; Liu, C.; Zhuang, J. C.; Hu, Z. P.; $\mathrm{Xu}, \mathrm{X}$.; Chen, J.; Wang, J. O.; Hao, W. C. et al. Activating titania for efficient electrocatalysis by vacancy engineering. ACS Catal. 2018, 8, 4288-4293.
[139] Beyerlein, I. J.; Demkowicz, M. J.; Misra, A.; Uberuaga, B. P. Defect-interface interactions. Prog. Mater. Sci. 2015, 74, 125-210.

[140] Zhou, Y. G.; Zhang, Z. Z.; Fang, Z. W.; Qiu, M.; Ling, L.; Long, J. L.; Chen, L.; Tong, Y. C.; Su, W. Y.; Zhang, Y. F. et al. Defect engineering of metal-oxide interface for proximity of photooxidation and photoreduction. Proc. Natl. Acad. Sci. USA 2019, 116, 10232-10237.

[141] Huang, Z. F.; Song, J. J.; Wang, X.; Pan, L.; Li, K.; Zhang, X. W.; Wang, L.; Zou, J. J. Switching charge transfer of $\mathrm{C}_{3} \mathrm{~N}_{4} / \mathrm{W}_{18} \mathrm{O}_{49}$ from type-II to z-scheme by interfacial band bending for highly efficient photocatalytic hydrogen evolution. Nano Energy 2017, 40, 308-316.

[142] Gao, H. H.; Cao, R. Y.; Xu, X. T.; Zhang, S. W.; Yongshun, H.; Yang, H. C.; Deng, X. L.; Li, J. X. Construction of dual defect mediated Z-scheme photocatalysts for enhanced photocatalytic hydrogen evolution. Appl. Catal. B: Environ. 2019, 245, 399-409.

[143] Yan, X.; Liu, D. L.; Cao, H. H.; Hou, F.; Liang, J.; Dou, S. X. Nitrogen reduction to ammonia on atomic-scale active sites under mild conditions. Small Methods 2019, 3, 1800501.

[144] Naliwajko, P.; Strunk, J. Photocatalysis-the heterogeneous catalysis perspective. In Heterogeneous Photocatalysis: From Fundamentals to Applications in Energy Conversion and Depollution. Strunk, J., Ed.; Wiley VCH: Weinheim, 2021; pp 384.

[145] Ran, L.; Hou, J. G.; Cao, S. Y.; Li, Z. W.; Zhang, Y. T.; Wu, Y. Z.; Zhang, B.; Zhai, P. L.; Sun, L. C. Defect engineering of photocatalysts for solar energy conversion. Sol. RRL 2020, 4, 1900487.

[146] Huang, Y. M.; Yu, Y.; Yu, Y. F.; Zhang, B. Oxygen vacancy engineering in photocatalysis. Sol. RRL 2020, 4, 2000037.

[147] Lan, M.; Zheng, N.; Dong, X. L.; Hua, C. H.; Ma, H. C.; Zhang, $\mathrm{X}$. F. Bismuth-rich bismuth oxyiodide microspheres with abundant oxygen vacancies as an efficient photocatalyst for nitrogen fixation. Dalton Trans. 2020, 49, 9123-9129.

[148] Hao, Y. C.; Dong, X. L.; Zhai, S. R.; Ma, H. C.; Wang, X. Y.; Zhang, X. F. Hydrogenated bismuth molybdate nanoframe for efficient sunlight-driven nitrogen fixation from air. Chem. Eur. J. 2016, 22, 18722-18728.

[149] Wang, J. P.; Lin, W.; Ran, Y.; Cui, J. Y.; Wang, L.; Yu, X. L.; Zhang, Y. H. Nanotubular $\mathrm{TiO}_{2}$ with remedied defects for photocatalytic nitrogen fixation. J. Phys. Chem. C 2020, 124, 1253-1259.

[150] Wang, H.; Bu, Y. D.; Wu, G.; Zou, X. The promotion of the photocatalytic nitrogen fixation ability of nitrogen vacancyembedded graphitic carbon nitride by replacing the corner-site carbon atom with phosphorus. Dalton Trans. 2019, 48, 11724-11731.

[151] Wu, S. Q.; Chen, Z. Y.; Liu, K. D.; Yue, W. H.; Wang, L. Z.; Zhang, J. L. Chemisorption-induced and plasmon-promoted photofixation of nitrogen on gold-loaded carbon nitride nanosheets. ChemSusChem 2020, 13, 3455-3461.

[152] Liu, D. L.; Wang, C. H.; Yu, Y. F.; Zhao, B. H.; Wang, W. C.; Du, Y. H.; Zhang, B. Understanding the nature of ammonia treatment to synthesize oxygen vacancy-enriched transition metal oxides. Chem 2019, 5, 376-389.

[153] Ge, J. H.; Zhang, L.; Xu, J.; Liu, Y. J.; Jiang, D. C.; Du, P. W. Nitrogen photofixation on holey $\mathrm{g}-\mathrm{C}_{3} \mathrm{~N}_{4}$ nanosheets with carbon vacancies under visible-light irradiation. Chin. Chem. Lett. 2020, 31, 792-796.

[154] Zhang, Y. Z.; Chen, X.; Zhang, S. Y.; Yin, L. F.; Yang, Y. Defective titanium dioxide nanobamboo arrays architecture for photocatalytic nitrogen fixation up to $780 \mathrm{~nm}$. Chem. Eng. J. 2020, 401, 126033.

[155] Yang, X. L.; Wang, S. Y.; Yang, N.; Zhou, W.; Wang, P.; Jiang, K.; Li, S.; Song, H.; Ding, X.; Chen, H. et al. Oxygen vacancies induced special $\mathrm{CO}_{2}$ adsorption modes on $\mathrm{Bi}_{2} \mathrm{MoO}_{6}$ for highly selective conversion to $\mathrm{CH}_{4}$. Appl. Catal. B: Environ. 2019, 259, 118088.

[156] Zheng, J. Y.; Lyu, Y.; Wang, R. L.; Xie, C.; Zhou, H. J.; Jiang, S. P.; Wang, S. Y. Crystalline $\mathrm{TiO}_{2}$ protective layer with graded oxygen defects for efficient and stable silicon-based photocathode. Nat. Commun. 2018, 9, 3572.

[157] Lei, F. C.; Sun, Y. F.; Liu, K. T.; Gao, S.; Liang, L.; Pan, B. C.; Xie, $\mathrm{Y}$. Oxygen vacancies confined in ultrathin indium oxide porous sheets for promoted visible-light water splitting. J. Am. Chem. Soc. 2014, 136, 6826-6829.

[158] Yang, J. H.; Guo, Y. Z.; Jiang, R. B.; Qin, F.; Zhang, H.; Lu, W. Z.; Wang, J. F.; Yu, J. C. High-efficiency "working-in-tandem" nitrogen photofixation achieved by assembling plasmonic gold nanocrystals 
on ultrathin titania nanosheets. J. Am. Chem. Soc. 2018, 140, $8497-8508$

[159] Wang, W. K.; Zhou, H. J.; Liu, Y. Y.; Zhang, S. B.; Zhang, Y. X.; Wang, G. Z.; Zhang, H. M.; Zhao, H. J. Formation of B-N-C coordination to stabilize the exposed active nitrogen atoms in $g-\mathrm{C}_{3} \mathrm{~N}_{4}$ for dramatically enhanced photocatalytic ammonia synthesis performance. Small 2020, 16, 1906880.

[160] Liang, C.; Niu, H. Y.; Guo, H.; Niu, C. G.; Huang, D. W.; Yang, Y. Y.; Liu, H. Y.; Shao, B. B.; Feng, H. P. Insight into photocatalytic nitrogen fixation on graphitic carbon nitride: Defect-dopant strategy of nitrogen defect and boron dopant. Chem. Eng. J. 2020, 396 , 125395.

[161] Zhao, Y. F.; Wang, E. D.; Jin, R. R. The effect of oxygen on the $\mathrm{N}_{2}$ photofixation ability over $\mathrm{N}$ vacancies embedded $g-\mathrm{C}_{3} \mathrm{~N}_{4}$ prepared by dielectric barrier discharge plasma treatment. Diam. Relat. Mater. 2019, 94, 146-154.

[162] Liu, M. X.; Wang, Y. C.; Kong, X. H.; Tan, L. D.; Li, L.; Cheng, S. B.; Botton, G.; Guo, H.; Mi, Z. T.; Li, C. J. Efficient nitrogen fixation catalyzed by gallium nitride nanowire using nitrogen and water. iScience 2019, 17, 208-216.

[163] Li, Z.; Gu, G. Z.; Hu, S. Z.; Zou, X.; Wu, G. Promotion of activation ability of $\mathrm{N}$ vacancies to $\mathrm{N}_{2}$ molecules on sulfur-doped graphitic carbon nitride with outstanding photocatalytic nitrogen fixation ability. Chin. J. Catal. 2019, 40, 1178-1186.

[164] Li, G.; Yang, W. Y.; Gao, S.; Shen, Q. Q.; Xue, J. B.; Chen, K. X.; $\mathrm{Li}, \mathrm{Q}$. Creation of rich oxygen vacancies in bismuth molybdate nanosheets to boost the photocatalytic nitrogen fixation performance under visible light illumination. Chem. Eng. J. 2021, 404, 127115.

[165] Zhao, Y. X.; Zheng, L. R.; Shi, R.; Zhang, S.; Bian, X. G.; Wu, F.; Cao, X. Z.; Waterhouse, G. I. N.; Zhang, T. R. Alkali etching of layered double hydroxide nanosheets for enhanced photocatalytic $\mathrm{N}_{2}$ reduction to $\mathrm{NH}_{3}$. Adv. Energy Mater. 2020, 10, 2002199.

[166] Zhao, Z. Q.; Hong, S.; Yan, C.; Choi, C.; Jung, Y.; Liu, Y.; Liu, S. Z.; Li, X.; Qiu, J. S.; Sun, Z. Y. Efficient visible-light driven $\mathrm{N}_{2}$ fixation over two-dimensional $\mathrm{Sb} / \mathrm{TiO}_{2}$ composites. Chem. Commun. 2019, 55, 7171-7174.

[167] Zhao, Z. Q.; Choi, C.; Hong, S.; Shen, H. D.; Yan, C.; Masa, J.; Jung, Y.; Qiu, J. S.; Sun, Z. Y. Surface-engineered oxidized two-dimensional $\mathrm{Sb}$ for efficient visible light-driven $\mathrm{N}_{2}$ fixation. Nano Energy 2020, 78, 105368.

[168] Yuan, J. L.; Yi, X. Y.; Tang, Y. H.; Liu, M. J.; Liu, C. B. Efficient photocatalytic nitrogen fixation: Enhanced polarization, activation, and cleavage by asymmetrical electron donation to $\mathrm{N} \equiv \mathrm{N}$ bond. Adv. Funct. Mater. 2020, 30, 1906983.

[169] Zhao, Y. F.; Zhao, Y. X.; Waterhouse, G. I. N.; Zheng, L. R.; Cao, X. Z.; Teng, F.; Wu, L. Z.; Tung, C. H.; O'Hare, D.; Zhang, T. R. Layered-double-hydroxide nanosheets as efficient visible-lightdriven photocatalysts for dinitrogen fixation. Adv. Mater. 2017, 29, 1703828 .

[170] Sun, B. T.; Liang, Z. Q.; Qian, Y. Y.; Xu, X. S.; Han, Y.; Tian, J. Sulfur vacancy-rich O-doped $1 \mathrm{~T}-\mathrm{MoS}_{2}$ nanosheets for exceptional photocatalytic nitrogen fixation over CdS. ACS Appl. Mater. Interfaces 2020, 12, 7257-7269.

[171] Li, X. Z.; He, C. L.; Zuo, S. X.; Yan, X. Y.; Dai, D.; Zhang, Y. Y.; Yao, C. Photocatalytic nitrogen fixation over fluoride/attapulgite nanocomposite: Effect of upconversion and fluorine vacancy. Sol. Energy 2019, 191, 251-262.

[172] Xue, X. L.; Chen, R. P.; Chen, H. W.; Hu, Y.; Ding, Q. Q.; Liu, Z. T.; Ma, L. B.; Zhu, G. Y.; Zhang, W. J.; Yu, Q. et al. Oxygen vacancy engineering promoted photocatalytic ammonia synthesis on ultrathin two-dimensional bismuth oxybromide nanosheets. Nano Lett. 2018, 18, 7372-7377.

[173] Di, J.; Xia, J. X.; Chisholm, M. F.; Zhong, J.; Chen, C.; Cao, X. Z.; Dong, F.; Chi, Z.; Chen, H. L.; Weng, Y. X. et al. Defect-tailoring mediated electron-hole separation in single-unit-cell $\mathrm{Bi}_{3} \mathrm{O}_{4} \mathrm{Br}$ nanosheets for boosting photocatalytic hydrogen evolution and nitrogen fixation. Adv. Mater. 2019, 31, 1807576

[174] Luo, J. Y.; Bai, X. X.; Li, Q.; Yu, X.; Li, C. Y.; Wang, Z. N.; Wu, W. W.; Liang, Y. P.; Zhao, Z. H.; Liu, H. Band structure engineering of bioinspired $\mathrm{Fe}$ doped $\mathrm{SrMoO}_{4}$ for enhanced photocatalytic nitrogen reduction performance. Nano Energy 2019, 66, 104187.

[175] Du, X. C.; Huang, J. W.; Zhang, J. J.; Yan, Y. C.; Wu, C. Y.; Hu, Y.;
Yan, C. Y.; Lei, T. Y.; Chen, W.; Fan, C. et al. Modulating electronic structures of inorganic nanomaterials for efficient electrocatalytic water splitting. Angew. Chem., Int. Ed. 2019, 58, 4484-4502.

[176] Zhao, Y. X.; Zhao, Y. F.; Shi, R.; Wang, B.; Waterhouse, G. I. N.; Wu, L. Z.; Tung, C. H.; Zhang, T. R. Tuning oxygen vacancies in ultrathin $\mathrm{TiO}_{2}$ nanosheets to boost photocatalytic nitrogen fixation up to $700 \mathrm{~nm}$. Adv. Mater. 2019, 31, 1806482.

[177] Zhang, S.; Zhao, Y. X.; Shi, R.; Zhou, C.; Waterhouse, G. I. N.; Wu, L. Z.; Tung, C. H.; Zhang, T. R. Efficient photocatalytic nitrogen fixation over $\mathrm{Cu}^{\delta+}$-modified defective $\mathrm{ZnAl}$-layered double hydroxide nanosheets. Adv. Energy Mater. 2020, 10, 1901973.

[178] Zhao, K.; Zhang, L. Z.; Wang, J. J.; Li, Q. X.; He, W. W.; Yin, J. J. Surface structure-dependent molecular oxygen activation of $\mathrm{BiOCl}$ single-crystalline nanosheets. J. Am. Chem. Soc. 2013, 135, $15750-15753$.

[179] Hou, T. T.; Xiao, Y.; Cui, P. X.; Huang, Y. N.; Tan, X. P.; Zheng, X. S.; Zou, Y.; Liu, C. X.; Zhu, W. K.; Liang, S. Q. et al. Operando oxygen vacancies for enhanced activity and stability toward nitrogen photofixation. Adv. Energy Mater. 2019, 9, 1902319.

[180] Wang, S. Y.; Hai, X.; Ding, X.; Chang, K.; Xiang, Y. G.; Meng, X. G.; Yang, Z. X.; Chen, H.; Ye, J. H. Light-switchable oxygen vacancies in ultrafine $\mathrm{Bi}_{5} \mathrm{O}_{7} \mathrm{Br}$ nanotubes for boosting solar-driven nitrogen fixation in pure water. Adv. Mater. 2017, 29, 1701774.

[181] Li, P. S.; Zhou, Z. A.; Wang, Q.; Guo, M.; Chen, S. W.; Low, J.; Long, R.; Liu, W.; Ding, P. R.; Wu, Y. Y. et al. Visible-light-driven nitrogen fixation catalyzed by $\mathrm{Bi}_{5} \mathrm{O}_{7} \mathrm{Br}$ nanostructures: Enhanced performance by oxygen vacancies. J. Am. Chem. Soc. 2020, 142, 12430-12439.

[182] Shen, A. L.; Zou, Y. Q.; Wang, Q.; Dryfe, R. A. W.; Huang, X. B.; Dou, S.; Dai, L. M.; Wang, S. Y. Oxygen reduction reaction in a droplet on graphite: Direct evidence that the edge is more active than the basal plane. Angew. Chem., Int. Ed. 2014, 53, 10804-10808.

[183] Zhao, Z. L.; Wang, Q.; Huang, X.; Feng, Q.; Gu, S.; Zhang, Z.; $\mathrm{Xu}, \mathrm{H}$.; Zeng, L.; Gu, M.; Li, H. Boosting the oxygen evolution reaction using defect-rich ultra-thin ruthenium oxide nanosheets in acidic media. Energy Environ. Sci. 2020, 13, 5143-5151.

[184] Zhang, H.; Dasbiswas, K.; Ludwig, N. B.; Han, G.; Lee, B.; Vaikuntanathan, S.; Talapin, D. V. Stable colloids in molten inorganic salts. Nature 2017, 542, 328-331.

[185] Wang, H. T.; Lee, H. W.; Deng, Y.; Lu, Z. Y.; Hsu, P. C.; Liu, Y. Y.; Lin, D. C.; Cui, Y. Bifunctional non-noble metal oxide nanoparticle electrocatalysts through lithium-induced conversion for overall water splitting. Nat. Commun. 2015, 6, 7261.

[186] Li, Z.; Gao, Z. Y.; Li, B. W.; Zhang, L. L.; Fu, R.; Li, Y.; Mu, X. Y.; Li, L. Fe-Pt nanoclusters modified mott-schottky photocatalysts for enhanced ammonia synthesis at ambient conditions. Appl. Catal. B: Environ. 2020, 262, 118276.

[187] Liu, Y. Y.; Wang, H. T.; Lin, D. C.; Liu, C.; Hsu, P. C.; Liu, W.; Chen, W.; Cui, Y. Electrochemical tuning of olivine-type lithium transition-metal phosphates as efficient water oxidation catalysts. Energy Environ. Sci. 2015, 8, 1719-1724.

[188] Qi, R. J.; Yu, P. F.; Zhang, J. C.; Guo, W. Q.; He, Y. Y.; Hojo, H.; Einaga, H.; Zhang, Q.; Liu, X. S.; Jiang, Z. et al. Efficient visible light photocatalysis enabled by the interaction between dual cooperative defect sites. Appl. Catal. B: Environ. 2020, 274, 119099.

[189] Yu, Z. L.; Gao, L. Z.; Yuan, S. Y.; Wu, Y. Solid defect structure and catalytic activity of perovskite-type catalysts $\mathrm{La}_{1-x} \mathrm{Sr}_{x} \mathrm{NiO}_{3-\lambda}$ and $\mathrm{La}_{1-1.333 x} \mathrm{Th}_{x} \mathrm{NiO}_{3-\lambda}$. J. Chem. Soc., Faraday Trans. 1992, 88, 3245-3249.

[190] Ulvestad, A.; Singer, A.; Clark, J. N.; Cho, H. M.; Kim, J. W.; Harder, R.; Maser, J.; Meng, Y. S.; Shpyrko, O. G. Topological defect dynamics in operando battery nanoparticles. Science 2015, 348, 1344-1347.

[191] Zhang, G. Q.; Yang, X.; He, C. X.; Zhang, P. X.; Mi, H. W. Constructing a tunable defect structure in $\mathrm{TiO}_{2}$ for photocatalytic nitrogen fixation. J. Mater. Chem. A 2020, 8, 334-341.

[192] Xie, C.; Yan, D. F.; Li, H.; Du, S. Q.; Chen, W.; Wang, Y. Y.; Zou, Y. Q.; Chen, R.; Wang, S. Y. Defect chemistry in heterogeneous catalysis: Recognition, understanding, and utilization. ACS Catal. 2020, 10, 11082-11098.

[193] Naldoni, A.; Allieta, M.; Santangelo, S.; Marelli, M.; Fabbri, F.; Cappelli, S.; Bianchi, C. L.; Psaro, R.; Dal Santo, V. Effect of 
nature and location of defects on bandgap narrowing in black $\mathrm{TiO}_{2}$ nanoparticles. J. Am. Chem. Soc. 2012, 134, 7600-7603.

[194] Pan, X. Y.; Yang, M. Q.; Fu, X. Z.; Zhang, N.; Xu, Y. J. Defective $\mathrm{TiO}_{2}$ with oxygen vacancies: Synthesis, properties and photocatalytic applications. Nanoscale 2013, 5, 3601-3614.

[195] Cheng, L.; Xiang, Q. J.; Liao, Y. L.; Zhang, H. W. CdS-based photocatalysts. Energy Environ. Sci. 2018, 11, 1362-1391.

[196] Samadi, M.; Shivaee, H. A.; Pourjavadi, A.; Moshfegh, A. Z. Synergism of oxygen vacancy and carbonaceous species on enhanced photocatalytic activity of electrospun $\mathrm{ZnO}$-carbon nanofibers: Charge carrier scavengers mechanism. Appl. Catal. A: Gen. 2013, 466, 153-160.

[197] Jing, K. Q.; Ma, W.; Ren, Y. H.; Xiong, J. H.; Guo, B. B.; Song, Y. J.; Liang, S. J.; Wu, L. Hierarchical $\mathrm{Bi}_{2} \mathrm{MoO}_{6}$ spheres in situ assembled by monolayer nanosheets toward photocatalytic selective oxidation of benzyl alcohol. Appl. Catal. B: Environ. 2019, 243, $10-18$.

[198] Zhang, X. H.; Pei, C. L.; Chang, X.; Chen, S.; Liu, R.; Zhao, Z. J.; $\mathrm{Mu}, \mathrm{R}$. T.; Gong, J. L. $\mathrm{FeO}_{6}$ octahedral distortion activates lattice oxygen in perovskite ferrite for methane partial oxidation coupled with $\mathrm{CO}_{2}$ splitting. J. Am. Chem. Soc. 2020, 142, 11540-11549.

[199] Chen, X. Q.; Liu, H. B.; Gu, G. B. Preparation of nanometer crystalline $\mathrm{TiO}_{2}$ with high photo-catalytic activity by pyrolysis of titanyl organic compounds and photo-catalytic mechanism. Mater. Chem. Phys. 2005, 91, 317-324.

[200] Sun, Y. F.; Gao, S.; Lei, F. C.; Xie, Y. Atomically-thin two-dimensional sheets for understanding active sites in catalysis. Chem. Soc. Rev. 2015, 44, 623-636.

[201] Mao, C. L.; Cheng, H. G.; Tian, H.; Li, H.; Xiao, W. J.; Xu, H.; Zhao, J. C.; Zhang, L. Z. Visible light driven selective oxidation of amines to imines with BiOCl: Does oxygen vacancy concentration matter? Appl. Catal. B: Environ. 2018, 228, 87-96.

[202] Yan, C. S.; Fang, Z. W.; Lv, C. D.; Zhou, X.; Chen, G.; Yu, G. H. Significantly improving lithium-ion transport via conjugated anion intercalation in inorganic layered hosts. ACS Nano 2018, 12, 8670-8677.

[203] Ischenko, V.; Polarz, S.; Grote, D.; Stavarache, V.; Fink, K.; Driess, M. Zinc oxide nanoparticles with defects. Adv. Funct. Mater. 2005, 15, 1945-1954.

[204] Rajh, T.; Poluektov, O. G.; Thurnauer, M. C. Charge separation in titanium oxide nanocrystalline semiconductors revealed by magnetic resonance. In Chemical Physics of Nanostructured Semiconductors. Kokorin, A. I.; Bahnemann, D. W., Eds.; VSP-Brill Academic Publishers: Utrecht, Boston, 2003; pp 1-34.

[205] Yu, B. L.; Zhu, C. S.; Gan, F. X.; Huang, Y. B. Electron spin resonance properties of zno microcrystallites. Mater. Lett. 1998, 33, 247-250.

[206] Howe, R. F.; Gratzel, M. EPR observation of trapped electrons in colloidal titanium dioxide. J. Phys. Chem. 1985, 89, 4495-4499.

[207] Howe, R. F.; Gratzel, M. EPR study of hydrated anatase under UV irradiation. J. Phys. Chem. 1987, 91, 3906-3909.

[208] Carter, E.; Carley, A. F.; Murphy, D. M. Evidence for $\mathrm{O}_{2}^{-}$radical stabilization at surface oxygen vacancies on polycrystalline $\mathrm{TiO}_{2} . J$. Phys. Chem. C 2007, 111, 10630-10638.

[209] Liu, Y.; Hu, Z. F.; Yu, J. C. Fe enhanced visible-light-driven nitrogen fixation on BiOBr nanosheets. Chem. Mater. 2020, 32, 1488-1494.

[210] Huang, H.; Wang, X. S.; Philo, D.; Ichihara, F.; Song, H.; Li, Y. X.; Li, D.; Qiu, T.; Wang, S. Y.; Ye, J. H. Toward visible-light-assisted photocatalytic nitrogen fixation: A titanium metal organic framework with functionalized ligands. Appl. Catal. B: Environ. 2020, 267, 118686.

[211] Jiang, J.; Pachter, R.; Mehmood, F.; Islam, A. E.; Maruyama, B.; Boeckl, J. J. A Raman spectroscopy signature for characterizing defective single-layer graphene: Defect-induced $I(\mathrm{D}) / I\left(\mathrm{D}^{\prime}\right)$ intensity ratio by theoretical analysis. Carbon 2015, 90, 53-62.

[212] Cançado, L. G.; Jorio, A.; Ferreira, E. H. M.; Stavale, F.; Achete, C. A.; Capaz, R. B.; Moutinho, M. V. O.; Lombardo, A.; Kulmala, T. S.; Ferrari, A. C. Quantifying defects in graphene via Raman spectroscopy at different excitation energies. Nano Lett. 2011, 11, 3190-3196.

[213] Fang, Y.; Xue, Y. R.; Hui, L.; Yu, H. D.; Li, Y. L. Graphdiyne@ janus magnetite for photocatalytic nitrogen fixation. Angew. Chem., Int. Ed. 2021, 60, 3170-3174.
[214] Wu, Q. P.; van de Krol, R. Selective photoreduction of nitric oxide to nitrogen by nanostructured $\mathrm{TiO}_{2}$ photocatalysts: Role of oxygen vacancies and iron dopant. J. Am. Chem. Soc. 2012, 134, 9369-9375.

[215] Aspnes, D. E. Spectroscopic ellipsometry-past, present, and future. Thin Solid Films 2014, 571, 334-344.

[216] Egbo, K. O.; Liu, C. P.; Ekuma, C. E.; Yu, K. M. Vacancy defects induced changes in the electronic and optical properties of $\mathrm{NiO}$ studied by spectroscopic ellipsometry and first-principles calculations. J. Appl. Phys. 2020, 128, 135705.

[217] Li, C. C.; Wang, T.; Zhao, Z. J.; Yang, W. M.; Li, J. F.; Li, A.; Yang, Z. L.; Ozin, G. A.; Gong, J. L. Promoted fixation of molecular nitrogen with surface oxygen vacancies on plasmon-enhanced $\mathrm{TiO}_{2}$ photoelectrodes. Angew. Chem., Int. Ed. 2018, 57, 5278-5282.

[218] Jin, H. Y.; Guo, C. X.; Liu, X.; Liu, J. L.; Vasileff, A.; Jiao, Y.; Zheng, Y.; Qiao, S. Z. Emerging two-dimensional nanomaterials for electrocatalysis. Chem. Rev. 2018, 118, 6337-6408.

[219] Zhang, J. F.; Liu, J. Y.; Xi, L. F.; Yu, Y. F.; Chen, N.; Sun, S. H.; Wang, W. C.; Lange, K. M.; Zhang, B. Single-atom Au/NiFe layered double hydroxide electrocatalyst: Probing the origin of activity for oxygen evolution reaction. J. Am. Chem. Soc. 2018, 140, $3876-3879$.

[220] Jiao, S. L.; Fu, X. W.; Zhang, L.; Zeng, Y. J.; Huang, H. W. Pointdefect-optimized electron distribution for enhanced electrocatalysis: Towards the perfection of the imperfections. Nano Today 2020, 31, 100833.

[221] Guan, R. Q.; Wang, D. D.; Zhang, Y. J.; Liu, C.; Xu, W.; Wang, J. O.; Zhao, Z.; Feng, M.; Shang, Q. K.; Sun, Z. C. Enhanced photocatalytic $\mathrm{N}_{2}$ fixation via defective and fluoride modified $\mathrm{TiO}_{2}$ surface. Appl. Catal. B: Environ. 2021, 282, 119580.

[222] Wang, W. K.; Zhang, H. M.; Zhang, S. B.; Liu, Y. Y.; Wang, G. Z.; Sun, C. H.; Zhao, H. J. Potassium-ion-assisted regeneration of active cyano groups in carbon nitride nanoribbons: Visible-light-driven photocatalytic nitrogen reduction. Angew. Chem., Int. Ed. 2019, 58, 16644-16650.

[223] Wang, H.; Yong, D. Y.; Chen, S. C.; Jiang, S. L.; Zhang, X. D.; Shao, W.; Zhang, Q.; Yan, W. S.; Pan, B. C.; Xie, Y. Oxygenvacancy-mediated exciton dissociation in $\mathrm{BiOBr}$ for boosting charge-carrier-involved molecular oxygen activation. J. Am. Chem. Soc. 2018, 140, 1760-1766.

[224] Lyu, M.; Liu, Y. W.; Zhi, Y. D.; Xiao, C.; Gu, B. C.; Hua, X. M.; Fan, S. J.; Lin, Y.; Bai, W.; Tong, W. et al. Electric-field-driven dual vacancies evolution in ultrathin nanosheets realizing reversible semiconductor to half-metal transition. J. Am. Chem. Soc. 2015, 137, 15043-15048.

[225] Jiang, X. D.; Zhang, Y. P.; Jiang, J.; Rong, Y. S.; Wang, Y. C.; Wu, Y. C.; Pan, C. X. Characterization of oxygen vacancy associates within hydrogenated $\mathrm{TiO}_{2}$ : A positron annihilation study. J. Phys. Chem. C 2012, 116, 22619-22624.

[226] Siegel, R. W. Positron annihilation spectroscopy. Annu. Rev. Mater. Sci. 1980, 10, 393-425.

[227] Zou, Y. Q.; Wang, S. Y. An investigation of active sites for electrochemical $\mathrm{CO}_{2}$ reduction reactions: From in situ characterization to rational design. Adv. Sci. 2021, 8, 2003579.

[228] Huang, T. X.; Cong, X.; Wu, S. S.; Lin, K. Q.; Yao, X.; He, Y. H.; Wu, J. B.; Bao, Y. F.; Huang, S. C.; Wang, X. et al. Probing the edge-related properties of atomically thin $\mathrm{MoS}_{2}$ at nanoscale. Nat. Commun. 2019, 10, 5544.

[229] Pfisterer, J. H. K.; Baghernejad, M.; Giuzio, G.; Domke, K. F. Reactivity mapping of nanoscale defect chemistry under electrochemical reaction conditions. Nat. Commun. 2019, 10, 5702.

[230] Li, S.; Yao, Z. P.; Zheng, J. M.; Fu, M. S.; Cen, J. J.; Hwang, S.; Jin, H. L.; Orlov, A.; Gu, L.; Wang, S. et al. Direct observation of defect-aided structural evolution in a nickel-rich layered cathode. Angew. Chem., Int. Ed. 2020, 59, 22092-22099.

[231] Kondo, S.; Mitsuma, T.; Shibata, N.; Ikuhara, Y. Direct observation of individual dislocation interaction processes with grain boundaries. Sci. Adv. 2016, 2, e1501926.

[232] Ding, Y.; Choi, Y.; Chen, Y.; Pradel, K. C.; Liu, M. L.; Wang, Z. L. Quantitative nanoscale tracking of oxygen vacancy diffusion inside single ceria grains by in situ transmission electron microscopy. Mater. Today 2020, 38, 24-34.

[233] Kwon, O.; Kim, Y. I.; Kim, K.; Kim, J. C.; Lee, J. H.; Park, S. S.; 
Han, J. W.; Kim, Y. M.; Kim, G.; Jeong, H. Y. Probing onedimensional oxygen vacancy channels driven by cation-anion double ordering in perovskites. Nano Lett. 2020, 20, 8353-8359.

[234] Zhu, K. Y.; Zhu, X. F.; Yang, W. S. Application of in situ techniques for the characterization of NiFe-based oxygen evolution reaction (OER) electrocatalysts. Angew. Chem., Int. Ed. 2019, 58, 1252-1265.

[235] Sartoretti, E.; Novara, C.; Fontana, M.; Giorgis, F.; Piumetti, M.; Bensaid, S.; Russo, N.; Fino, D. New insights on the defect sites evolution during Co oxidation over doped ceria nanocatalysts probed by in situ Raman spectroscopy. Appl. Catal. A: Gen. 2020, $596,117517$.

[236] Liu, X.; Meng, J. S.; Zhu, J. X.; Huang, M.; Wen, B.; Guo, R. T.; Mai, L. Comprehensive understandings into complete reconstruction of precatalysts: Synthesis, applications, and characterizations. $A d v$. Mater. 2021, 33, 2007344.

[237] Xiao, Z. H.; Huang, Y. C.; Dong, C. L.; Xie, C.; Liu, Z. J.; Du, S. Q.; Chen, W.; Yan, D. F.; Tao, L.; Shu, Z. W. et al. Operando identification of the dynamic behavior of oxygen vacancy-rich $\mathrm{Co}_{3} \mathrm{O}_{4}$ for oxygen evolution reaction. J. Am. Chem. Soc. 2020, 142, 12087-12095.

[238] Yang, Y. Q.; Yin, L. C.; Gong, Y.; Niu, P.; Wang, J. Q.; Gu, L.; Chen, X. Q.; Liu, G.; Wang, L. Z.; Cheng, H. M. An unusual strong visible-light absorption band in red anatase $\mathrm{TiO}_{2}$ photocatalyst induced by atomic hydrogen-occupied oxygen vacancies. Adv. Mater. 2018, 30, 1704479 .

[239] Zhao, D. M.; Dong, C. L.; Wang, B.; Chen, C.; Huang, Y. C.; Diao, Z. D.; Li, S. Z.; Guo, L. J.; Shen, S. H. Synergy of dopants and defects in graphitic carbon nitride with exceptionally modulated band structures for efficient photocatalytic oxygen evolution. $A d v$. Mater. 2019, 31, 1903545.

[240] Mohebinia, M.; Wu, C.; Yang, G.; Dai, S.; Hakimian, A.; Tong, T.; Ghasemi, H.; Wang, Z.; Wang, D.; Ren, Z. et al. Ultrathin bismuth oxyiodide nanosheets for photocatalytic ammonia generation from nitrogen and water under visible to near-infrared light. Mater. Today Phys. 2021, 16, 100293.

[241] Liang, C.; Niu, H. Y.; Guo, H.; Niu, C. G.; Yang, Y. Y.; Liu, H. Y.; Tang, W. W.; Feng, H. P. Efficient photocatalytic nitrogen fixation to ammonia over bismuth monoxide quantum dots-modified defective ultrathin graphitic carbon nitride. Chem. Eng. J. 2021, 406, 126868

[242] Fu, F.; Shen, H. D.; Sun, X.; Xue, W. W.; Shoneye, A.; Ma, J. N.; Luo, L.; Wang, D. J.; Wang, J. G.; Tang, J. W. Synergistic effect of surface oxygen vacancies and interfacial charge transfer on $\mathrm{Fe}(\mathrm{III})$ $\mathrm{Bi}_{2} \mathrm{MoO}_{6}$ for efficient photocatalysis. Appl. Catal. B: Environ. 2019, 247, 150-162.

[243] Li, Y. S.; Tang, Z. L.; Zhang, J. Y.; Zhang, Z. T. Defect engineering of air-treated $\mathrm{WO}_{3}$ and its enhanced visible-light-driven photocatalytic and electrochemical performance. J. Phys. Chem. C 2016, 120, 9750-9763.

[244] Xu, C. M.; Qiu, P. X.; Li, L. Y.; Chen, H.; Jiang, F.; Wang, X. Bismuth subcarbonate with designer defects for broad-spectrum photocatalytic nitrogen fixation. ACS Appl. Mater. Interfaces 2018, 10, 25321-25328.

[245] Li, Q.; Bai, X. X.; Luo, J. Y.; Li, C. Y.; Wang, Z. N.; Wu, W. W.; Liang, Y. P.; Zhao, Z. H. Fe doped $\mathrm{SrWO}_{4}$ with tunable band structure for photocatalytic nitrogen fixation. Nanotechnology 2020, 31, 375402.

[246] Xue, Y. J.; Guo, Y. C.; Liang, Z. Q.; Cui, H. Z.; Tian, J. Porous $g-\mathrm{C}_{3} \mathrm{~N}_{4}$ with nitrogen defects and cyano groups for excellent photocatalytic nitrogen fixation without co-catalysts. J. Colloid Interface Sci. 2019, 556, 206-213.

[247] Wu, D. P.; Wang, R.; Yang, C.; An, Y. P.; Lu, H.; Wang, H. J.; Cao, K.; Gao, Z. Y.; Zhang, W. C.; Xu, F. et al. Br doped porous bismuth oxychloride micro-sheets with rich oxygen vacancies and dominating $\{001\}$ facets for enhanced nitrogen photo-fixation performances. J. Colloid Interface Sci. 2019, 556, 111-119.

[248] Shi, L.; Li, Z.; Ju, L. C.; Carrasco-Pena, A.; Orlovskaya, N.; Zhou, H. Q.; Yang, Y. Promoting nitrogen photofixation over a periodic $\mathrm{WS}_{2} @ \mathrm{TiO}_{2}$ nanoporous film. J. Mater. Chem.A 2020, 8, 1059-1065.

[249] Bu, T. A.; Hao, Y. C.; Gao, W. Y.; Su, X.; Chen, L. W.; Zhang, N.; Yin, A. X. Promoting photocatalytic nitrogen fixation with alkali metal cations and plasmonic nanocrystals. Nanoscale 2019, 11 , 10072-10079.
[250] Zhao, Y. Y.; Zhou, S.; Zhao, J. J.; Du, Y.; Dou, S. X. Control of photocarrier separation and recombination at bismuth oxyhalide interface for nitrogen fixation. J. Phys. Chem. Lett. 2020, 11, 9304-9312.

[251] Xue, J. W.; Fujitsuka, M.; Majima, T. Defect-mediated electron transfer in photocatalysts. Chem. Commun. 2021, 57, 3532-3542.

[252] Bai, S.; Jiang, J.; Zhang, Q.; Xiong, Y. J. Steering charge kinetics in photocatalysis: Intersection of materials syntheses, characterization techniques and theoretical simulations. Chem. Soc. Rev. 2015, 44, 2893-2939.

[253] Li, H.; Shang, J.; Ai, Z. H.; Zhang, L. Z. Efficient visible light nitrogen fixation with $\mathrm{BiOBr}$ nanosheets of oxygen vacancies on the exposed $\{001\}$ facets. J. Am. Chem. Soc. 2015, 137, 6393-6399.

[254] Niu, X. Y.; Zhu, Q.; Jiang, S. L.; Zhang, Q. Photoexcited electron dynamics of nitrogen fixation catalyzed by ruthenium single-atom catalysts. J. Phys. Chem. Lett. 2020, 11, 9579-9586.

[255] Brunauer, S.; Emmett, P. H.; Teller, E. Adsorption of gases in multimolecular layers. J. Am. Chem. Soc. 1938, 60, 309-319.

[256] Dong, G. H.; Ho, W.; Wang, C. Y. Selective photocatalytic $\mathrm{N}_{2}$ fixation dependent on $g-\mathrm{C}_{3} \mathrm{~N}_{4}$ induced by nitrogen vacancies. $J$. Mater. Chem. A 2015, 3, 23435-23441.

[257] Li, H.; Shang, J.; Shi, J. G.; Zhao, K.; Zhang, L. Z. Facet-dependent solar ammonia synthesis of $\mathrm{BiOCl}$ nanosheets via a proton-assisted electron transfer pathway. Nanoscale 2016, 8, 1986-1993.

[258] Mao, C. L.; Li, H.; Gu, H. G.; Wang, J. X.; Zou, Y. J.; Qi, G. D.; $\mathrm{Xu}$, J.; Deng, F.; Shen, W. J.; Li, J. et al. Beyond the thermal equilibrium limit of ammonia synthesis with dual temperature zone catalyst powered by solar light. Chem 2019, 5, 2702-2717.

[259] Xue, X. L.; Chen, R. P.; Yan, C. Z.; Hu, Y.; Zhang, W. J.; Yang, S. Y.; Ma, L. B.; Zhu, G. Y.; Jin, Z. Efficient photocatalytic nitrogen fixation under ambient conditions enabled by the heterojunctions of n-type $\mathrm{Bi}_{2} \mathrm{MoO}_{6}$ and oxygen-vacancy-rich p-type $\mathrm{BiOBr}$. Nanoscale 2019, 11, 10439-10445.

[260] Wang, T. Y.; Feng, C. T.; Liu, J. Q.; Wang, D. J.; Hu, H. M.; Hu, J.; Chen, Z.; Xue, G. L. $\mathrm{Bi}_{2} \mathrm{WO}_{6}$ hollow microspheres with high specific surface area and oxygen vacancies for efficient photocatalysis $\mathrm{N}_{2}$ fixation. Chem. Eng. J. 2021, 414, 128827.

[261] Wu, H. Y.; Li, X.; Cheng, Y.; Xiao, Y. H.; Li, R. F.; Wu, Q. P.; Lin, H.; Xu, J.; Wang, G. Q.; Lin, C. et al. Plasmon-driven $\mathrm{N}_{2}$ photofixation in pure water over $\mathrm{MoO}_{3-x}$ nanosheets under visible to NIR excitation. J. Mater. Chem. A 2020, 8, 2827-2835.

[262] Li, Y. H.; Chen, X.; Zhang, M. J.; Zhu, Y. M.; Ren, W. J.; Mei, Z. W.; Gu, M.; Pan, F. Oxygen vacancy-rich $\mathrm{MoO}_{3-x}$ nanobelts for photocatalytic $\mathrm{N}_{2}$ reduction to $\mathrm{NH}_{3}$ in pure water. Catal. Sci. Technol. 2019, 9, 803-810.

[263] Fan, J. Y.; Zuo, M. M.; Ding, Z. X.; Zhao, Z. W.; Liu, J.; Sun, B. A readily synthesis of oxygen vacancy-induced $\operatorname{In}(\mathrm{OH})_{3} /$ carbon nitride $0 \mathrm{D} / 2 \mathrm{D}$ heterojunction for enhanced visible-light-driven nitrogen fixation. Chem. Eng. J. 2020, 396, 125263.

[264] Liu, Q.; Yuan, J. L.; Gan, Z. W.; Liu, C.; Li, J.; Liang, Y.; Chen, R. Photocatalytic $\mathrm{N}_{2}$ reduction: Uncertainties in the determination of ammonia production. ACS Sustain. Chem. Eng. 2021, 9, 560-568.

[265] Ran, Y.; Yu, X. L.; Liu, J. Q.; Cui, J. Y.; Wang, J. P.; Wang, L.; Zhang, Y. H.; Xiang, X.; Ye, J. Polymeric carbon nitride with frustrated lewis pair sites for enhanced photofixation of nitrogen. J. Mater. Chem. A 2020, 8, 13292-13298.

[266] Liu, S. Z.; Wang, Y. J.; Wang, S. B.; You, M. M.; Hong, S.; Wu, T. S.; Soo, Y. L.; Zhao, Z. Q.; Jiang, G. Y.; Qiu, J. S. et al. Photocatalytic fixation of nitrogen to ammonia by single $\mathrm{Ru}$ atom decorated $\mathrm{TiO}_{2}$ nanosheets. ACS Sustain. Chem. Eng. 2019, 7, 6813-6820.

[267] Hou, T. T.; Li, Q.; Zhang, Y. D.; Zhu, W. K.; Yu, K. F.; Wang, S. M.; Xu, Q.; Liang, S. Q.; Wang, L. B. Near-infrared light-driven photofixation of nitrogen over $\mathrm{Ti}_{3} \mathrm{C}_{2} \mathrm{~T}_{x} / \mathrm{TiO}_{2}$ hybrid structures with superior activity and stability. Appl. Catal. B: Environ. 2020, 273, 119072.

[268] Xue, Y. J.; Kong, X. K.; Guo, Y. C.; Liang, Z. Q.; Cui, H. Z.; Tian, J. Synthesis of porous few-layer carbon nitride with excellent photocatalytic nitrogen fixation. J. Materiomics 2020, 6, 128-137.

[269] Wu, G.; Yu, L. H.; Liu, Y. F.; Zhao, J. M.; Han, Z.; Geng, G. One step synthesis of $\mathrm{N}$ vacancy-doped $g-\mathrm{C}_{3} \mathrm{~N}_{4} / \mathrm{Ag}_{2} \mathrm{CO}_{3}$ heterojunction catalyst with outstanding "two-path" photocatalytic $\mathrm{N}_{2}$ fixation ability via in-situ self-sacrificial method. Appl. Surf. Sci. 2019, 
481, 649-660.

[270] Ding, Z.; Wang, S.; Chang, X.; Wang, D. H.; Zhang, T. H. NanoMOF@defected film $\mathrm{C}_{3} \mathrm{~N}_{4}$ Z-scheme composite for visible-light photocatalytic nitrogen fixation. RSC Adv. 2020, 10, 26246-26255.

[271] Zhou, N.; Qiu, P. X.; Chen, H.; Jiang, F. KOH etching graphitic carbon nitride for simulated sunlight photocatalytic nitrogen fixation with cyano groups as defects. J. Taiwan Inst. Chem. Eng. 2018, 83, 99-106.

[272] Hu, X. L.; Zhang, W. J.; Yong, Y. W.; Xu, Y.; Wang, X. H.; Yao, X. X. One-step synthesis of iodine-doped $g-\mathrm{C}_{3} \mathrm{~N}_{4}$ with enhanced photocatalytic nitrogen fixation performance. Appl. Surf. Sci. 2020, $510,145413$.

[273] Cao, S. H.; Fan, B.; Feng, Y. C.; Chen, H.; Jiang, F.; Wang, X. Sulfur-doped $g-\mathrm{C}_{3} \mathrm{~N}_{4}$ nanosheets with carbon vacancies: General synthesis and improved activity for simulated solar-light photocatalytic nitrogen fixation. Chem. Eng. J. 2018, 353, 147-156.

[274] He, Z. Y.; Wang, Y.; Dong, X. L.; Zheng, N.; Ma, H. C.; Zhang, X. F. Indium sulfide nanotubes with sulfur vacancies as an efficient photocatalyst for nitrogen fixation. RSC Adv. 2019, 9, 21646-21652.

[275] Cao, Y. H.; Hu, S. Z.; Li, F. Y.; Fan, Z. P.; Bai, J.; Lu, G.; Wang, Q. Photofixation of atmospheric nitrogen to ammonia with a novel ternary metal sulfide catalyst under visible light. $R S C A d v$. 2016, 6 , 49862-49867.

[276] Hu, S. Z.; Chen, X.; Li, Q.; Zhao, Y. F.; Mao, W. Effect of sulfur vacancies on the nitrogen photofixation performance of ternary metal sulfide photocatalysts. Catal. Sci. Technol. 2016, 6, 5884-5890.

[277] Zhang, Q.; Hu, S. Z.; Fan, Z. P.; Liu, D. S.; Zhao, Y. F.; Ma, H. F.; $\mathrm{Li}$, F. Y. Preparation of $g-\mathrm{C}_{3} \mathrm{~N}_{4} / \mathrm{ZnMoCdS}$ hybrid heterojunction catalyst with outstanding nitrogen photofixation performance under visible light via hydrothermal post-treatment. Dalton Trans. 2016, 45, 3497-3505.

[278] Li, H. T.; Liu, Y. D.; Liu, Y. L.; Wang, L. Z.; Tang, R.; Deng, P. J.; Xu, Z. Q.; Haynes, B.; Sun, C. H.; Huang, J. Efficient visible light driven ammonia synthesis on sandwich structured $\mathrm{C}_{3} \mathrm{~N}_{4} / \mathrm{MoS}_{2} / \mathrm{Mn}_{3} \mathrm{O}_{4}$ catalyst. Appl. Catal. B: Environ. 2021, 281, 119476.

[279] Ye, X. H.; Yan, X. Y.; Chu, X. N.; Zuo, S. X.; Liu, W. J.; Li, X. Z.; Yao, C. Construction of upconversion fluoride/attapulgite nanocomposite for visible-light-driven photocatalytic nitrogen fixation. Front. Mater. Sci. 2020, 14, 469-480.

[280] Jia, H. L.; Du, A. X.; Zhang, H.; Yang, J. H.; Jiang, R. B.; Wang, J. F.; Zhang, C. Y. Site-selective growth of crystalline ceria with oxygen vacancies on gold nanocrystals for near-infrared nitrogen photofixation. J. Am. Chem. Soc. 2019, 141, 5083-5086.

[281] Sun, C.; Chen, Z. Q.; Cui, J.; Li, K.; Qu, H. X.; Xie, H. F.; Zhong, Q. Site-exposed $\mathrm{Ti}_{3} \mathrm{C}_{2}$ mxene anchored in N-defect $g-\mathrm{C}_{3} \mathrm{~N}_{4}$ heterostructure nanosheets for efficient photocatalytic $\mathrm{N}_{2}$ fixation. Catal. Sci. Technol. 2021, 11, 1027-1038.

[282] Kong, Y.; Lv, C. D.; Zhang, C. M.; Chen, G. Cyano group modified $g-\mathrm{C}_{3} \mathrm{~N}_{4}$ : Molten salt method achievement and promoted photocatalytic nitrogen fixation activity. Appl. Surf. Sci. 2020, 515, 146009.

[283] Ye, T. N.; Park, S. W.; Lu, Y. F.; Li, J.; Sasase, M.; Kitano, M.; Tada, T.; Hosono, $\mathrm{H}$. Vacancy-enabled $\mathrm{N}_{2}$ activation for ammonia synthesis on an Ni-loaded catalyst. Nature 2020, 583, 391-395.

[284] Ye, T. N.; Park, S. W.; Lu, Y. F.; Li, J.; Sasase, M.; Kitano, M.; Hosono, H. Contribution of nitrogen vacancies to ammonia synthesis over metal nitride catalysts. J. Am. Chem. Soc. 2020, 142, 14374-14383.

[285] Hu, S. Z.; Li, Y. M.; Li, F. Y.; Fan, Z. P.; Ma, H. F.; Li, W.; Kang, X. X. Construction of $g-\mathrm{C}_{3} \mathrm{~N}_{4} / \mathrm{Zn}_{0.11} \mathrm{Sn}_{0.12} \mathrm{Cd}_{0.88} \mathrm{~S}_{1.12}$ hybrid heterojunction catalyst with outstanding nitrogen photofixation performance induced by sulfur vacancies. ACS Sustain. Chem. Eng. 2016, 4, 2269-2278.

[286] Wang, W.; Huang, Y.; Wang, Z. Y. Defect engineering in twodimensional graphitic carbon nitride and application to photocatalytic air purification. Acta Phys. -Chim. Sin. 2021, 37, 2011073.

[287] Zhang, Y.; Di, J.; Ding, P. H.; Zhao, J. Z.; Gu, K. Z.; Chen, X. L.; Yan, C.; Yin, S.; Xia, J. X.; Li, H. M. Ultrathin $g-\mathrm{C}_{3} \mathrm{~N}_{4}$ with enriched surface carbon vacancies enables highly efficient photocatalytic nitrogen fixation. J. Colloid Interface Sci. 2019, 553, 530-539.

[288] He, C. L.; Li, X. Z.; Chen, X. F.; Ma, S. J.; Yan, X. Y.; Zhang, Y. Y.; Zuo, S. X.; Yao, C. Palygorskite supported rare earth fluoride for photocatalytic nitrogen fixation under full spectrum. Appl. Clay Sci. 2020, 184, 105398

[289] Jiao, X. C.; Chen, Z. W.; Li, X. D.; Sun, Y. F.; Gao, S.; Yan, W. S.; Wang, C. M.; Zhang, Q.; Lin, Y.; Luo, Y. et al. Defect-mediated electron-hole separation in one-unit-cell $\mathrm{ZnIn}_{2} \mathrm{~S}_{4}$ layers for boosted solar-driven $\mathrm{CO}_{2}$ reduction. J. Am. Chem. Soc. 2017, 139, 7586-7594.

[290] Meng, S. G.; Chen, C.; Gu, X. M.; Wu, H. H.; Meng, Q. Q.; Zhang, J. F.; Chen, S. F.; Fu, X. L.; Liu, D.; Lei, W. W. Efficient photocatalytic $\mathrm{H}_{2}$ evolution, $\mathrm{CO}_{2}$ reduction and $\mathrm{N}_{2}$ fixation coupled with organic synthesis by cocatalyst and vacancies engineering. Appl. Catal. B: Environ. 2021, 285, 119789.

[291] Sun, S.; An, Q.; Wang, W. Z.; Zhang, L.; Liu, J. J.; Goddard III, W. A. Efficient photocatalytic reduction of dinitrogen to ammonia on bismuth monoxide quantum dots. J. Mater. Chem. A 2017, 5, 201-209.

[292] Huang, B. M.; Liu, Y.; Pang, Q.; Zhang, X. Y.; Wang, H. T.; Shen, P. K. Boosting the photocatalytic activity of mesoporous $\mathrm{SrTiO}_{3}$ for nitrogen fixation through multiple defects and strain engineering. J. Mater. Chem. A 2020, 8, 22251-22256.

[293] Cheng, Y. W.; Song, Y.; Zhang, Y. M. The doping and oxidation of 2D black and blue phosphorene: A new photocatalyst for nitrogen reduction driven by visible light. Phys. Chem. Chem. Phys. 2019, 21, 24449-24457.

[294] Wang, K. Y.; Gu, G. Z.; Hu, S. Z.; Zhang, J.; Sun, X. L.; Wang, F.; Li, P.; Zhao, Y. F.; Fan, Z. P.; Zou, X. Molten salt assistant synthesis of three-dimensional cobalt doped graphitic carbon nitride for photocatalytic $\mathrm{N}_{2}$ fixation: Experiment and DFT simulation analysis. Chem. Eng. J. 2019, 368, 896-904.

[295] Hu, Y. Z.; Zhao, G. X.; Pan, Q. S.; Wang, H. H.; Shen, Z. W.; Peng, B. X.; Busser, G. W.; Wang, X. K.; Muhler, M. Highly selective anaerobic oxidation of alcohols over Fe-doped $\mathrm{SrTiO}_{3}$ under visible light. ChemCatChem 2019, 11, 5139-5144.

[296] Li, B. F.; Hong, J. H.; Ai, Y. J.; Hu, Y. Z.; Shen, Z. W.; Li, S. J.; Zou, Y. T.; Zhang, S.; Wang, X. K.; Zhao, G. X. et al. Visible-nearinfrared-light-driven selective oxidation of alcohols over nanostructured $\mathrm{Cu}$ doped $\mathrm{SrTiO}_{3}$ in water under mild condition. J. Catal. 2021, 399, 142-149.

[297] MacKay, B. A.; Fryzuk, M. D. Dinitrogen coordination chemistry: On the biomimetic borderlands. Chem. Rev. 2004, 104, 385-402.

[298] Légaré, M. A.; Bélanger-Chabot, G.; Dewhurst, R. D.; Welz, E.; Krummenacher, I.; Engels, B.; Braunschweig, H. Nitrogen fixation and reduction at boron. Science 2018, 359, 896-900.

[299] Li, J. X.; Wang, D. D.; Guan, R. Q.; Zhang, Y. J.; Zhao, Z.; Zhai, H. J.; Sun, Z. C. Vacancy-enabled mesoporous $\mathrm{TiO}_{2}$ modulated by nickel doping with enhanced photocatalytic nitrogen fixation performance. ACS Sustain. Chem. Eng. 2020, 8, 18258-18265.

[300] Shen, Z. F.; Li, F. F.; Lu, J. R.; Wang, Z. D.; Li, R.; Zhang, X. C.; Zhang, C. M.; Wang, Y. W.; Wang, Y. F.; Lv, Z. P. et al. Enhanced $\mathrm{N}_{2}$ photofixation activity of flower-like BiOCl by in situ $\mathrm{Fe}(\mathrm{III})$ doped as an activation center. J. Colloid Interface Sci. 2021, 584, 174-181.

[301] Mao, Y. H.; Yang, X. W.; Gong, W. B.; Zhang, J.; Pan, T.; Sun, H. Z.; Chen, Z. G.; Wang, Z.; Zhu, J. F.; Hu, J. et al. A dopant replacementdriven molten salt method toward the synthesis of sub-5-nm-sized ultrathin nanowires. Small 2020, 16, 2001098.

[302] Li, H. D.; Gu, S. N.; Sun, Z. J.; Guo, F.; Xie, Y. M.; Tao, B. R.; He, X.; Zhang, W. F.; Chang, H. X. The in-built bionic "MoFe cofactor" in Fe-doped two-dimensional $\mathrm{MoTe}_{2}$ nanosheets for boosting the photocatalytic nitrogen reduction performance. J. Mater. Chem. A 2020, 8, 13038-13048.

[303] Tian, C. S.; Sheng, W. L.; Tan, H.; Jiang, H.; Xiong, C. R. Fabrication of lattice-doped $\mathrm{TiO}_{2}$ nanofibers by vapor-phase growth for visible light-driven $\mathrm{N}_{2}$ conversion to ammonia. ACS Appl. Mater. Interfaces 2018, 10, 37453-37460.

[304] Ying, Z. H.; Chen, S. T.; Zhang, S.; Peng, T. Y.; Li, R. J. Efficiently enhanced $\mathrm{N}_{2}$ photofixation performance of sea-urchin-like $\mathrm{W}_{18} \mathrm{O}_{49}$ microspheres with Mn-doping. Appl. Catal. B: Environ. 2019, 254, 351-359.

[305] Meng, Q. Q.; Lv, C. D.; Sun, J. X.; Hong, W. Z.; Xing, W. N.; Qiang, L. S.; Chen, G.; Jin, X. L. High-efficiency Fe-mediated $\mathrm{Bi}_{2} \mathrm{MoO}_{6}$ nitrogen-fixing photocatalyst: Reduced surface work 
function and ameliorated surface reaction. Appl. Catal. B: Environ. 2019, 256, 117781.

[306] Zeng, L.; Zhe, F.; Wang, Y.; Zhang, Q. L.; Zhao, X. Y.; Hu, X.; $\mathrm{Wu}, \mathrm{Y}$.; He, Y. M. Preparation of interstitial carbon doped BiOI for enhanced performance in photocatalytic nitrogen fixation and methyl orange degradation. J. Colloid Interface Sci. 2019, 539, 563-574.

[307] Feng, X. W.; Chen, H.; Jiang, F.; Wang, X. Enhanced visible-light photocatalytic nitrogen fixation over semicrystalline graphitic carbon nitride: Oxygen and sulfur co-doping for crystal and electronic structure modulation. J. Colloid Interface Sci. 2018, 509, 298-306.

[308] Han, Q.; Wu, C. B.; Jiao, H. M.; Xu, R. Y.; Wang, Y. Z.; Xie, J. J.; Guo, Q.; Tang, J. W. Rational design of high-concentration $\mathrm{Ti}^{3+}$ in porous carbon-doped $\mathrm{TiO}_{2}$ nanosheets for efficient photocatalytic ammonia synthesis. Adv. Mater. 2021, 33, 2008180

[309] Xue, X. L.; Chen, H. W.; Xiong, Y.; Chen, R. P.; Jiang, M. H.; Fu, G.; Xi, Z. H.; Zhang, X. L.; Ma, J.; Fang, W. H. et al. Near-infraredresponsive photo-driven nitrogen fixation enabled by oxygen vacancies and sulfur doping in black $\mathrm{TiO}_{2-x} \mathrm{~S}_{y}$ nanoplatelets. $A C S$ Appl. Mater. Interfaces 2021, 13, 4975-4983.

[310] Qiao, B. T.; Wang, A. Q.; Yang, X. F.; Allard, L. F.; Jiang, Z.; Cui, Y. T.; Liu, J. Y.; Li, J.; Zhang, T. Single-atom catalysis of CO oxidation using $\mathrm{Pt}_{1} / \mathrm{FeO}_{x}$. Nat. Chem. 2011, 3, 634-641.

[311] Tao, H. C.; Choi, C.; Ding, L. X.; Jiang, Z.; Han, Z. S.; Jia, M. W.; Fan, Q.; Gao, Y. N.; Wang, H. H.; Robertson, A. W. et al. Nitrogen fixation by Ru single-atom electrocatalytic reduction. Chem $\mathbf{2 0 1 9}$, $5,204-214$

[312] Li, J.; Liu, P.; Tang, Y. Z.; Huang, H. L.; Cui, H. Z.; Mei, D. H.; Zhong, C. L. Single-atom Pt- $\mathrm{N}_{3}$ sites on the stable covalent triazine framework nanosheets for photocatalytic $\mathrm{N}_{2}$ fixation. ACS Catal. 2020, 10, 2431-2442.

[313] Hou, T. T.; Peng, H. L.; Xin, Y.; Wang, S. M.; Zhu, W. K.; Chen, L. L.; Yao, Y.; Zhang, W. H.; Liang, S. Q.; Wang, L. B. Fe singleatom catalyst for visible-light-driven photofixation of nitrogen sensitized by triphenylphosphine and sodium iodide. ACS Catal. 2020, 10, 5502-5510.

[314] Lv, X. S.; Wei, W.; Li, F. P.; Huang, B. B.; Dai, Y. Metal-free B@g-CN: Visible/infrared light-driven single atom photocatalyst enables spontaneous dinitrogen reduction to ammonia. Nano Lett. 2019, 19, 6391-6399.

[315] Liu, J. D.; Wei, Z. X.; Dou, Y. H.; Feng, Y. Z.; Ma, J. M. Ru-doped phosphorene for electrochemical ammonia synthesis. Rare Met. 2020, 39, 874-880.

[316] Huang, P. C.; Liu, W.; He, Z. H.; Xiao, C.; Yao, T.; Zou, Y. M.; Wang, C. M.; Qi, Z. M.; Tong, W.; Pan, B. C. et al. Single atom accelerates ammonia photosynthesis. Sci. China Chem. 2018, 61, $1187-1196$

[317] Ling, C. Y.; Niu, X. H.; Li, Q.; Du, A. J.; Wang, J. L. Metal-free single atom catalyst for $\mathrm{N}_{2}$ fixation driven by visible light. J. Am. Chem. Soc. 2018, 140, 14161-14168.

[318] Zhang, C. M.; Xu, Y. L.; Lv, C. D.; Bai, L. C.; Liao, J.; Zhai, Y. C.; Zhang, H. W.; Chen, G. Amorphous engineered cerium oxides photocatalyst for efficient nitrogen fixation. Appl. Catal. B: Environ. 2020, 264, 118416

[319] Ran, J. R.; Jaroniec, M.; Qiao, S. Z. Cocatalysts in semiconductorbased photocatalytic $\mathrm{CO}_{2}$ reduction: Achievements, challenges, and opportunities. Adv. Mater. 2018, 30, 1704649.

[320] Marschall, R. Semiconductor composites: Strategies for enhancing charge carrier separation to improve photocatalytic activity. $A d v$. Funct. Mater. 2014, 24, 2421-2440.

[321] Wang, T. Y.; Liu, J. Q.; Wu, P. F.; Feng, C. T.; Wang, D. J.; Hu, H. M.; Xue, G. L. Direct utilization of air and water as feedstocks in the photo-driven nitrogen reduction reaction over a ternary $\mathrm{Z}$-scheme $\mathrm{SiW}_{9} \mathrm{CO}_{3} / \mathrm{PDA} / \mathrm{BWO}$ hetero-junction. J. Mater. Chem. A 2020, 8, 16590-16598.

[322] Li, X. B.; Wang, W. W.; Dong, F.; Zhang, Z. Q.; Han, L.; Luo, X. D.; Huang, J. T.; Feng, Z. J.; Chen, Z.; Jia, G. H. et al. Recent advances in noncontact external-field-assisted photocatalysis: From fundamentals to applications. ACS Catal. 2021, 11, 4739-4769.

[323] Zhao, Z.; Wang, D. D.; Gao, R.; Wen, G. B.; Feng, M.; Song, G. X.; Zhu, J. B.; Luo, D.; Tan, H. Q.; Ge, X. et al. Magnetic-fieldstimulated efficient photocatalytic $\mathrm{N}_{2}$ fixation over defective $\mathrm{BaTiO}_{3}$ perovskites. Angew. Chem., Int. Ed. 2021, 60, 11910-11918.

[324] Zhang, K.; Guo, L. J. Metal sulphide semiconductors for photocatalytic hydrogen production. Catal. Sci. Technol. 2013, 3, 1672-1690.

[325] Zhang, S. Q.; Si, Y. M.; Li, B.; Yang, L. X.; Dai, W. L.; Luo, S. L. Atomic-level and modulated interfaces of photocatalyst heterostructure constructed by external defect-induced strategy: A critical review. Small 2021, 17, 2004980.

[326] Nakayama, M.; Martin, M. First-principles study on defect chemistry and migration of oxide ions in ceria doped with rare-earth cations. Phys. Chem. Chem. Phys. 2009, 11, 3241-3249.

[327] Yang, X. Y.; Fernández-Carrión, A. J.; Wang, J. H.; Porcher, F.; Fayon, F.; Allix, M.; Kuang, X. J. Cooperative mechanisms of oxygen vacancy stabilization and migration in the isolated tetrahedral anion scheelite structure. Nat. Commun. 2018, 9, 4484.

[328] Wu, Q. P.; Zheng, Q.; van de Krol, R. Creating oxygen vacancies as a novel strategy to form tetrahedrally coordinated $\mathrm{Ti}^{4+}$ in $\mathrm{Fe} / \mathrm{TiO}_{2}$ nanoparticles. J. Phys. Chem. C 2012, 116, 7219-7226.

[329] Xiong, X. Y.; Mao, C. L.; Yang, Z. J.; Zhang, Q. H.; Waterhouse, G. I. N.; Gu, L.; Zhang, T. R. Photocatalytic $\mathrm{CO}_{2}$ reduction to $\mathrm{CO}$ over Ni single atoms supported on defect-rich zirconia. Adv. Energy Mater. 2020, 10, 2002928.

[330] Zhang, Y. Q.; Guo, L.; Tao, L.; Lu, Y. B.; Wang, S. Y. Defect-based single-atom electrocatalysts. Small Methods 2019, 3, 1800406.

[331] Pan, J. B.; Wang, B. H.; Wang, J. B.; Ding, H. Z.; Zhou, W.; Liu, X.; Zhang, J. R.; Shen, S.; Guo, J. K.; Chen, L. et al. Activity and stability boosting of an oxygen-vacancy-rich $\mathrm{BiVO}_{4}$ photoanode by NiFe-MOFs thin layer for water oxidation. Angew. Chem., Int. Ed. 2021, 60, 1433-1440.

[332] Zu, X. L.; Zhao, Y.; Li, X. D.; Chen, R. H.; Shao, W. W.; Wang, Z. Q.; Hu, J.; Zhu, J. F.; Pan, Y.; Sun, Y. F. et al. Ultrastable and efficient visible-light-driven $\mathrm{CO}_{2}$ reduction triggered by regenerative oxygen-vacancies in $\mathrm{Bi}_{2} \mathrm{O}_{2} \mathrm{CO}_{3}$ nanosheets. Angew. Chem., Int. Ed. 2021, 60, 13840-13846. 